\author{
UNIVERSIDADE DE SÃO PAULO - USP \\ INSTITUTO DE ASTRONOMIA, GEOFÍSICA E CIÊNCIAS ATMOSFÉRICAS \\ DEPARTAMENTO DE GEOFÍSICA
}

CAMILLA FACTORI CAMARGO

CARACTERIZAÇÃO GEOELÉTRICA DE ARENITOS ASFÁLTICOS DA FORMAÇÃO PIRAMBÓIA, BACIA DO PARANÁ.

São Paulo 


\section{CARACTERIZAÇÃO GEOELÉTRICA DE ARENITOS ASFÁLTICOS DA FORMAÇÃO PIRAMBÓIA, BACIA DO PARANÁ}

Dissertação apresentada ao Instituto de Astronomia, Geofísica e Ciências Atmosféricas da Universidade de São Paulo para obtenção do título de mestre em Geofísica.

"Versão corrigida. O original encontra-se disponível na Unidade."

Área de concentração: Geofísica

Orientador: prof. Dr. Vagner Roberto Elis

São Paulo 


\section{AGRADECIMENTOS}

Agradeço ao Prof. Dr. Vagner Roberto Elis, por sempre me apoiar e incentivar, por orientar com amizade.

Ao Prof. Dr. Jorge Hachiro, do Instituto de Geociências da USP, pela grande contribuição ao tema do trabalho e pelo interesse e disponibilidade em colaborar sempre.

Ao Prof. Dr. Jorge Luis Porsani, pela contribuição ao trabalho através de críticas e sugestões.

Ao técnico da Geofísica Aplicada Marcelo Cesar Stangari, pela fundamental ajuda nos trabalhos de campo.

Ao departamento de Geofísica do IAG pela oportunidade e estrutura oferecidas. Ao Capes - PROAP pela ajuda financeira nos trabalhos de campo.

Ao Pr. Dr. Éder Cassola Molina, pela amizade e incentivo durante todo o processo.

Ao Sr. Jairson de Lima, pela confiança depositada e pela amizade construída.

A todos os funcionários do IAG, especialmente da secretaria de graduação, secretaria de pós graduação e da gráfica, sempre muito eficientes e dispostos a ajudar.

Ao programa PRH 19 da ANP, pela bolsa concedida.

Aos colegas da pós graduação Cleiton Kefrof Pavan, Júlio Cesar Ardito, Sérgio Fachin e Andréa Ustra, pela ajuda, incentivo e amizade. Ao Franklin Bispo pelo grande apoio no momento crucial!

A todos os meus amigos, em especial à Fabiana "Pará", Giovanni Moreira, Andrea "Fri". Ao Gabriel Kuhlmann, sem o qual essa etapa de trabalho e de vida não teria sido concluída.

Aos meus pais e irmão, Jeanete, Paulo e Marcel, por todo o amor e incentivo sempre. 


\section{RESUMO}

CAMARGO, C. F. Caracterização geoelétrica de arenitos asfálticos da Formação Pirambóia, Bacia do Paraná - SP. Dissertação (mestrado). Instituto de Astronomia, Geofísica e Ciências Atmosféricas - IAG. Universidade de São Paulo - USP. 2013.

A sociedade humana teve seu desenvolvimento atrelado à exploração de recursos naturais do planeta e atualmente dependemos significativamente de bens de consumo derivados destes recursos, principalmente dos recursos provenientes do petróleo. A diversificação da matriz energética é lenta e nossa dependência dos combustíveis fósseis permanecerá durante várias décadas. Em função deste cenário econômico, são crescentes e fundamentais as pesquisas de acumulações não convencionais de óleo e gás, o que motivou o presente projeto. A área de estudo escolhida se constitui de um afloramento de arenito asfáltico (arenito impregnado, nos poros, por betume) relativo à rochareservatório do sistema petrolífero Irati - Pirambóia, e se localiza na borda leste da Bacia do Paraná, nas proximidades do município de Anhembi - SP. O objetivo do projeto foi identificar e mapear a camada de arenito com presença do óleo (pesado, de baixo grau API), em meio a camadas com pouco ou nenhum óleo, verificando uma assinatura geofísica associável à mesma que pudesse ser utilizada em pesquisas em outras áreas com o mesmo tipo de acumulação. Os métodos utilizados, Eletrorresistividade, Polarização Induzida e Eletromagnético Indutivo, foram escolhidos por serem amplamente aplicados de forma integrada em estudos ambientais, em áreas contaminadas por derivados de hidrocarbonetos. Os dados, adquiridos com a técnica de caminhamento elétrico e arranjo eletródico dipolo-dipolo, geraram perfis 2D de resistividade e cargabilidade que permitiram visualizar a camada alvo, e linhas de $C E$ paralelas foram interpretadas com uma técnica 3D para inferir a geometria e os limites da mesma. Foram realizadas algumas sondagens elétricas verticais e caminhamentos eletromagnéticos, para corroborar os resultados principais e para comparação com dados de um poço perfurado no local pela Petrobras, com resultados bastante satisfatórios, o que sugere um potencial de aplicação dos métodos geoelétricos em outras áreas de interesse. 
PALAVRAS - CHAVE: Eletrorresistividade; polarização induzida; eletromagnético indutivo; arenito asfáltico; Formação Pirambóia. 


\section{ABSTRACT}

CAMARGO, C.F. Geoelectric characterization of bituminous sandstones of Pirambóia Formation, Paraná Basin. Dissertation (Master Degree). Instituto de Astronomia, Geofísica e Ciências Atmosféricas - IAG. Universidade de São Paulo - USP. 2013.

Human society had its development linked to the exploitation of the Earth's natural resources and nowadays we depend significantly on consumer goods derived from these resources, especially the ones from oil. The diversification of the energy matrix is slow and our dependence on fossil fuels should last for several decades. Due to this economic scenario, oil and gas unconventional accumulation exploration are growing and are fundamental, which motivated this project. The area of study consists of an asphaltic sandstone outcrop (sandstone impregnated in the pores by bitumen) concerning the Irati Pirambóia oil system's reservoir rock, and is located on the eastern edge of the Paraná Basin, near the city of Anhembi - SP. The goal for this project was to identify and map the sandstone layer with the presence of oil (heavy, with low API grade), in between layers low on oil or with no oil at all, by checking a matching geophysical signature that could be used in other research areas with the same type of accumulation. The geophysical methods, Electrical Resistivity, Induced Polarization and Inductive Electromagnetic, were chosen because of their wide integrated application on environmental studies, in areas contaminated by hydrocarbon derivatives. The data obtained through the electrical profiling and dipole-dipole electrode array technique generated 2D resistivity and chargeability profiles that allowed us to visualize the target layer, and EP parallel lines were interpreted through a 3D technique to infer its geometry and limits. Some vertical electrical surveys and electromagnetic profiling were performed to corroborate with the main results and for comparison with data from a well drilled on the site by Petrobras, with very satisfactory results, suggesting a potential of geoelectrical methods applications in other areas of interest. 
KEY - WORDS: Electrical Resistivity; Induced Polarization; Electromagnetic Inductive; asphaltic sandstones; Pirambóia Formation. 


\section{LISTA DE FIGURAS}

Figura 1.1: Tabela de recursos de arenitos asfálticos disponíveis no mundo (OSRRN, 2003)

Figura 1.2: Gráficos de estimativa de recursos petrolíferos mundiais (por tipos de óleo)

e distribuição mundial das reservas (Schlumberger, 2006)......

Figura 1.3: Elementos de um sistema petrolífero hipotético (modificado de Lisboa, 2006)

Figura 3.1: Localização do município de Anhembi no Estado de São Paulo. 14

Figura 3.2: Coluna estratigráfica da Bacia do Paraná (Milani, 2007)..... .16

Figura 3.3: Tabela de caracterização dos sistemas petrolíferos da Bacia do Paraná (modificada de Magalhães, 2010).

Figura 3.4: Principais estágios na gênese dos arenitos asfálticos (modificado de Araújo, 2003)

Figura 3.5: Mapa geológico simplificado da área de estudo (a partir de CPRM,

2001)

Figura 3.6: Quadro de eventos cronológicos relacionados à gênese de arenitos asfálticos (Araújo et al, 2000).

Figura 4.1: Prisma teórico para ilustração da Lei de Ohm em meio homogêneo e isotrópico

Figura 4.2: Tabela de valores de resistividade elétrica de alguns materiais conhecidos

Figura 4.3: Eletrodo na origem de um sistema de coordenadas (Ward, 1990).

Figura 4.4: Direção do fluxo radial de corrente no semi-espaço

Figura 4.5: Associação de resistividades e cargabilidades aparentes e tipos de sedimentos (modificado de Draskovits et al.,1990).

Figura 4.6: Formato de onda de corrente elétrica e representação do efeito IP (Sumner, 1976)

Figura 4.7: Representação do efeito de polarização de membrana (modificado de Telford et al., 1990).

Figura 4.8: Representação do efeito de polarização de eletrodo (modificado de Telford et al., 1990) 
Figura 4.9: Arranjos eletródicos mais utilizados

Figura 4.10: Disposição do arranjo dipolo dipolo.

Figura 4.11: Plotagem dos pontos e sequência das medidas utilizadas na medição com arranjo dipolo dipolo

Figura 4.12: Disposição dos eletrodos em aquisição com arranjo 3D completo e 3D diagonal cruzado (modificado de Loke e Barker,1996)...........................................47

Figura 4.13: Rotina básica de inversão de dados de resistividade.

Figura 4.14: Malha de células utilizada na modelagem 2D (modificado de Loke, 1999)

Figura 4.15: Princípio de operação do método EM. "Tx"é a bobina transmissora; "Rx" a bobina receptora (Santos, 2009)

Figura 4.16: Disposição das bobinas EM em dipolo vertical e horizontal. 54

Figura 4.17: Espaçamento entre bobinas, frequiência de operação e profundidade de investigação de acordo com a disposição das bobinas.

Figura 5.1: Foto do Syscal R2, Elrec Pro e conversor de voltagem, utilizados na aquisição com a técnica de caminhamento elétrico.

Figura 5.2: Syscal R2 e conversor de voltagem, utilizado na aquisição com a técnica de sondagem elétrica vertical.

Figura 5.3: Esquema dos eletrodos não polarizáveis, com solução de sulfato de cobre (CuSO4), utilizados no caminhamento elétrico. 58

Figura 5.4: Equipamento EM 34, composto por bobina transmissora, bobina receptora, módulo de controle e transmissão de corrente e módulo de leitura. 58

Figura 5.5: Foto do afloramento sobre o qual foram realizados as linhas L1 a L4 e SEV 1. No nível da base do afloramento foram feitas a linha L5 e a SEV 3. .59

Figura 5.6: Imagem apresentando o esquema em planta dos CE e SEVs realizados na Betumita.

Figura 6.1: Interpretação da SEV1 .62

Figura 6.2: Interpretação da SEV2

Figura 6.3: Interpretação da SEV3. 65

Figura 6.4: Seção de resistividade da linha "L1", com espaçamento entre eletrodos de 2,5 metros .66 
Figura 6.5: Seção de resistividade da linha "L1" com espaçamento de 5 metros entre eletrodos.

Figura 6.6: Seção de resistividade da linha "L1" com espaçamento de 10 metros entre eletrodos

Figura 6.7: Seção composta da Linha 1 com os ensaios para diferentes espaçamentos entre eletrodos e sua relação com o afloramento .68

Figura 6.8: Seção de resistividade da linha "L2", com espaçamento de 10 metros entre os eletrodos .68

Figura 6.9: Seção de resistividade da linha "L3", com espaçamento de 10 metros entre eletrodos

Figura 6.10: Seção de resistividade da linha "L4", com espaçamento de 10 metros entre eletrodos.

Figura 6.11: Sobreposição dos resultados da SEV 1 e do CE da linha L3. 70

Figura 6.12: Seção de resistividade da linha "L5", com espaçamento de 10 metros entre os eletrodos .70

Figura 6.13: Sobreposição dos resultados da SEV 3 e do CE da linha L5.................71

Figura 6.14: Visualização do conjunto de perfis 2D de resistividade........................71

Figura 6.15: Modelo 3D da camada de arenito asfáltico. . .72

Figura 6.16: Comparação entre cromatrogramas da Fm Pirambóia e da Fm Irati....74

Figura 6.17: Seção de cargabilidade da linha "L1"......................................................75

Figura 6.18: Seção de cargabilidade da linha “L2"....................................................76

Figura 6.19: Seção de cargabilidade da linha "L3"......................................................76

Figura 6.20: Seção de cargabilidade da linha “L4"......................................................76

Figura 6.21: Seção de cargabilidade da linha "L5".....................................................77

Figura 6.22: Medição em afloramento de arenito asfáltico com arranjo Wenner........78

Figura 6.23: Medição em afloramento em flanco do paredão......................................78

Figura 6.24: Seção de condutividade da linha "L1" ".............................................. 79 


\section{SUMÁRIO}

CAPÍTULO I - INTRODUÇÃO.................................................................

1.1 Aspectos gerais.....................................................................................

1.2 Introdução e objetivos...................................................................................

1.3 Conceitos complementares.......................................................................

1.3.1 Sistemas petrolíferos......................................................................

1.3.2 Arenito asfáltico (..............................................................................

CAPÍTULO II - REVISÃO BIBLIOGRÁFICA................................................

2.1 Geofísica/hidrocarbonetos.........................................................................

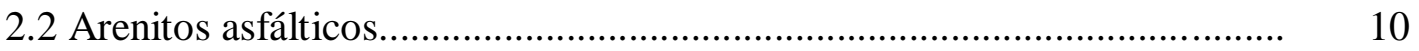

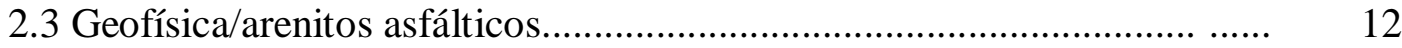

CAPÍTULO III - ÁREA DE ESTUDO............................................................ 14

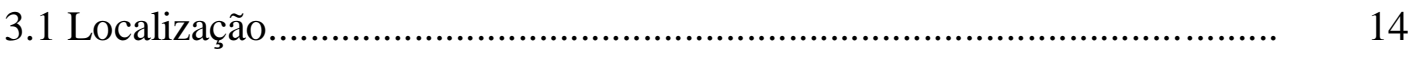

3.2 Contexto geológico regional.................................................................... 15

3.2.1. Bacia do Paraná................................................................................ 15

3.2.2 Sistemas petrolíferos da Bacia do Paraná............................................ 17

3.2 3. Formação Irati............................................................................... 19

3.2.4. Formação Pirambóia........................................................................... 20

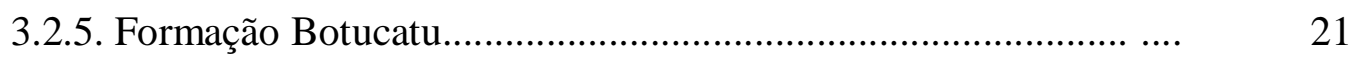

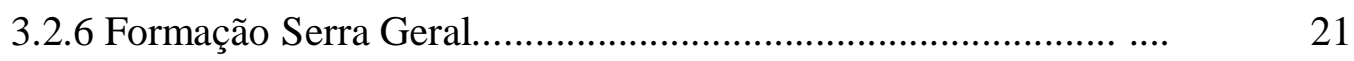

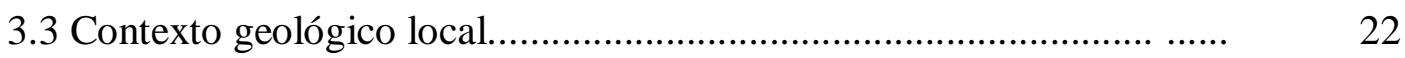

3.3.1 Gênese e caracterização dos arenitos asfálticos.............................. 22 
CAPÍTULO IV-METODOLOGIA....................................................... 28

4.1 Método da eletrorresistividade (ER) ............................................... 28

4.1.1 Fundamentos teóricos...................................................................... 28

4.2 Método da polarização induzida (IP) ................................................... 34

4.2.1 IP no domínio do tempo............................................................... 36

4.2.2 Fontes de efeito de polarização induzida.................................................... 38

4.2.2.1 Polarização de membrana............................................................ 38

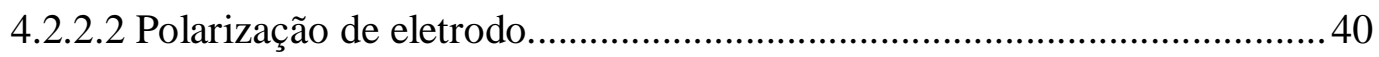

4.2.3 Aquisição de dados de eletrorresistividade e polarização induzida......... 41

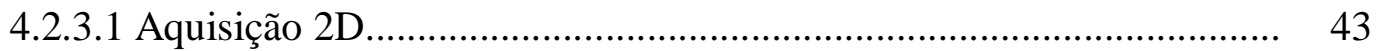

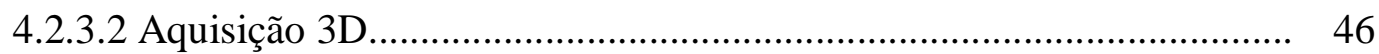

4.2.4 Interpretação dos dados de ER e IP........................................................ 47

4.2.4.1 Interpretação qualitativa............................................................ 47

4.2.4.2 Interpretação quantitativa............................................................. 48

4.3 Método eletromagnético indutivo (EM) ............................................... 51

4.3.1 Fundamentos teóricos................................................................. 52

4.3.2 Aquisição e interpretação de dados eletromagnéticos....................... 54

CAPÍTULO V - AQUISIÇÃO E PROCESSAMENTO DOS DADOS......... 56

5.1 Equipamentos utilizados............................................................ 56

5.2 Trabalhos realizados em campo..................................................... 58

CAPÍTULO VI - INTERPRETAÇÃO E DISCUSSÃO DOS RESULTADOS/ CONCLUSÕ EES .................................................................................. 61

6.1 Sondagens elétricas verticais......................................................... 61

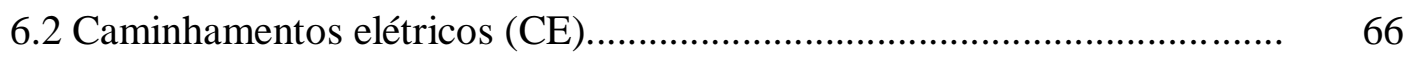

6.2.1 Dados de resistividade.................................................................... 66 
6.2.2 Dados de polarização induzida........................................................ 74

6.3 Levantamentos ER em afloramento.................................................. 77

6.4 Caminhamento eletromagnético......................................................... 79

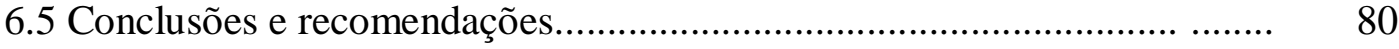

REFERÊNCIAS BIBLIOGRÁFICAS...................................................... 82 


\section{CAPÍTULO I - INTRODUÇÃO}

\subsection{ASPECTOS GERAIS}

O presente trabalho está estruturado em seis capítulos, divididos com o intuito de organizar o assunto e os dados e introduzí-los em uma ordem que melhor proporcione sua compreensão para quem o consulte. Os capítulos estão divididos da seguinte forma:

O capítulo 1, Introdução, apresenta a descrição sucinta da dissertação, o contexto que determinou a escolha do tema da pesquisa, sua motivação e objetivos, e introduz alguns conceitos básicos considerados relevantes para a inserção do leitor no tema.

O capítulo 2, Revisão bibliográfica, elenca trabalhos anteriores relacionados ao tema e/ ou principais trabalhos realizados na área de estudo e os que serviram como base ou direcionamento para alguns aspectos da pesquisa.

O capítulo 3, Área de estudo, apresenta os contextos geológicos regional e local, a caracterização dos arenitos asfálticos e uma síntese de sua formação na área de estudo.

O capítulo 4, Metodologia, apresenta os fundamentos teóricos dos métodos utilizados: eletrorresistividade, polarização induzida e eletromagnético indutivo.

O capítulo 5, Aquisição e processamento dos dados, descreve os ensaios realizados em campo, os equipamentos utilizados e a forma como os dados foram processados.

O capítulo 6, Interpretação e discussão dos resultados, discute as informações obtidas, sua adequação aos objetivos e suas possibilidades de aplicação, encerrando com a conclusão. 


\subsection{INTRODUÇÃO E OBJETIVOS}

A sociedade humana, desde muito tempo, tem se desenvolvido em torno das mesmas fontes de energia. A vida, como conhecemos hoje, está totalmente atrelada à atividade de exploração de combustíveis fósseis, que respondem por cerca de $90 \%$ da matriz energética global, representados pelo petróleo, GNP (gás natural de petróleo) e carvão mineral. Em 2012, apenas os derivados de petróleo e o gás natural responderam por $50,7 \%$ da matriz energética brasileira e por $53,2 \%$ na matriz energética mundial (Ministério de Minas e Energia, 2013). O petróleo é particularmente determinante no nosso desenvolvimento econômico e o grau de dependência em relação ao mesmo aumentou hiperbolicamente nas últimas décadas.

É consenso a necessidade de expansão da matriz energética, de inserção de hábitos que reduzam o consumo de bens e energia em nossa cultura, de implementação de práticas sustentáveis que assegurem a perpetuação da nossa sociedade, através principalmente do desenvolvimento de tecnologias direcionadas à exploração de energia proveniente de fontes renováveis, mas na realidade atual esta mudança caminha a passos muito lentos, e a pesquisa relacionada aos recursos de combustíveis fósseis, inclusive o desenvolvimento de tecnologias que nos permitam explorar economicamente reservas antes inviáveis, ainda é extremamente necessária.

As reservas mundiais de petróleo mais acessíveis ou economicamente viáveis, devido à sua extensão ou qualidade do óleo, têm vida útil restrita e acumulações não convencionais tem sido exploradas. Essas reservas não convencionais de óleo ocorrem em várias regiões do mundo e, apesar do tamanho real das reservas não estar bem definido, estima-se uma quantidade de cerca de 354 a 670 bilhões de barris de betume recuperáveis (OSRRN, Oil Sands Reclamation Research Network, Universidade de Alberta, 2003), como mostra a figura 1.1. As reservas do Canadá, que talvez perfaçam $1 / 3$ das reservas mundiais de arenitos asfálticos (além de ser a maior acumulação mundial de hidrocarbonetos em geral), podem conter uma quantidade de óleo da ordem de 1.6 a 2.5 trilhões de barris, e as da Venezuela de 1.2 trilhões de barris (O Estado de São Paulo, agosto de 2003, apud Araújo, 2003), ou seja, 
essas acumulações tem volume suficientemente expressivo para constituir uma fonte alternativa às grandes acumulações do Oriente Médio. Também são conhecidas ocorrências menores em vários estados norte americanos, na Nigéria e em Trinidad \& Tobago (Araújo, op. cit.). Uma estimativa da distribuição dos recursos petrolíferos mundiais e das reservas de óleo pesado é mostrada na figura 1.2.

\begin{tabular}{|cc|}
\hline Região & Reservas recuperáveis \\
\hline Canadá & 265,5 \\
Rússia & 76,2 \\
Estados Unidos & 4,3 \\
África & 4,0 \\
Transcaucácia e Ásia Central & 2,0 \\
China & 1,0 \\
América do Sul & 0,9 \\
Europa Oriental & 0,1 \\
Total Mundial & 354,0 \\
\hline *Em bilhões de barris assumindo um fator de recuperação de $10 \%$; dados adaptados do \\
USGS, OIL \& Gas Journal e AAPG \\
\hline
\end{tabular}

Figura 1.1: Recursos de arenitos asfálticos recuperáveis no mundo, segundo a OSRRN (2003). Modificado de Araújo (2003).

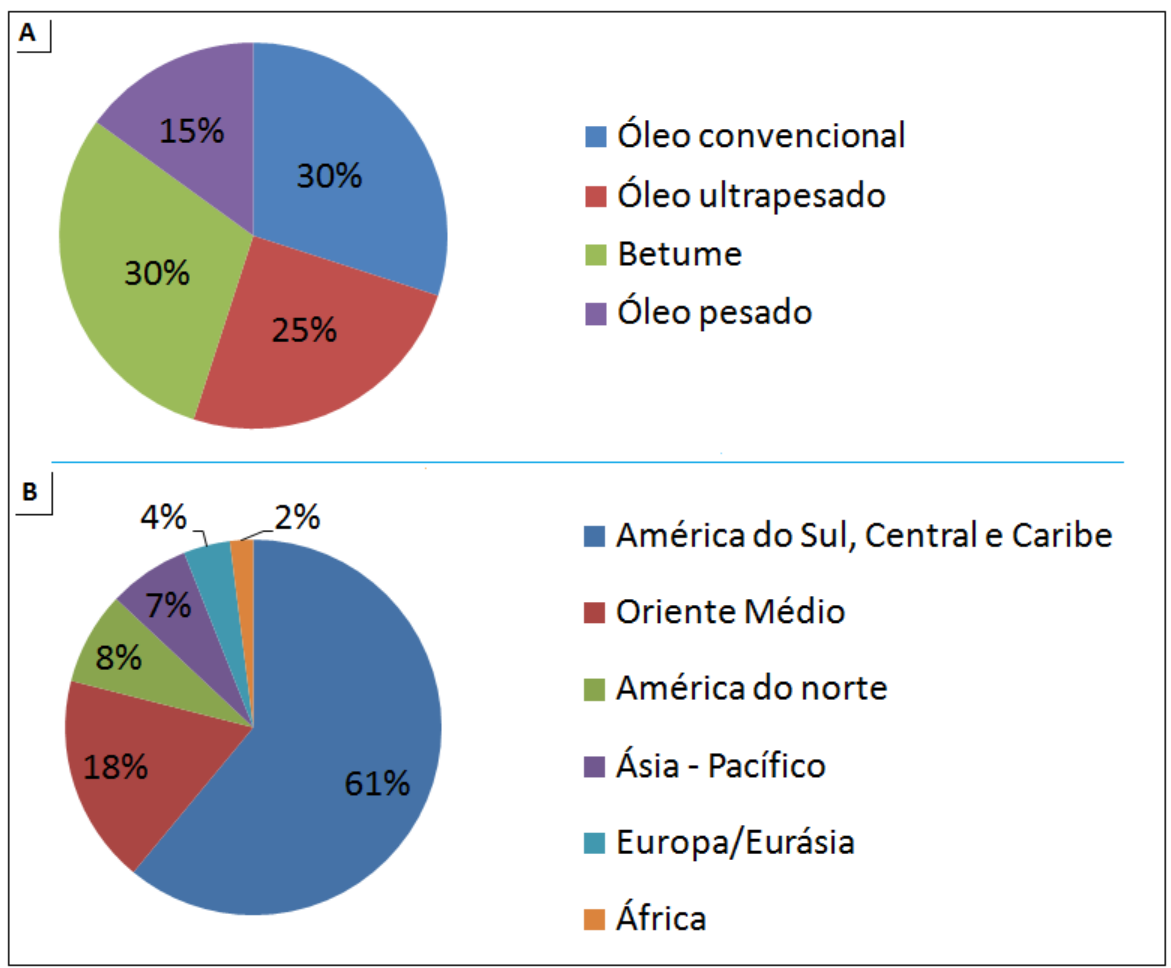

Figura 1.2: Estimativa dos recursos petrolíferos mundiais $(A)$ e distribuição das reservas de óleo pesado por continente (B). Adaptado de Schlumberger (2006). 
Ao desviarmos um pouco a atenção do cenário principal da exploração de petróleo no Brasil (mais concentrado nas bacias marítimas e costeiras) vemos que a Bacia do Paraná, do tipo intracratônica, tem seu potencial para prospectividade de hidrocarbonetos sendo pesquisado a algumas décadas, por apresentar as condições geológicas básicas para a acumulação de HCs em diferentes partes da bacia (possui formações geradoras conhecidas e formações com boas características para reservatório, com relações espaciais adequadas). Bacias intra-cratônicas são exploradas com bons resultados em vários países, algumas bacias norte americanas desse tipo, em fase avançada de exploração, produzem cerca de 10 milhões de barris de óleo por $1000 \mathrm{~km}^{2}$ (Yoshida \& Gama Jr., 1982), mas no Brasil ainda há uma carência em estudos nas bacias continentais.

A pesquisa de petróleo é indireta e muito interdisciplinar, sendo necessária uma pesquisa dividida entre diversas áreas de conhecimento para investigar os parâmetros básicos necessários (estratigrafia, estudos de características de permo-porosidade, geologia estrutural, geoquímica de rochas, geofísica). A complexidade relativa a essa atividade exploratória torna a pesquisa altamente interpretativa e baseada na quantidade e qualidade de dados disponíveis. Yoshida e Gama Jr. (op cit.) enfatizam que as etapas de sucesso nos estudos de prospecção de HCs são sempre iniciadas a partir de reavaliações da potencialidade de uma área, desencadeadas pela introdução de novos dados adquiridos na bacia.

Os arenitos asfálticos da Bacia do Paraná constituem uma acumulação não convencional de hidrocarbonetos, e foram alvo de vários trabalhos nos últimos anos, a maioria de cunho geológico, intencionando entender e descrever sua gênese e suas relações com o arcabouço estratigráfico e evolução tectônica da bacia. Alguns deles propõem a possibilidade de se encontrar áreas com acumulações de melhor qualidade em regiões centrais da bacia, o que torna ainda mais importante o estudo desse tipo de rocha nas áreas de borda da mesma, que pode servir de base para a procura de outros alvos posteriormente. 
Em função de todos esses fatores, esse trabalho foi desenvolvido com o objetivo de contribuir com o estudo de reservatórios não convencionais de óleo e com o entendimento do sistema petrolífero Irati-Pirambóia, aplicando uma técnica ainda não utilizada anteriormente na caracterização da acumulação, gerando assim novos dados que, espera-se, possam ser utilizados na pesquisa de hidrocarbonetos em outras áreas da Bacia do Paraná.

\subsection{CONCEITOS COMPLEMENTARES}

\subsubsection{SISTEMAS PETROLÍFEROS}

O conceito de sistema petrolífero surgiu a partir dos estudos realizados por Dow (1972) e rapidamente se difundiu na indústria do petróleo, tornando-se uma ferramenta exploratória eficiente e muito utilizada. Demaison e Huizinga (1991) classificam o termo como um sistema físico-químico dinâmico, gerador e concentrador de petróleo, cuja funcionalidade se dá numa determinada escala de tempo e espaço geológicos.

A definição mais utilizada na literatura, de Magoon e Dow (1994), descreve um sistema petrolífero como "um sistema natural que abrange um gerador ativo e 0 petróleo a este relacionado, incluindo todos os elementos essenciais e os processos necessários para a formação de acumulações." Os elementos essenciais seriam a rocha geradora, a rocha reservatório, a rocha selante, rochas de sobrecarga e armadilha; os processos necessários seriam a geração de hidrocarbonetos, a formação da armadilha, a migração do $\mathrm{HC}$, e o sincronismo para que o resultado seja uma acumulação ideal (figura 1.3).

De acordo com os autores (Magoon \& Dow, 1994) estabelecer a relação genética entre rocha geradora e reservatório é fundamental para definir um sistema petrolífero, que é designado pelo nome da rocha geradora, seguido pelo nome da rocha reservatório principal (o que contenha o maior volume cubado de hidrocarbonetos), seguido por fim pelo símbolo indicativo do nível de certeza atribuído ao sistema. A relação genética entre uma rocha fonte e uma rocha reservatório é estabelecida através de estudos geoquímicos da matéria 
orgânica contida nas duas camadas em questão, e o resultado dessa análise pode classificar o sistema em três níveis de certeza:

- Conhecido: quando existe uma boa correlação geoquímica entre a rocha geradora e as acumulações. É representado pelo símbolo (!);

- Hipotético: quando a informação geoquímica demonstra a existência de uma rocha geradora mas não consegue estabelecer uma relação entre a mesma e 0 óleo das acumulações. Usa-se o símbolo (.);

- Especulativo: quando a existência da rocha geradora é baseada apenas em evidências geológicos e/ou geofísicos, mas ainda não foi possível realizar análises químicas. Usa-se o símbolo (?).

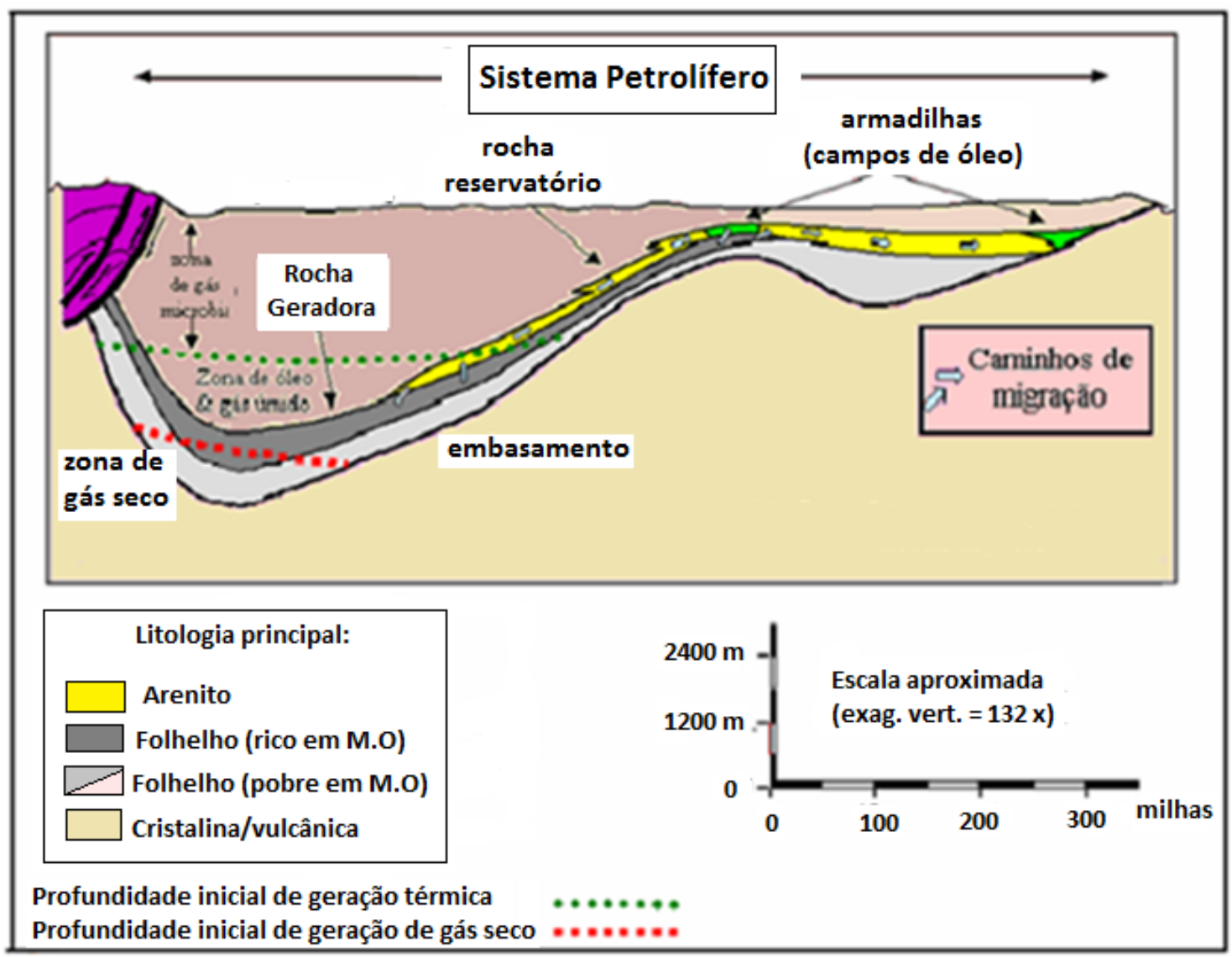

Figura 1.3: Elementos de um sistema petrolífero hipotético (modificado de Magoon \& Dow, 1994 e Lisboa, 2006). 


\subsubsection{ARENITO ASFÁLTICO}

$\mathrm{O}$ arenito asfáltico ou arenito betuminoso (em inglês oil sands, tar sands, asphaltic sandstones, bitumen-impregnated sandstones ou heavy-oil deposits) é um arenito composto por grãos siliciclásticos ou carbonáticos impregnados, nos poros, por um óleo cru pesado, semelhante ao asfalto, chamado betume. Contém, em média, de 10 a $15 \%$ de óleo, sendo o restante composto pela matriz mineral (Araújo, 2003). Acumulações de arenitos asfálticos, geralmente, correspondem a reservatórios exudados de petróleo, onde a falta de uma camada capeadora (ou sua ineficácia) ou a erosão da mesma permitiram o escape dos hidrocarbonetos para a superfície e sua consequente degradação. Devido à sua alta viscosidade, o óleo desses arenitos pode ser explorado, mas precisa ser extraído através de técnicas não convencionais, o que aumenta bastante o custo de produção. Outro problema apresentado na exploração desse tipo de acumulação é ambiental, devido aos níveis de poluição gerados na lavra e tratamento de rejeitos (OSRRN, Oil Sands Reclamation Research Network, Universidade de Alberta, 2012). 


\section{CAPÍTULO II - REVISÃO BIBLIOGRÁFICA}

\subsection{GEOFÍSICA E HIDROCARBONETOS}

O uso dos métodos geofísicos em estudos relacionados a hidrocarbonetos costuma ocorrer em duas frentes principais: uma aplicação em trabalhos na área ambiental (na investigação indireta de áreas contaminadas por derivados de hidrocarbonetos, por exemplo) e uma aplicação efetiva na procura de hidrocarbonetos comercialmente exploráveis. Seu uso em investigações ambientais é muito comum, onde são empregados principalmente os métodos geoelétricos, em especial os métodos de eletrorresistividade, polarização induzida, eletromagnético indutivo e radar de penetração no solo (GPR). A eficiência de sua aplicação nessa área se deve ao fato de que a presença de contaminantes nos meios geológico e hidrológico altera significativamente os parâmetros físicos pesquisados nesses métodos (condutividade, resistividade, cargabilidade), tornando possível a confirmação e delimitação de plumas de contaminantes e o monitoramento de sua dispersão no solo ou no lençol freático. Além disso sua execução é rápida e seu custo relativamente baixo. Diversos tipos de indústrias, especialmente as indústrias químicas, utilizam derivados de petróleo em todas ou alguma fase de seus processos de produção, e comumente os resíduos e efluentes industriais são dispostos de maneira incorreta no ambiente, resultando na contaminação do solo e consequentemente da água subterrânea. Um meio impactado por um contaminante derivado de hidrocarbonetos pode apresentar uma resposta geofísica de anomalia de alta ou de baixa resistividade, dependendo do tempo de permanência do contaminante no meio e o grau de exposição aos processos de degradação.

Líquidos contaminantes são denominados de líquidos de fase não aquosa (NAPL - nonaqueous phase liquid), e podem ser divididos em LNAPLs (light nonaqueous phase liquid), menos densos que a água, e DNAPLs (dense nonaqueous phase liquid), mais densos que a água. A maioria dos combustíveis se comporta como LNAPLs, flutuando sobre a água subterrânea. 
De acordo com o API, American Petroleum Institute, os principais tipos de LNAPLs são a gasolina, os destilados médios de petróleo (diesel e querosene), combustíveis pesados e óleos lubrificantes (além do etanol, no caso do Brasil). Os compostos predominantes na composição da gasolina são alifáticos e aromáticos, sendo que a este segundo grupo pertencem os compostos BTEX (benzeno, tolueno, etilbenzeno e xileno), que apresentam alto risco de contaminação para águas subterrâneas devido à sua volatilidade e solubilidade (Marques, 2007).

Uma prática comum na geofísica ambiental é o uso integrado de diferentes métodos, aliados ainda à análises químicas em amostras de água subterrânea retiradas dos locais contaminados, e inúmeros trabalhos podem ser citados para exemplificar esse ramo de atuação da geofísica. Lima et al. (1995) utilizaram as técnicas combinadas de Caminhamento Elétrico e Sondagem Elétrica Vertical para detectar plumas de contaminação provenientes de um aterro de resíduos líquidos derivados de petróleo, em que a correlação das pseudo-seções de resistividade aparente e das amostras de poços de monitoramento permitiram a associação de intervalos de baixa resistividade à zona de concentração de contaminantes. Benson et al. (1997) utilizou métodos elétricos e eletromagnéticos para mapear plumas compostas por benzeno, tolueno, xileno e etil-benzeno e grande quantidade de sólidos totais dissolvidos, conseguindo detectar uma anomalia de alta resistividade e associá-la à uma zona de alta concentração de hidrocarbonetos sob a forma de fase livre pouco degradada. Moreira, Dourado \& Braga (2006) utilizaram a técnica de caminhamento elétrico no monitoramento da atenuação natural de uma pluma de contaminantes por derivados de petróleo em uma área industrial desativada identificando anomalias de alta resistividade associadas ao poço de injeção dos resíduos. Na mesma área Moreira e Dourado (2006) utilizaram GPR que também identificou zonas de alta condutividade no lençol freático, associadas à pluma em processo de biodegradação avançado, uma vez que o sinal eletromagnético é atenuado em meios com elevada condutividade.

Azambuja et al (1999) destacam o uso da eletrorresistividade com as técnicas de caminhamento elétrico e sondagem elétrica vertical na detecção de hidrocarbonetos em cinco contaminações de postos de combustível, nas quais 
zonas de anomalias resistivas corresponderam às zonas contaminadas (dados corroborados por análises geoquímicas de amostras).

Atekawana et. al (2000) utilizaram os métodos eletrorresistividade, GPR e EM para identificar uma pluma de contaminação por hidrocarbonetos antiga, onde zonas de sombra e regiões com atenuação das reflexões de GPR, coincidentes com as menores resistividades aparentes, foram associadas à biodegradação da pluma.

Em outra frente, a geofísica é uma ferramenta fundamental para a indústria petrolífera, sendo aplicada principalmente nas fases de análise regional para identificação de zonas de interesse. Os levantamentos geofísicos nesse âmbito são muito complexos, caros e demorados, devido à extensão das áreas pesquisadas, sendo portanto realizados em várias etapas e a partir de iniciativa privada, não sendo comum pesquisas acadêmicas desse tipo. Os métodos mais utilizados para essa análise regional procuram identificar feições estruturais passíveis de gerar acumulações, e são a aeromagnetometria, a gravimetria e os métodos sísmicos. Após a etapa de pesquisa regional, uma pesquisa de semidetalhe será feita, e nessa etapa utilizam-se alguns métodos em poços, como perfilagem elétrica, perfilagem sônica, sondagem elétrica vertical e sondagem magnetotelúrica para um mapeamento geológico de detalhe, além da sísmica de reflexão.

\subsection{ARENITOS ASFÁLTICOS}

O primeiro trabalho sobre uma ocorrência de arenito asfáltico na Bacia do Paraná foi apresentado por Auguste Collon em 1897 (apud Araújo, 2003), no qual sugeriu que o betume presente no arenito na região do Morro de Bofete (bem próximo à área de estudo deste trabalho) seria proveniente de um reservatório profundo de petróleo que teria sofrido uma ruptura.

Oliveira (1920) fez uma das primeiras descrições de afloramentos de arenitos asfálticos do Estado de São Paulo, notando suas proximidades com diques de rochas magmáticas. 
Washburne (1930) infere, pela posição estratigráfica dos arenitos da Formação Pirambóia, a provável origem do óleo na Formação Irati.

Andrade e Soares (1971, apud Araújo, 2003), baseando-se também na análise da posição geográfica das jazidas de arenitos asfálticos, reforçam a origem do óleo nos folhelhos da Formação Irati.

Franzinelli (1972) faz a descrição e análise de vários afloramentos de arenito asfáltico na região em torno da área de estudo (região de Anhembi, Bofete, Torre de Pedra e Angatuba), detalhando características sedimentológicas e mineralógicas das ocorrências e características geoquímicas dos betumes, e sugere a origem do óleo na camada de calcários do Irati.

Thomaz Filho (1982) estudou a ocorrência de Anhembi, na área de estudo, em um projeto desenvolvido pela Petrobrás com o objetivo de definir a quantidade de óleo presente nas ocorrências e determinar os parâmetros geológicos envolvidos nos processos de geração, migração e acumulação do óleo. $\mathrm{Na}$ pesquisa 26 furos foram realizados, testemunhados e perfilados, e as principais informações obtidas foram sobre os teores de óleo encontrados (graus de impregnação por óleo desde indícios até cerca de 17\%, área de ocorrência do óleo em torno de $0,4 \mathrm{~km}^{2}$ e espessura dos arenitos impregnados de mais de 80 metros).

Araújo (2003) faz uma compilação dos principais trabalhos relacionados ao tema, além de realizar algumas aquisições geofísicas (gravimétricas) e uma análise detalhada (sedimentológica, geoquímica, estrutural) da maioria das ocorrências da borda leste da Bacia do Paraná no Estado de São Paulo para propor um modelo genético para os arenitos asfálticos, segundo o qual a migração do óleo, proveniente dos folhelhos da Fm. Irati, sofreu influência das rochas básicas da Fm. Serra Geral, que agiram ora como caminhos de migração, ora como barreiras para a mesma, acumulando-se, por fim, nos arenitos basais da Fm. Pirambóia, devido à suas características permo-porosas e dissipação da força de impulsão.

Garcia et al (2011) realizaram um estudo de correlação entre os condicionantes faciológicos e geoquímicos dos arenitos asfálticos da área de estudo, no qual 
sugerem que o controle de fácies sobre as características geoquímicas dos óleos nesses reservatórios pode estar associado à forma como o reservatório foi preenchido ou aos processos de biodegradação dos óleos.

\subsection{GEOFÍSICA E ARENITOS ASFÁLTICOS}

Os trabalhos de geofísica relacionados a arenitos asfálticos no Brasil se concentram nos arenitos da área de estudo e próximos a ela, pois todas as ocorrências conhecidas se encontram nessa região (borda leste da Bacia do Paraná).

Thomaz Filho (1982) faz uma síntese da pesquisa realizada na área de estudo por geólogos da Petrobrás e da Geosol em 1981. Neste trabalho foram feitos 26 furos de sondagem (perfurados continuamente até o contato da Formação Pirambóia com a Formação Teresina) posicionados em uma malha de 200 metros, com a intenção de delimitar a extensão da ocorrência. Os furos foram perfilados utilizando-se raios gama, potencial espontâneo e resistividade.

Em um nível regional, a gravimetria foi utilizada para estudar o comportamento do embasamento e de grandes compartimentos tectônicos. Quintas (1994) estudou o arcabouço da Bacia do Paraná utilizando gravimetria, cujos dados possibilitaram uma análise de diversos elementos estruturais relevantes.

Araújo (2003), além de utilizar os dados gravimétricos regionais anteriores, citados acima, realizou um levantamento em uma região ao sul da área de estudo, também uma área de ocorrência de arenitos asfálticos. O levantamento cobriu uma área de aproximadamente $1225 \mathrm{~km}^{2}$, com 372 pontos gravimétricos terrestres. Uma segunda fase de levantamento gravimétrico foi feita pelo autor na região do Alto Estrutural de Anhembi, com 163 pontos gravimétricos terrestres cobrindo uma área de $614 \mathrm{~km}^{2}$

A aeromagnetometria foi utilizada na área de estudo durante o projeto Botucatu, contratado pela Paulipetro em 1980 para a avaliação dos blocos 46, 47, 48 e 49 concedidos pela Petrobrás para a prospecção de petróleo (Araújo, 2003). Os dados serviram para detectar corpos de rochas básicas da 
Formação Serra Geral e falhamentos e mostraram que os arenitos asfálticos da região de Anhembi se localizam nas zonas de lineamentos magnéticos.

Ceia et al. (2003) utilizaram os métodos GPR em duas (2D) e três (3D) dimensões e perfilagem de poço com imageamento acústico, calíper e raios gama (além da análise dos testemunhos) com o objetivo de definir a litologia e a estratigrafia da zona impregnada com hidrocarbonetos na área de estudo. De acordo com os autores, o fato de o arenito em questão ser muito friável (tornando necessário revestir os primeiros 7 metros do poço) limitou a integração dos dados de perfilagem e testemunhos com o perfil GPR (que teve seu sinal atenuado a partir de 13 metros de profundidade), mas as informações obtidas com o perfil acústico televisivo (BHTV) mostrou boa correlação com a análise dos testemunhos. 


\section{CAPÍTULO III - ÁREA DE ESTUDO}

\subsection{LOCALIZAÇÃO}

A área de estudo situa-se no município de Anhembi, região centro-leste do Estado de São Paulo, cujos limites se dão com os municípios de Botucatu, Conchas, Piracicaba, Bofete e Santa Maria da Serra. Trata-se de uma antiga pedreira abandonada conhecida como lavra Betumita, que foi explorada da metade da década de 1930 até aproximadamente 1945 para fornecimento de material para pavimentação, sendo a ocorrência mais significativa de arenitos asfálticos entre as ocorrências conhecidas na região da borda leste da Bacia do Paraná (Araújo, 2003). O acesso ao local se dá aproximadamente no km 197 da Rodovia Samuel de Castro Neves (SP - 147), sentido Anhembi Piracicaba, cerca de $14 \mathrm{~km}$ a nordeste do município.

Trabalhos anteriores descreveram uma frente de lavra principal com cerca de 150 metros de comprimento e 20 metros de espessura, na qual podem ser observados dois maciços homogêneos de arenitos asfálticos intercalados com arenitos estéreis (Steveaux et al., 1980 apud Araújo, 2003) e também apresentaram uma estimativa de volume cubado de óleo de cerca de 5.712.000 barris (Thomaz Filho, 1982). A figura 3.1 mostra a localização do município de Anhembi no estado de São Paulo.

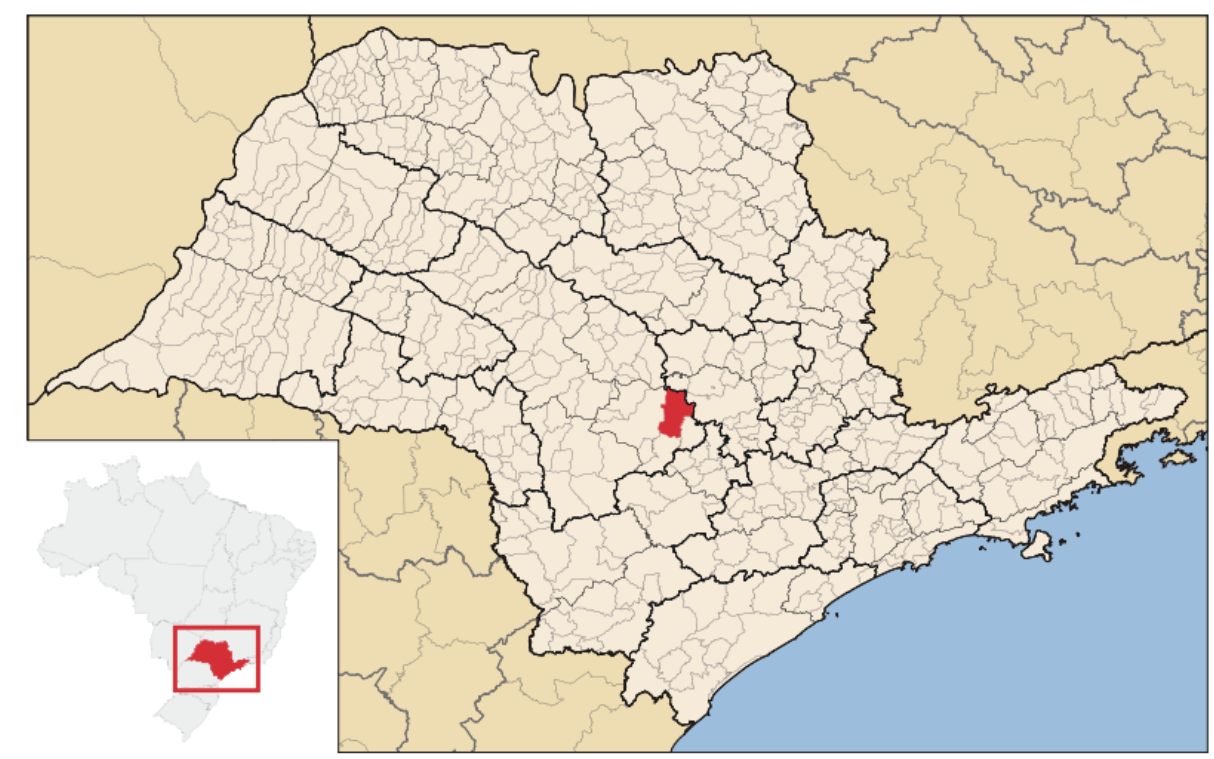

Figura 3.1: Localização de Anhembi no Estado de São Paulo. 


\subsection{CONTEXTO GEOLÓGICO REGIONAL}

\subsubsection{BACIA DO PARANÁ}

A Bacia do Paraná, do tipo intracratônica, é uma das maiores bacias sedimentares da América do Sul (sua área total ultrapassa 1.500.000 quilômetros quadrados) e sua sucessão sedimentar-magmática possui idades que variam do Neo-Ordoviciano até o Neo cretáceo. Foi originada por subsidência termal no Cambro-ordoviciano e sua evolução tectono-sedimentar ocorreu em três sequências sedimentares transgressivo-regressivas principais durante o Paleozóico e duas durante o Mesozóico, todas influenciadas pelo clima, anomalias termais e tensões relacionadas com o manto e derivadas da ruptura entre a América do Sul e a África (Zalan et al., 1991). As formações envolvidas na gênese dos arenitos asfálticos, pertinentes à este trabalho, pertencem à Supersequência Gondwana I, cuja deposição se deu do Carbonífero superior ao Triássico inferior, e compreendem principalmente as Formações Irati (Grupo Passa Dois), Pirambóia, Botucatu e Serra Geral (Grupo São Bento). A Formação Serra Geral será descrita brevemente nesse capítulo, devido à sua participação na geração e migração dos hidrocarbonetos do sistema petrolífero Irati-Pirambóia. Além das rochas do Grupo São Bento, também afloram na área de estudo rochas do Subgrupo Irati e da Formação Teresina. Diversos autores analisaram as ocorrências conhecidas de arenitos asfálticos na região da área de estudo (Franzinelli, 1972; Araújo, 2003) descrevendo a sequência aflorante iniciando-se, na base, por folhelhos e calcários relativos à rochas do Subgrupo Irati. Em seguida, siltitos roxos intensamente fraturados das Formações Serra Alta (inferior) e Teresina (superior); acima da Formação Teresina, a camada Porangaba, composta principalmente por brechas de matriz pelítica ou arenosa, pode ser observada, localmente (Matos, 1995). Acima, iniciando a sequência do Grupo São Bento, encontra-se a Formação Pirambóia, que constitui a rocha reservatório do sistema petrolífero Irati-Pirambóia, na qual ocorrem a quase totalidade das ocorrências de arenitos asfálticos, descrita no item 3.2.3. Em seguida encontrase a Formação Botucatu, composta por arenitos avermelhados, com estratificações cruzadas de grande porte, tangenciais na base (Araújo, 2003) e, 
por fim, rochas básicas da Formação Serra Geral, descrita no item 3.2.6. A figura 3.2 apresenta a coluna estratigráfica da Bacia do Paraná.

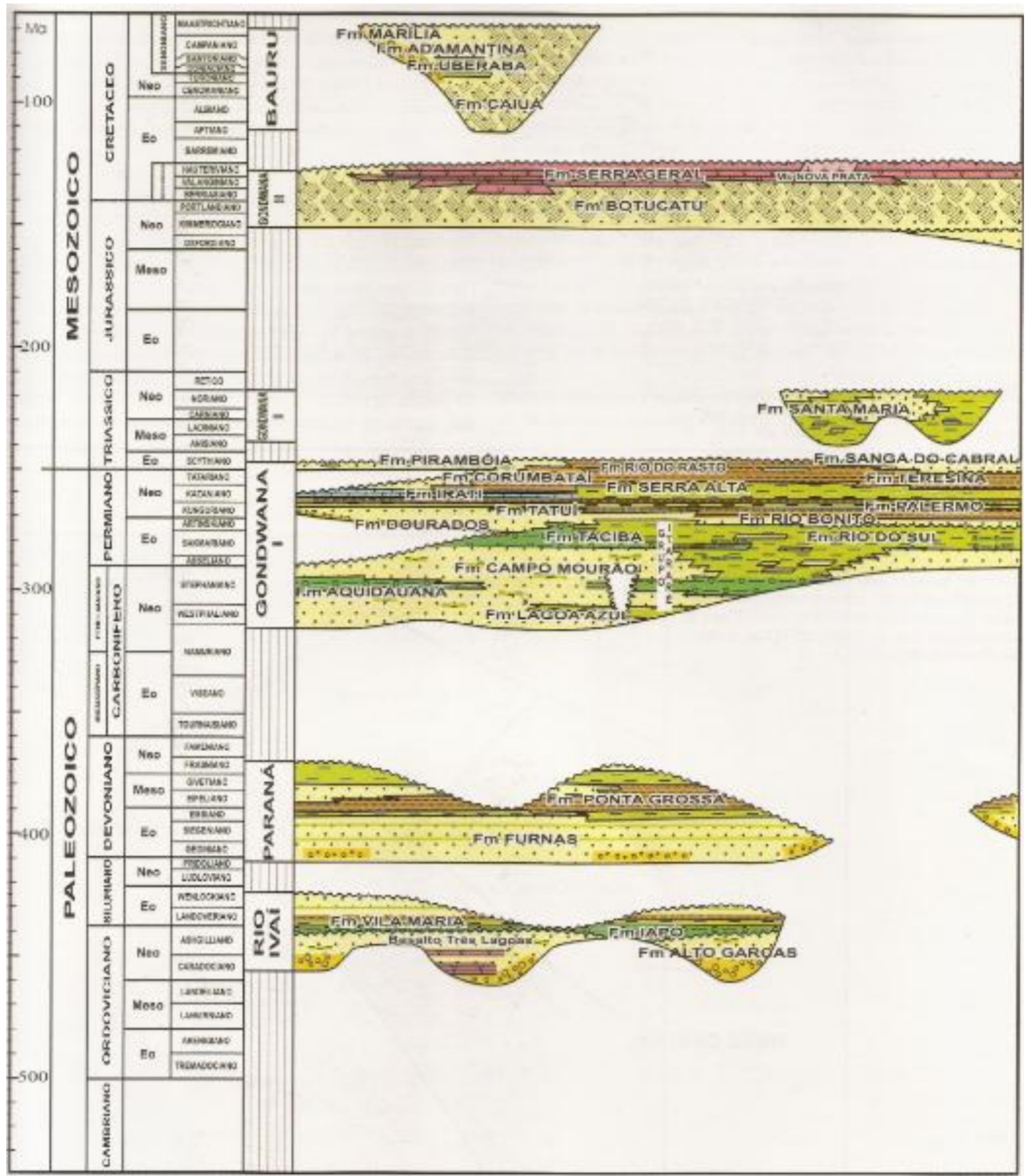

Figura 3.2: Coluna estratigráfica da Bacia do Paraná (Milani, 2007). 


\subsubsection{SISTEMAS PETROLIIFEROS DA BACIA DO PARANÁ}

Apesar de atualmente as bacias sedimentares marítimas e costeiras serem as principais produtoras de petróleo no Brasil, foi na Bacia do Paraná que se iniciou a pesquisa de hidrocarbonetos no país, em 1892, e desde então houve inúmeras campanhas investigativas e esforços sistemáticos em função de seu potencial de geração, tanto de iniciativas privadas quanto governamentais, os quais mostraram que a bacia possui as condições geológicas básicas necessárias para a ocorrência de acumulações de hidrocarbonetos (Yoshida \& Gama Jr, 1982). Milani et al. (1998) identificam dois sistemas petrolíferos principais na bacia: Ponta Grossa - Itararé e Irati - Rio Bonito. Ou seja, as rochas geradoras na bacia pertencem às Formações Ponta Grossa e Irati, mas existe maior diversidade de rochas reservatório. Pode-se identificar a presença de hidrocarbonetos migrados da Fm. Irati nas rochas das formações Rio Bonito, Pirambóia e Palermo, por exemplo, e de hidrocarbonetos migrados da Fm. Ponta Grossa em rochas das formações Itararé e Furnas (Lisboa, 2006). Conforme mencionado no Capítulo I, Magoon e Dow (1994) definem que o principal reservatório é aquele que possui maior volume de óleo in place, mas há controvérsias entre os autores na literatura. Como a grande maioria das ocorrências de arenitos asfálticos pertencem à arenitos da Formação Pirambóia, o que resulta no reconhecimento do sistema Irati-Pirambóia, assim denominado e estudado por diversos autores (Araújo, 2003; Ferreira, 2010), esse será o sistema petrolífero citado neste trabalho.

Scheneider et al., (1974) descrevem a Fm. Ponta Grossa como uma sequência de folhelhos, folhelhos siltosos e siltitos (estes podem ser localmente carbonosos, fossilíferos e micáceos) intercalados à arenitos cinza-claros. $\mathrm{O}$ COT (teor médio de carbono orgânico) da formação varia de $0.1 \%$ (muito pobre) a $0.6 \%$ (médio), com uma média em torno de $0.5 \%$, e estudos de caracterização da matéria orgânica identificaram uma subdivisão quanto à origem da mesma: material de origem predominantemente marinha e/ou mista à oeste da formação, e material de origem predominantemente continental à leste (Goulart e Jardim, 1982). Estes autores delimitam quatro zonas de "potencialidade de geração" na formação: as zonas "muito boa" e "boa" correspondem à área em que há predominância de matéria orgânica de origem 
marinha e as zonas "regular" e "pobre" à área com predominância de matéria orgânica de origem continental. Os folhelhos possuem nível elevado de evolução termal e potencial para produção de gás e condensado, sendo o valor máximo do potencial gerador de HCs em torno de $6.6 \mathrm{~kg}$ de HCs /Ton de rocha (Zalán et al, 1990).

Os folhelhos da Formação Irati são ricos em matéria orgânica amorfa, com potencial para gerar HCs líquidos, possuindo valores de COT variando de $0.1 \%$ a $23 \%$, mas com média de $2 \%$. O potencial gerador de HCs chega ao máximo de 100 200 mg de $\mathrm{HCs} / \mathrm{g}$ de rocha e a formação em geral possui um grau muito baixo de maturação térmica, o que não possibilitou a geração de hidrocarbonetos líquidos maduros, mas alguns autores sugerem áreas de exceção em relação a isso, como no depocentro da bacia sedimentar e regiões que sofreram alto efeito de elevação térmica devida às intrusões ígneas da Formação Serra Geral (Goulart e Jardim, 1982). Zalán et al (1990) caracteriza o óleo recuperado em poços na Fm. Rio Bonito na região sul do Paraná, proveniente da Fm. Irati, como um óleo pesado (grau API entre $22^{\circ}$ e $33^{\circ}$ ), acidez abaixo de $0.22 \mathrm{mg}$ de $\mathrm{KOH} / \mathrm{g}$ e teor de enxofre entre $0.2 \%$ e $9 \%$.

Os hidrocarbonetos gerados na Fm. Ponta Grossa encontram-se acumulados preferencialmente nos arenitos glaciogênicos do Grupo Itararé, cuja porosidade varia de $6 \%$ a $16 \%$ (suficiente para produzir gás e condensado). Como exemplo pode-se citar a ocorrência de Cuiabá Paulista, SP, reservatório de gás com porosidade entre $8 \%$ e 10\%, com uma vazão de 51000 m²/dia (Zalán et. al, 1990). Já os HCs gerados na Fm. Irati encontram-se acumulados em arenitos deltaicos de ótimas propriedadas permo-porosas (até 20\% de porosidade e boas condições de transmissibilidade) no caso dos reservatórios da Fm. Rio Bonito, ou em arenitos eólicos de granulometria média e boa porosidade/permeabilidade, no caso dos reservatórios da Fm. Pirambóia (Milani et al., 1990). No caso da extração em São Mateus do Sul, PR, o óleo é retirado diretamente de rochas da $\mathrm{Fm}$. Irati, através do processamento diário de cerca de 7800 toneladas de folhelho, a partir dos quais são geradas 480 toneladas de óleo combustível, 90 toneladas de nafta, 120 toneladas de gás combustível, 45 toneladas de GLP e 75 toneladas de enxofre (Revista Petro \& Química, 2004). 
Nos sistemas petrolíferos da Bacia do Paraná um fator importante para o não desenvolvimento de acumulações comercialmente relevantes foram as rochas selantes ou capeadoras do sistema. Folhelhos intraformacionais do Grupo Itararé seriam os selantes do sistema Ponta Grossa-Itararé, por exemplo, mas sua qualidade e continuidade lateral não são propícias, além de se encontrarem muito distantes da rocha reservatório. O sistema Irati-Rio Bonito tem como selantes os pelitos da Fm. Rio Bonito, Palermo e Irati, sendo nos dois primeiros casos selantes pouco eficientes e no terceiro o problema foi novamente a distância muito grande entre reservatório e selante.

\begin{tabular}{|c|c|c|c|c|}
\hline $\begin{array}{l}\text { Sistema } \\
\text { Geradora }\end{array}$ & $\begin{array}{l}\text { Ponta Grossa-Itararé } \\
\text { Folhelho }\end{array}$ & $\begin{array}{l}\text { Ponta Grossa-Rio Bonito } \\
\text { Folhelho }\end{array}$ & $\begin{array}{l}\text { Irati-Rio Bonito } \\
\text { Folhelho }\end{array}$ & $\begin{array}{l}\text { Irati-Piramboia } \\
\text { Folhelho }\end{array}$ \\
\hline $\begin{array}{l}\text { Supersequência (SS) } \\
\text { Grupo (G) } \\
\text { Formaçäo (F) } \\
\text { Membro }(\mathrm{M})\end{array}$ & $\begin{array}{l}\text { SS: Paraná } \\
\text { F: Ponta Grossa } \\
\text { M: Jaguariaiva }(20 \mathrm{~m})\end{array}$ & $\begin{array}{l}\text { SS: Paraná } \\
\text { F: Ponta Grossa } \\
\text { M: Jaguariaiva }(20 \mathrm{~m})\end{array}$ & $\begin{array}{l}\text { SS: Paraná } \\
\text { G: Passa Dois } \\
\text { F: Irati } \\
\text { M: Assistência }(30 \mathrm{~m})\end{array}$ & $\begin{array}{l}\text { SS: Paraná } \\
\text { G: Passa Dois } \\
\text { F: Irati } \\
\text { M: Assistência }(30 \mathrm{~m})\end{array}$ \\
\hline Idade da geradora & Devoniano & Devoniano & Permiano & Permiano \\
\hline $\operatorname{COT}(\%)$ & 1,7 a 2,3; máximo 3,0 & 1.7 a 2,3; máximo 3.0 & 1,0 a $13 ;$ máximo 23,0 & 1,0 a 13 ; máximo 23,0 \\
\hline Tipo de querogènio & II & II & 1 & 1 \\
\hline$P G(\mathrm{kgHC} / \mathrm{t})$ & 6 & 8 & 100 a 200 & 100 a 200 \\
\hline Reservatório & Arenito $(1500 \mathrm{~m})$ & Arenito $(280 \mathrm{~m})$ & Arenito $(280 \mathrm{~m})$ & Arenito $(130 \mathrm{~m})$ \\
\hline $\begin{array}{l}\text { Supersequência (SS) } \\
\text { Grupo (G) } \\
\text { Formação (F) } \\
\text { Membro (M) }\end{array}$ & $\begin{array}{l}\text { SS: Gondwana I } \\
\text { G: Itararé } \\
\text { F: Campo Mouräo e Taciba }\end{array}$ & $\begin{array}{l}\text { SS: Gondwana I } \\
\text { G: Guatá } \\
\text { F: Rio Bonito }\end{array}$ & $\begin{array}{l}\text { SS: Gondwana I } \\
\text { G: Cuatá } \\
\text { F: Rio Bonito }\end{array}$ & $\begin{array}{l}\text { SS: Gondwana I } \\
\text { F: Piramboia }\end{array}$ \\
\hline Idade do reservatório & Permiano & Permiano & Permiano & Triássico \\
\hline ø (\%) & 10 a 15 & 20 & 20 & 18 \\
\hline Possiveis selos & $\begin{array}{l}\text { Rochas vulcânicas e soleiras de } \\
\text { diabásio e folhelhos } \\
\text { intraformacionais do Grupo } \\
\text { Itararé }\end{array}$ & $\begin{array}{l}\text { Folhelhos da Formação Irati e } \\
\text { da Formaçäo Palermo }\end{array}$ & $\begin{array}{l}\text { Folhelhos da Formação Irati e } \\
\text { da Formaçäo Palermo }\end{array}$ & $\begin{array}{l}\text { Diques de rocha básica e as } \\
\text { fácies interduna e fluvial da } \\
\text { Formaçäo Pirambóia }\end{array}$ \\
\hline
\end{tabular}

Figura 3.3: Caracterização dos sistemas petrolíferos da Bacia do Paraná. "COT" é carbono orgânico total; os tipos de querogênio de acordo com Tissot \& Welte (1984); "PG" é potencial gerador; espessuras das camadas indicadas em metros entre parênteses; porosidade indicada (Ø). (Modificada de Magalhães, 2010).

\subsubsection{FORMAÇÃO IRATI}

Descrita originalmente como "Série de Itapetininga" por Oliveira (1889, apud Hachiro, 1991) e posteriormente chamada de "folhelho preto de Iraty" por White (1908, apud Hachiro, 1991), a formação se estende do Estado de São Paulo ao Rio Grande do Sul, sendo conhecida principalmente por seus folhelhos abundantes em restos fósseis do réptil Mesosaurus brasiliensis, mas compõese também por calcários, dolomitos e nódulos de sílex. De acordo com Hachiro (1991) a formação típica é descrita como uma "sucessão de siltitos e argilitos cinza escuros a pretos, folhelhos pretos (pirobetuminosos ou não), intercalados por leitos de rochas carbonáticas (calcários e dolomitos) e delgadas lentes centimétricas de sílex nodular". Tendo sido alvo de inúmeras investigações 
acerca de seu potencial como geradora de hidrocarbonetos na bacia, a formação é subdividida em dois membros, Taquaral (inferior) e Assistência (superior), subdivisão também adotada pelos geólogos da Petrobrás (Scheneider et al, 1974).

O Membro Taquaral apresenta, no Estado de São Paulo, espessuras variando entre 5 e 20 metros e se encontra em contato inferior concordante com a Fm. Palermo (em São Paulo, localmente, pode estar em contato discordante com a Fm. Tatuí). Compõe-se principalmente por folhelhos siltosos cinza escuros. $O$ Membro Assistência apresenta espessuras de 15 a 40 metros, e encontra-se em contato com o Membro taquaral (inferior) e a Fm. Serra Alta, ou, localmente, Fm. Corumbataí (superior), ambos concordantes. É composto por folhelhos pretos, pirobetuminosos, folhelhos e argilitos cinza escuros e carbonatos (geralmente dolomíticos; em São Paulo apresentam-se muito silicificados), segundo Hachiro (1991).

\subsubsection{FORMAÇÃO PIRAMBÓIA}

A Formação Pirambóia (neopermiano/eotriássico) é constituída por sedimentos de sistemas deposicionais flúvio-eólicos, em geral arenitos de granulometria fina a grossa, às vezes conglomeráticos, subarredondados e moderadamente selecionados. As camadas possuem coloração predominantemente avermelhada, e na área de estudo (na qual a espessura aflorante da Fm. pode chegar a 270 metros) colorações acinzentadas e pretas, em função da presença dos hidrocarbonetos asfaltênicos (Caetano- Chang e Wu, 2003; Milani et.al, 2007). Apresenta fácies de dunas, interdunas e lençóis de areia, típicas de deposição eólica, truncadas localmente por fácies argilosas, típicas de canais fluviais temporários (Caetano-Chang e Wu, 2003). O contato inferior da Fm. Pirambóia com as unidades do Grupo Passa Dois é transicional para alguns autores e discordante para outros. No topo encontra-se em contato discordante com a Fm. Botucatu, interdigitada com rochas ígneas da Fm. Serra Geral. 


\subsubsection{FORMAÇÃO BOTUCATU}

A Formação Botucatu é constituída por arenitos quartzosos de granulação fina a média, grãos bem selecionados e com alta esfericidade, depositados por sedimentação eólica em um ambiente desértico, mas pode-se observar em sua porção basal estruturas típicas de deposição em ambiente sub-aquoso. Representa, em geral, um extenso campo de dunas, apresentando colorações avermelhadas, róseas ou amarelo-claras. No Estado de São Paulo a formação apresenta espessuras variando entre 50 e 100 metros, mas pode chegar à 200 metros de espessura em outros locais da bacia. Em sua porção inferior faz contato com a Fm. Pirambóia de maneira transicional, e na porção superior mantém contato interdigitado com rochas ígneas da Fm. Serra Geral ou contato discordante com rochas do Grupo Bauru.

\subsubsection{FORMAÇÃO SERRA GERAL}

A formação Serra Geral é constituída por rochas magmáticas de caráter predominantemente básico (subordinadamente intermediário e ácido), provenientes de derrames e intrusões diversos relacionados ao maior evento vulcânico global conhecido, que se iniciou no Período Jurássico e se estendeu até o Terciário. Na Bacia do Paraná o evento datado como Neocomiano foi o mais expressivo, e recobriu o paleodeserto Botucatu, com estruturas de caráter intrusivo (diques e soleiras de diabásio) e extrusivo (derrames de basalto), pertencendo à Supersequência Gondwana III. A maioria dos derrames são basálticos toleíticos, com rochas de cor cinza escuro a preto, textura afanítica e espessuras variando desde dezenas de metros até $1,7 \mathrm{~km}$. A importância da formação para este trabalho reside no fato de que os derrames tiveram papel fundamental em todas as etapas envolvidas na formação dos arenitos asfálticos. As soleiras e intrusões básicas na bacia foram responsáveis pelo aumento da temperatura nas rochas geradoras e consequente maturação anômala da matéria orgânica nelas contida, que, na verdade, era bastante imatura. $\mathrm{O}$ aquecimento resulta em alterações estruturais e petrográficas nas rochas do pacote sedimentar, o que também facilitou a migração dos hidrocarbonetos gerados, e os diques e sills funcionaram ora como caminhos 
facilitadores para a migração, ora como barreiras para a migração horizontal ou vertical. Recentemente há novos estudos sobre a influência do magmatismo na geração de petróleo nas bacias sedimentares brasileiras, tanto intracontinentais quanto costeiras (por exemplo Araújo et al, 2205, 2006; Thomaz Filho et al, 2008).

\subsection{CONTEXTO GEOLÓGICO LOCAL}

\subsection{GÊNESE E CARACTERIZAÇÃO DOS ARENITOS ASFÁLTICOS}

A área de estudo do presente trabalho é constituída por afloramentos de arenitos da Formação Pirambóia onde pode-se observar facilmente as fácies de dunas e as fácies de inter-dunas do sistema deposicional flúvio-eólico. Nos paredões abertos durante a antiga atividade de lavra observam-se intercalações de arenitos finos com estratificações cruzadas acanaladas em séries métricas (representando as fácies de dunas) impregnados por óleo, intercalados com séries decimétricas a métricas de arenitos siltosos maciços (fácies interdunas). Ferreira (2010) descreve as duas fácies sedimentares principais no local:

- Arenito fino com estratificações cruzadas acanaladas, séries com 1 a 5 metros de espessura, com coloração acinzentada devido à presença de óleo;

- Arenito fino maciço, séries com 1 a 3 metros de espessura, coloração variando de cinza a esbranquiçada.

Em geral, arenitos asfálticos são compostos por grãos siliciclásticos ou carbonáticos impregnados, nos poros, por um óleo cru pesado semelhante ao asfalto. Contém, em média, de 10 a $15 \%$ de betume e o restante é composto por arenito ou outros materiais inorgânicos. Os arenitos asfálticos das ocorrências da Fm. Piramboia possuem granulometria média e boa permeabilidade e porosidade, tendo sido preenchidos secundariamente pelos hidrocarbonetos (Araújo, 2003). Ferreira (op.cit.) realizou uma estimativa visual e qualitativa para os graus de impregnação por betume na área de estudo, dividindo os afloramentos em quatro graus de impregnação (as porcentagens se referem à área da fácies): 
- Grau "0" : arenitos contendo de 0 a 10\% de óleo impregnado;

- Grau "1" : arenitos contendo de 11 a $40 \%$ de óleo impregnado;

- Grau "2" : arenitos contendo de 41 a $75 \%$ de óleo impregnado;

- Grau "3" : arenitos contendo de 75 a $90 \%$ de óleo.

Os maiores teores de óleo encontram-se em fácies de dunas eólicas, mais porosas, sendo que as fácies de interdunas e fluviais agiram como armadilhas horizontais (Araújo, op cit.). O mesmo autor propôs um modelo para a gênese desses arenitos asfálticos, dividindo os principais elementos relacionados à sua formação em quatro estágios principais, descritos resumidamente a seguir:

(1) A atividade tectônica na área gerou zonas de fraqueza e reativação de estruturas no embasamento. As rochas geradoras (folhelhos) foram fraturadas e formaram-se sismitos penecontemporâneos (figura 3.4 "A");

(2) Teve início a reativação Pós-Paleozóica, continuando o fraturamento das geradoras, junto com a deposição das Formações Pirambóia e Botucatu, bem como o início dos eventos magmáticos do Jurássico superior. As intrusões de rochas vulcânicas básicas da Formação Serra Geral promoveram um aquecimento anômalo nas rochas geradoras fraturadas e um aumento generalizado do grau geotérmico na bacia. Isso fez com que a matéria orgânica presente nos folhelhos sofresse uma maturação anômala, e a migração primária se iniciasse (figura 3.4"B");

(3) Inicia-se a migração secundária (através tanto de zonas de fraqueza antigas como de estruturas geradas na reativação Pós-Paleozóica) que foi principalmente influenciada por dois fatores:

A. Um fator estrutural, relacionado à contribuição dessa intensa atividade tectônica, que possibilitou a migração da matéria orgânica de áreas de baixo estrutural para áreas de centro de altos estruturais e determinou caminhos de migração em zonas de falhas e limites de blocos tectônicos;

B. Um fator estratigráfico, que condicionou o acúmulo preferencial da matéria orgânica na porção basal da Fm. Pirambóia, devida à variação de permeabilidade das diferentes fácies presentes, eólica, interdunas e fluviais (figura 3.4 "C"). 
(4) Ocorre a acumulação, preferencialmente nos arenitos da base da Formação, ao longo dos planos de estratificação e sob camadas de matriz argilosa de fácies de inter-dunas. Os diques de rochas vulcânicas básicas também serviram de barreira à migração horizontal da matéria orgânica, tornando comum a acumulação junto às paredes dos mesmos (figura 3.4 "D").

Observando que as ocorrências de arenito asfáltico se encontram nas bordas de altos estruturais, entende-se que os hidrocarbonetos migraram neste sentido e se acumularam nas rochas com características de reservatório presentes no alto dessas estruturas. Estes altos estruturais sofreram erosão desde o final do Período Cretáceo até hoje, destruindo as acumulações, e as ocorrências encontradas se encontram em áreas remanescentes que ainda não foram totalmente erodidas, estando em posições intermediárias entre altos e baixos estruturais (Araújo, 2003).

Especificamente para os arenitos da área de estudo (Anhembi), Ferreira (2010) sugere três fatores determinantes para a acumulação do óleo nas camadas basais do arenito Pirambóia:

1- A região está dentro da zona de influência dos calcários do Subgrupo Irati (nordeste a leste da bacia), que foram reservatórios intermediários entre a rocha geradora (folhelhos) e os arenitos permeáveis da Formação Pirambóia.;

2- A área está nas proximidades da Falha de Jacutinga com direção NE, que propiciou a formação de diques de mesma direção, que serviram como barreiras para a migração horizontal e caminho de migração vertical, propiciando a migração e acumulação do óleo na rocha reservatório;

3- A região localiza-se na borda leste da Bacia do Paraná, onde as espessuras das unidades intermediárias, entre as rochas geradoras e reservatórios, são menores. Isto torna o caminho de migração entre a rocha geradora e a rocha reservatório mais curto.

A figura 3.5 mostra um mapa geológico simplificado da área de estudo e a figura 3.7 mostra um quadro de sucessão de eventos na formação dos arenitos asfálticos. 


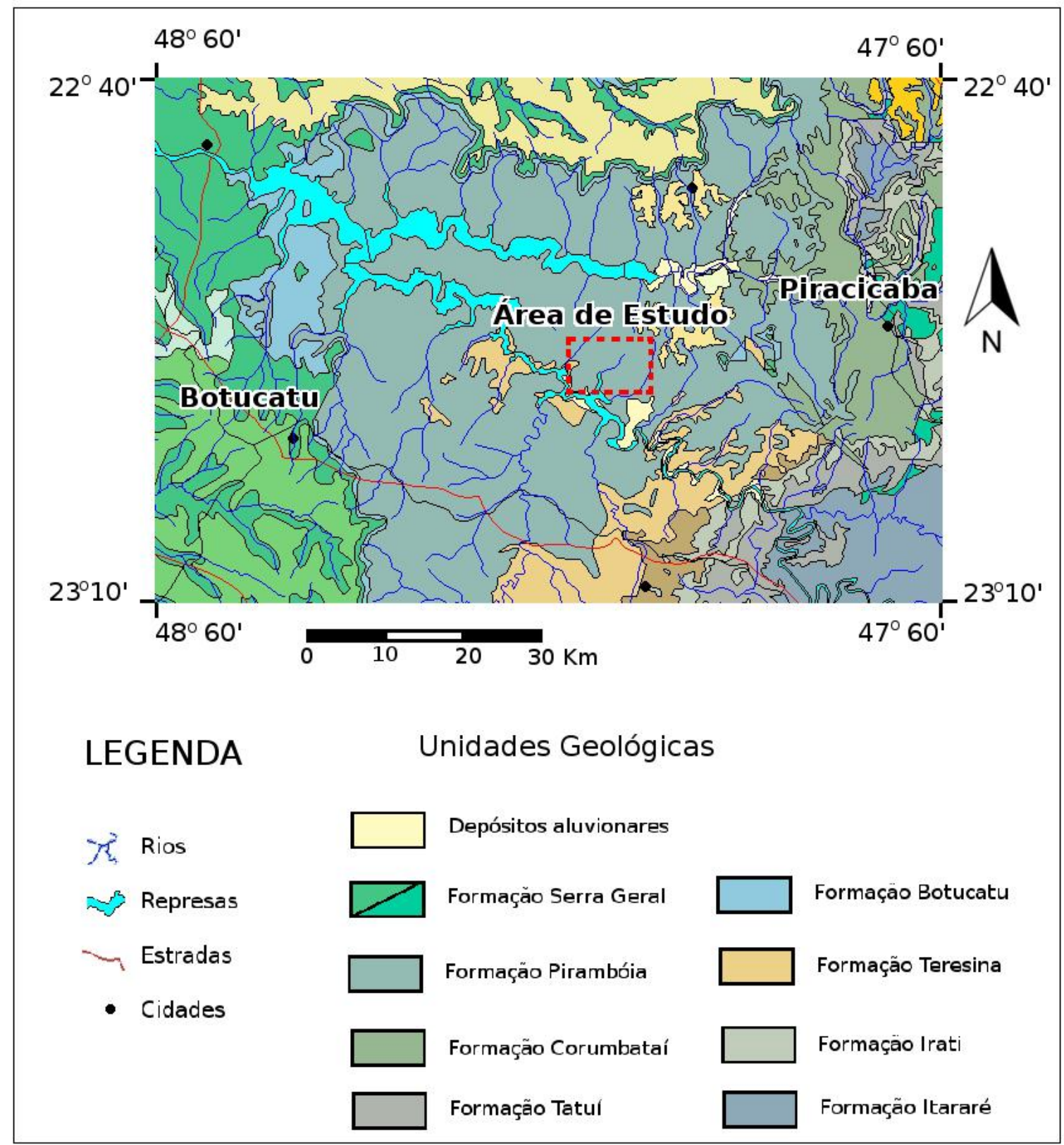

Figura 3.5: Mapa geológico da área de estudo (modificado de CPRM, 2001). 


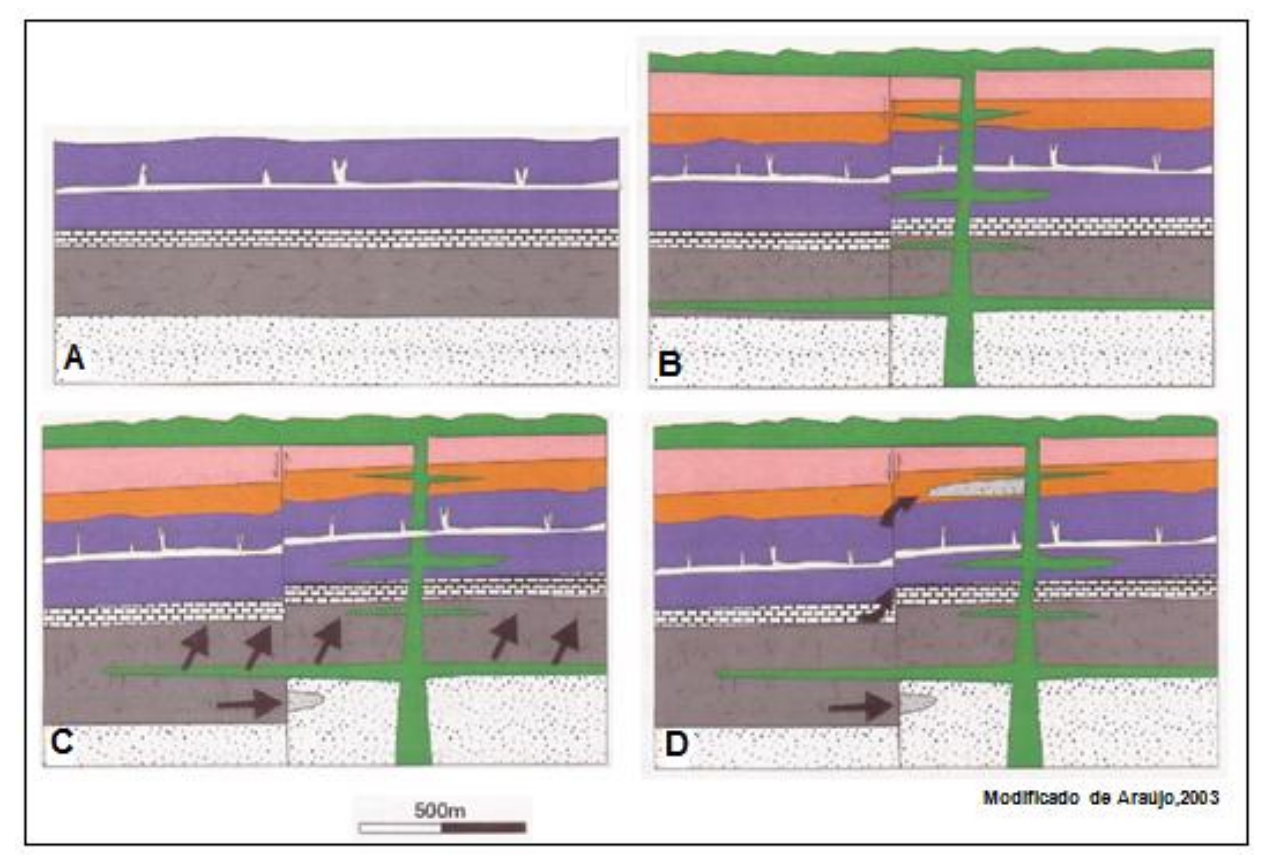

Figura 3.4: Principais estágios relacionados à gênese dos arenitos asfálticos. (Legenda: arenito asfáltico; $\square$ Fm. Serra Geral; $\square$ Fm. Botucatu; Fm. Pirambóia; Fm. Teresina (siltito/argilito); $\square$ Fm. Teresina (arenito/sismito); 監 Fm. Assistência; — Fm. Taquaral; Fm. Tatuí).

O óleo contido na ocorrência estudada foi classificado, segundo Thomaz Filho (1982), como um óleo pesado, imaturo, de alta viscosidade (aproximadamente 5o API) e teor de enxofre médio a alto ( 2 a $3 \%$ em peso). Amostras retiradas de poços de sondagens das diversas ocorrências no estado de São Paulo foram analisadas por Triguis (1986) e tiveram seus parâmetros de maturidade analisados a partir de razões isoméricas (que podem ser alteradas por acão bacteriólogica), e os resultados nas amostras de Anhembi indicam um óleo quase no final do ponto de isomeria, o que corresponde ao início da zona de geração de óleo e indica seu baixo nível de maturidade. $O$ autor conclui que a fonte geradora do óleo de Anhembi possuía maturidade juvenil. Estudos geoquímicos de comparação isotópica e de cromatrografia líquida e gasosa dos óleos de Anhembi e dos extratos orgânicos das diferentes rochas geradoras da Bacia do Paraná foi realizado por Quadros (1982), apud Thomaz Filho (1982), sugeriu a geração do óleo em camadas do então chamado Subgrupo Irati, e diversos trabalhos posteriores de análises geoquímicas corroboraram a proposta, sendo a origem aceita hoje do óleo da área de estudo a Formação Irati, mais especificamente o Membro Assistência. 


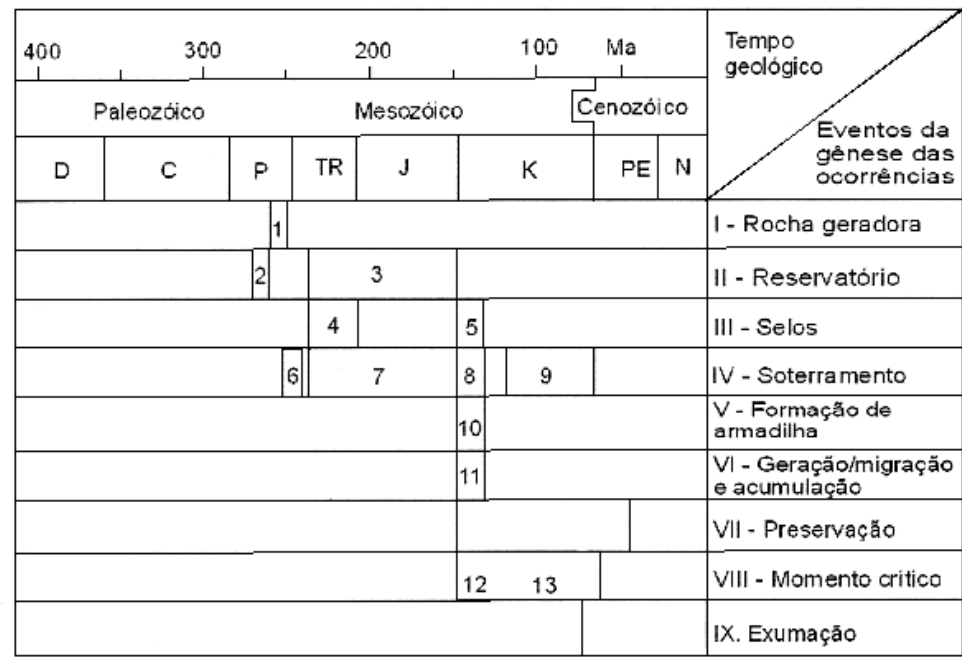

Eventos

Rocha geradora

1. Fm. Assistên cia (Kazaniano)

II. Reservatorios

2. Fm. Tatuí

3. Fm. Piramboia e Botucatu

III. Selos

4. Fm.Pirambcia - fácies fluvial

fácies eölica (interduna)

5. Fm. Serra Geral

IV. Soterramento

6. Permiano Superior - Triássico Inferio

7. Triássico Superior-Jurássico

. Cretáceo Inferior

9. Cretáce o Superior

V. Formação da armadilha

10. Fase de rifteamento

VI. Geraçăo/migraçăoe

acumulaçăo

11. Efeito termal da rochas

igneas intrusivas

VII. Preservação

VIII. Momentos criticos

12. Reativaçăo Pós-Paleozóica

13 Soerguimento no Cretáceo SuperiorCenozóico.

IX. Exumaçăo

Figura 3.6: Quadro de eventos cronológicos para correlação dos elementos relacionados à gênese dos arenitos asfálticos (Araújo et al, 2000). 


\section{CAPÍTULO IV - METODOLOGIA}

\subsection{MÉTODO DA ELETRORRESISTIVIDADE (ER)}

\subsubsection{FUNDAMENTOS TEÓRICOS}

Os métodos geoelétricos têm como objetivo determinar a distribuição de alguns parâmetros físicos elétricos em um meio subsuperficial através de medições em superfície. O método da eletrorresistividade utiliza o parâmetro resistividade para caracterizar um material ou meio geológico, grandeza que está relacionada aos mecanismos de propagação de correntes elétricas nos mesmos. Basicamente, a resistividade elétrica quantifica a resistência que um determinado material oferece à passagem de correntes elétricas, bem como seu parâmetro inverso, a condutividade, quantifica a facilidade que um material possui para transmitir corrente em seu interior, isto é, permitir sua passagem.

De acordo com Telford et aL. (1990), se considerarmos um corpo cilíndrico feito de material homogêneo e condutor, de comprimento $L$ e seção transversal $S$, podemos definir sua resistividade $(\rho)$ teórica conforme descrito na equação 4.1 , abaixo.

$$
\rho=\frac{\mathrm{R} \cdot \mathrm{S}}{\mathrm{L}}
$$

(equação 4.1), onde:

$\rho=$ Resistividade elétrica (Ohm.m)

$\mathrm{R}=$ Resistência elétrica (Ohm)

$\mathrm{S}=$ Área da seção transversal do cilindro $\left(\mathrm{m}^{2}\right)$

$\mathrm{L}=$ Comprimento do cilindro (metros)

Quando atravessado por uma corrente elétrica, o cilindro será submetido a uma diferença de potencial elétrico e sua resistência (dada pela Lei de Ohm) será :

$$
\mathrm{R}=\frac{\Delta \mathrm{V}}{\mathrm{I}}
$$

(equação 4.2), onde:

$\Delta \mathrm{V}=$ Diferença de potencial elétrico (Volt) 
$I=$ Corrente elétrica (Ampère)

A figura 4.1 ilustra o cilindro homogêneo e isotrópico no qual, após passagem de corrente elétrica, observa-se a manifestação da Lei de Ohm e, consequentemente, a resistividade $(\rho)$.

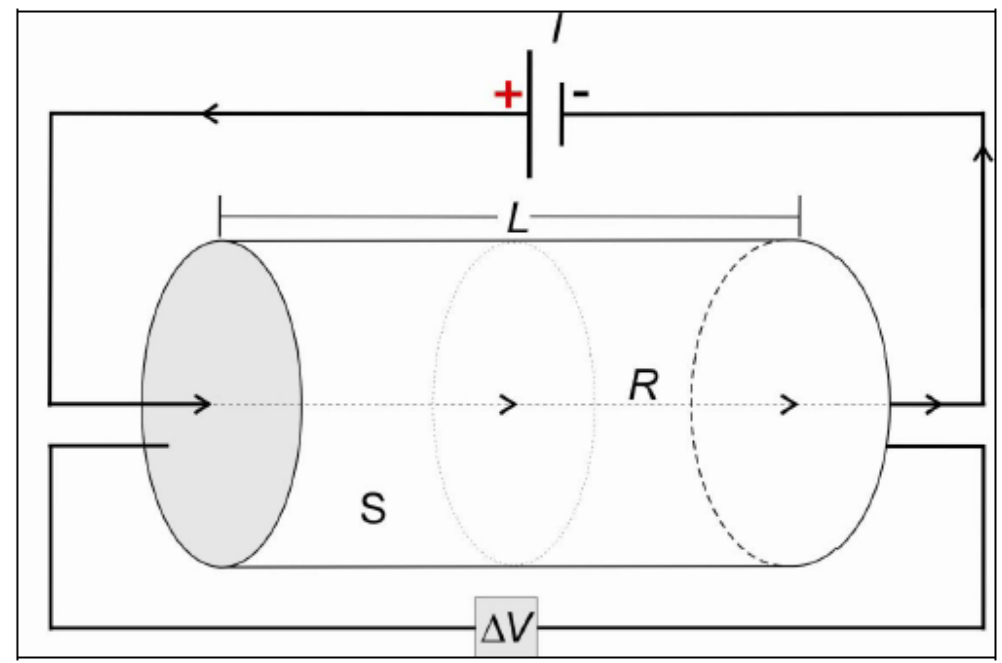

Figura 4.1: Prisma cilíndrico teórico para ilustração da atuação da Lei de Ohm em meio homogêneo e isotrópico.

Ao contrário da resistência $(R)$, resistividade e condutividade são grandezas bastante específicas dos materiais, dependendo de características microscópicas intrínsecas dos mesmos, o que as tornam boas ferramentas para o "diagnóstico" de uma área subsuperficial. Os mecanismos mais comuns de propagação de corrente elétrica em solos e rochas são a condutividade eletrônica e a condutividade eletrolítica. A condutividade eletrônica é devida à presença de minerais metálicos ou outros minerais condutores (como a grafita, por exemplo) em sua matriz, sendo então mais restrita à certas suítes mineralógicas nas rochas, uma vez que a presença desses minerais precisa ser suficiente para elevar sua condutividade global. A condutividade eletrolítica é mais comum e ocorre por conta do deslocamento de íons dissolvidos na água contida nos poros, fissuras e fraturas. Por ocorrer preferencialmente nos fluidos intersticiais e nas superfícies dos grãos dos solos e rochas, esse tipo de condução sofre grande influência dos seguintes fatores: 


\section{- porosidade}

- composição mineralógica

- teor de água

- natureza e teor dos sais dissolvidos.

Entre esses fatores, os teores de água e de salinidade são os mais importantes, sendo que a elevação dos mesmos é inversamente proporcional à resistividade (portanto diretamente proporcional aos valores de condutividade). A resistividade pode apresentar, portanto, uma grande variação de valores, o que incrementa sua aplicabilidade em estudos de diferentes naturezas, especialmente hidrogeológicos e ambientais. A figura 4.2 exemplifica esse amplo intervalo de variação.

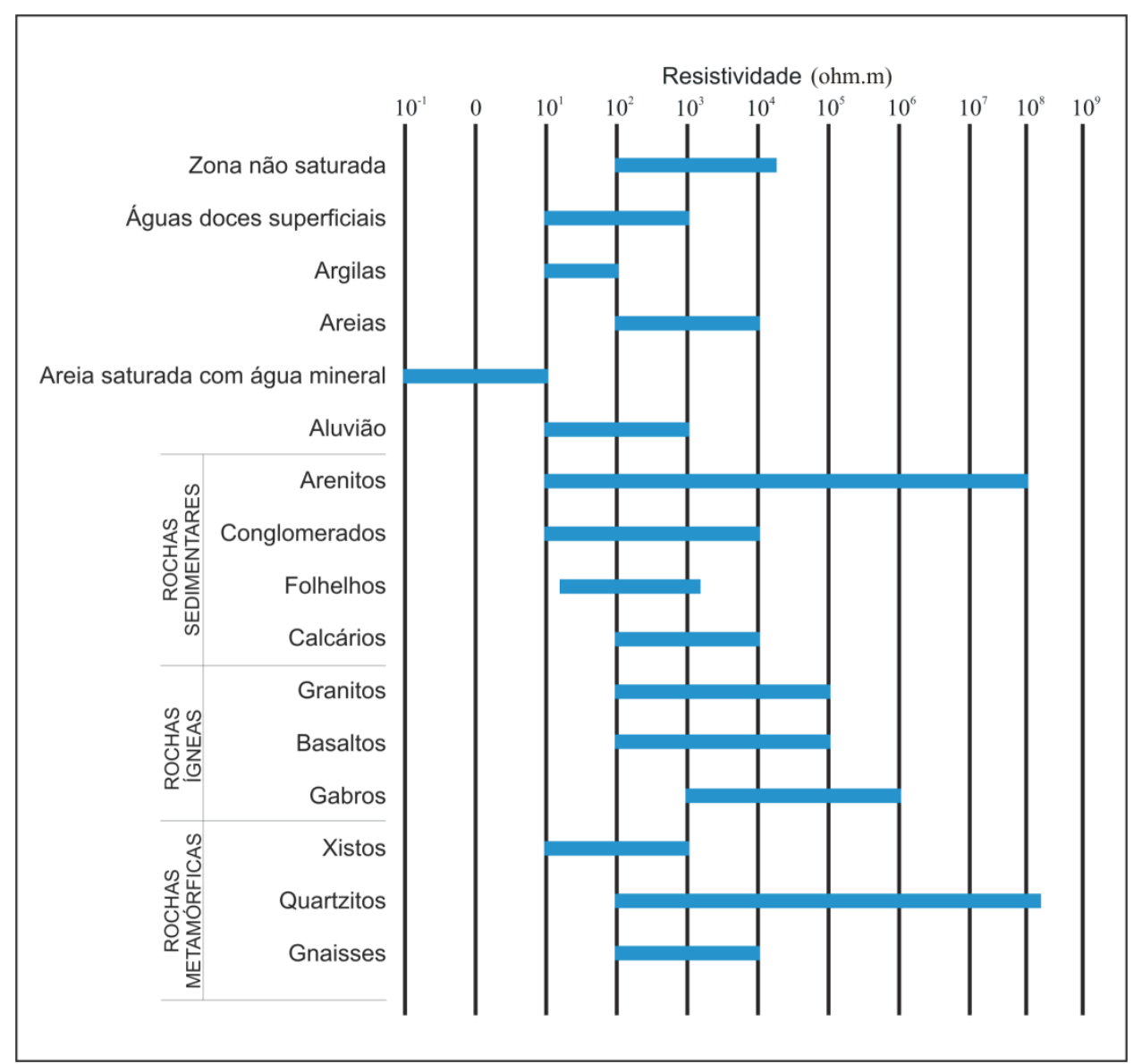

Figura 4.2: Valores de resistividade elétrica de alguns materiais conhecidos (modificado de Elis, 1999 e Loke, 2004). 
O método da Eletrorresistividade é aplicado introduzindo-se uma corrente elétrica artificial no terreno, através de dois eletrodos (convencionalmente chamados de eletrodos de corrente,"A" e "B") e medindo-se o potencial gerado em outros dois eletrodos localizados nas proximidades do fluxo de corrente (eletrodos de potencial, "M" e "N"), o que nos permitirá calcular a resistividade real ou aparente em subsuperfície. O método trabalha com correntes a baixas frequências, tipicamente $0,03 \mathrm{~Hz}$ a 3,0 Hz (Ward,1990).

Em um sistema básico de coordenadas representativas de um terreno, supondo a existência de um eletrodo como fonte na origem do mesmo, a corrente elétrica introduzida através do eletrodo irá fluir radialmente à distância $r$ da origem, em qualquer superfície esférica $S$, conforme descrito por Ward (1990), e mostrado na figura 4.3. A área da superfície esférica $S$ é $4 \pi r^{2}$, e a densidade de corrente $J_{r}$ à distância $r$ é dada por:

$$
J_{r}=\frac{I}{4 \pi r^{2}}
$$

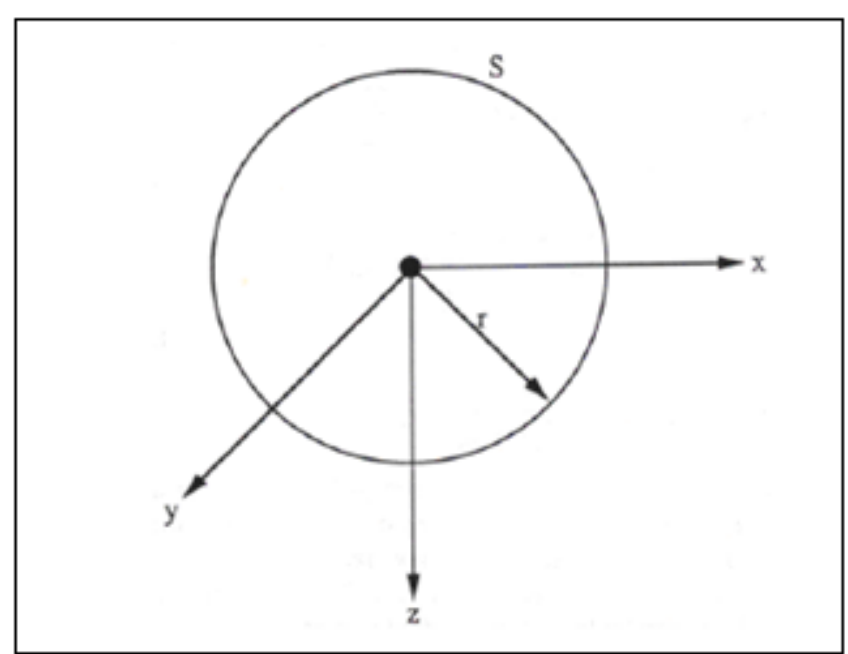

Figura 4.3: Eletrodo no centro (origem) de um sistema de coordenadas. "S" é a superfície de uma esfera de raio " $r$ " (Ward, 1990).

Sendo $\rho=\frac{1}{\sigma}$ a resistividade isotrópica e homogênea, a Lei de Ohm pode ser escrita como: 


$$
\mathrm{E}_{\mathrm{r}}=\mathrm{J}_{\mathrm{r}} \rho=\frac{\mathrm{I} \rho}{4 \pi \mathrm{r}^{2}}
$$

em que $E_{r}$ é o campo elétrico gerado por $l$.

À distância $r$ do eletrodo, o potencial é dado pela integral de $E_{r}$ entre $r$ e o infinito:

$$
\mathrm{V} \int_{\mathrm{r}}^{\infty} \mathrm{E}_{\mathrm{r}} \mathrm{d}_{\mathrm{r}}=\frac{\mathrm{I} \rho}{4 \pi \mathrm{r}}
$$

Como os eletrodos estão dispostos na superfície do terreno, o que será medido será o fluxo de corrente transmitido no meio geológico, em subsuperfície, uma vez que a resistividade do ar será considerada infinita, ou seja, a corrente injetada no terreno através de um eletrodo fluirá radialmente em um meioespaço, conforme a figura 4.4 .

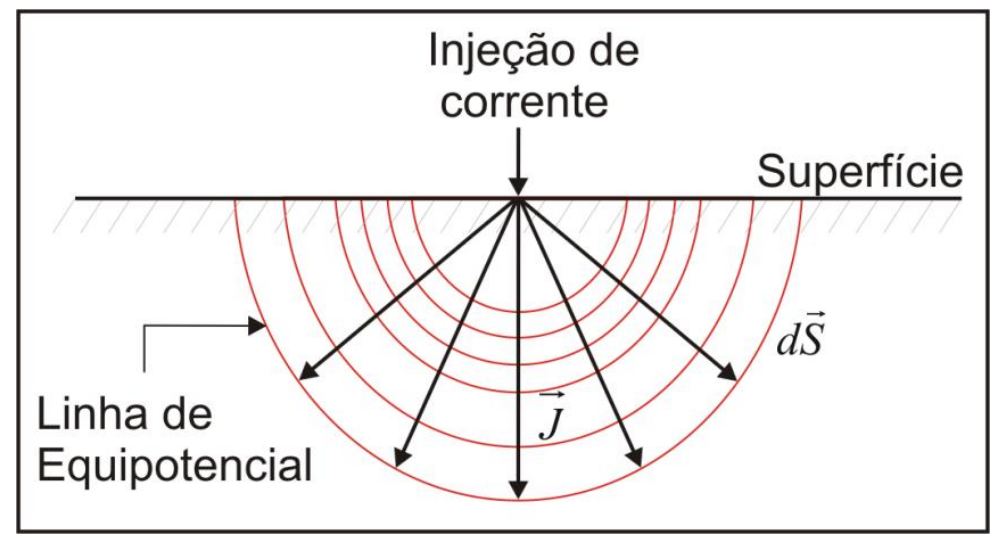

Figura 4.4: Direção do fluxo radial de corrente no semi-espaço .

Portanto, a corrente elétrica I aplicada flui através de uma semi-esfera de raio $r$ e superfície $2 \pi r^{2}$. Assim, a densidade de corrente $\vec{J}$ é a corrente $\vec{I}$ dividida pela área $A$ por onde ela está sendo transmitida, e a mesma diminui conforme se afasta da fonte injetora de corrente. A densidade de corrente para um eletrodo pontual em um semi-espaço homogêneo é dada por:

$$
\vec{J}=\frac{I}{2 \pi r^{2}}
$$


Sendo a resistividade " $\rho$ " homogênea e isotrópica, a lei de Ohm pode ser escrita como:

$$
\mathrm{E}_{\mathrm{r}}=\mathrm{J}_{\mathrm{r}} \rho=\frac{\mathrm{I} \rho}{2 \pi \mathrm{r}^{2}}
$$

A fórmula do potencial elétrico " $\mathrm{V}$ ", à uma distância "r" dos eletrodos será então a integral de $E_{r}$ entre " $r$ " e o infinito (equação que fornece a relação fundamental para todos os métodos elétricos realizados na superfície da Terra), conforme:

$$
\mathrm{V}=\int_{\mathrm{r}}^{\infty} \mathrm{E}_{\mathrm{r}} \mathrm{d}_{\mathrm{r}}=\frac{\mathrm{I} \rho}{2 \pi \mathrm{r}}
$$

Posicionando dois eletrodos de corrente, "A" (+ I) e "B" (- I), na superfície de um sólido condutor nas posições " $\mathrm{C}_{1}$ " e " $\mathrm{C}_{2}$ ", respectivamente, os potenciais resultantes medidos nos pontos "M" e "N" (eletrodos de potencial), serão dados pelas equações a seguir:

$$
\mathrm{V}_{\mathrm{M}}=\frac{\mathrm{I} \rho}{2 \mathrm{~T}}\left[\frac{1}{\mathrm{AM}}-\frac{1}{\mathrm{MB}}\right]
$$

(equação 4.9), onde:

$A M$ é a distância entre $\mathrm{P}_{1}$ e $\mathrm{C}_{1}$, e $M B$ a distância entre $\mathrm{C}_{2}$ e $\mathrm{P}_{1}$

$$
\mathrm{V}_{\mathrm{N}}=\frac{\mathrm{I} \rho}{2 \pi}\left[\frac{1}{\mathrm{AN}}-\frac{1}{\mathrm{NB}}\right]
$$

(equação 4.10), onde:

$A N$ é a distância entre $\mathrm{C}_{1}$ e $\mathrm{P}_{2}$ e $N B$ a distância entre $\mathrm{C}_{2}$ e $\mathrm{P}_{2}$.

Como utilizamos arranjos de quatro eletrodos para medir a diferença de potencial, e não um potencial, a equação para esta medição fica:

$$
\Delta \mathrm{V}_{\mathrm{MN}}=\mathrm{V}_{\mathrm{M}}-\mathrm{V}_{\mathrm{N}}=\frac{\mathrm{I} \rho}{2 \mathrm{~T}}\left\{\left[\frac{1}{\mathrm{AM}}-\frac{1}{\mathrm{MB}}\right]-\left[\frac{1}{\mathrm{AN}}-\frac{1}{\mathrm{NB}}\right]\right\}
$$

Reescrevendo esta equação em função da resistividade, teremos:

$$
\begin{gathered}
\rho=\frac{\Delta \mathrm{V}_{\mathrm{MN}} \mathrm{K}}{\mathrm{I}} \\
\rho=\text { resistividade elétrica (Ohm.m) }
\end{gathered}
$$


$\mathrm{K}$ = fator geométrico

$\Delta \mathrm{V} \mathrm{MN}=$ diferença de potencial entre os eletrodos $\mathrm{M}$ e $\mathrm{N}$

$\mathrm{I}$ = intensidade de corrente que passa entre os eletrodos A e B

O fator geométrico depende da geometria do arranjo eletródico utilizado, e é dado pela equação:

$$
\mathrm{K}=\frac{2 \pi}{\left(\frac{1}{\mathrm{AM}}\right)-\left(\frac{1}{\mathrm{MB}}\right)-\left(\frac{1}{\mathrm{AN}}\right)+\left(\frac{1}{\mathrm{NB}}\right)}
$$

Se pensarmos no meio geológico a ser investigado como sendo homogêneo e isotrópico poderíamos calcular sua resistividade real conforme a equação 4.14, mas na prática, devido às heterogeneidades do meio, a resistividade calculada não corresponde à verdadeira, mas sim a um valor aparente que reflete a resistividade do terreno, considerado como um meio homogêneo para o mesmo arranjo de eletrodos. Ou seja, a resistividade aparente é interpretada como um desvio em relação a um meio totalmente uniforme. Então, para meios heterogêneos, a resistividade aparente é calculada conforme:

$$
\rho=K \frac{\Delta V_{M N}}{I}
$$

\subsection{MÉTODO DA POLARIZAÇÃO INDUZIDA (IP)}

Em 1920, durante investigações geofísicas direcionadas à busca de sulfetos, Conrad Schlumberger observou que o campo elétrico gerado artificialmente no meio geológico não desaparecia instantaneamente após a interrupção da injeção da corrente, mas sim decaía lentamente. Este fenômeno elétrico é conhecido como Polarização Induzida e pode ser descrito como uma resposta retardada à passagem de corrente elétrica em materiais naturais, de acordo com Sumner (1976). Alguns corpos, após serem atravessados por uma corrente elétrica, e após a interrupção da mesma, não perdem a diferença de potencial gerada bruscamente, ela decai gradativamente até sua total 
dissipação, representando o tempo em que o material está retornando ao seu estado natural após ter sido perturbado pela passagem da corrente elétrica injetada, presumindo-se que o fluxo original de corrente deixe alguma energia armazenada no material. O Método da Polarização Induzida, portanto, se baseia na medição dessas variações de voltagem em função do tempo. $O$ fenômeno de armazenamento de energia nos materiais durante o fluxo original injetado provavelmente se manifesta em diversas formas de energia, como mecânica, elétrica, química, mas diversos estudos de polarização estabeleceram a energia química como a mais importante (Telford et al, 1990). Algumas características importantes sobre o fenômeno de polarização induzida nos meios geológicos puderam ser observadas por Braga (1999) após realizar diversos trabalhos sobre o efeito IP em hidrogeologia, como:

- a magnitude do efeito IP depende da resistividade da solução, da quantidade e espécie de argila, e do cátion que satura a argila;

- a capacidade de polarização diminui conforme a resistividade diminui (águas salgadas e meios ricos em argila apresentam efeito IP baixos, por exemplo);

- areia quartzosa pura, saturada em água, apresenta efeito IP muito baixo;

- argilas puras possuem baixa resistividade e apresentam muito baixo efeito IP;

- meios arenosos possuem alta resistividade mas efeito IP intermediário;

- a resposta do efeito IP em camadas que contém areia + argila é bem maior do que em camadas compostas apenas de argila.

Draskovits et al. (1990), também devido aos trabalhos em prospecção de águas subterrâneas, acrescenta às observações anteriores:

- camadas siltosas possuem valores médios de resistividade e alta resposta IP. Para entender o fenômeno da polarização induzida imaginamos que as partículas polarizáveis do solo ou rocha se comportem como inúmeros pequenos condensadores, que são carregados durante a passagem da corrente e descarregados após a mesma (Gallas, 2000), isto é, acumulam e perdem carga elétrica, por isso o termo utilizado para expressar esse efeito capacitivo dos materiais é denominado cargabilidade (M), e será explicado mais a frente.

Draskovits et al (1990) elaboraram um gráfico correlacionando as resistividades aparentes e cargabilidades aparentes para os principais tipos de sedimentos (figura 4.5). 


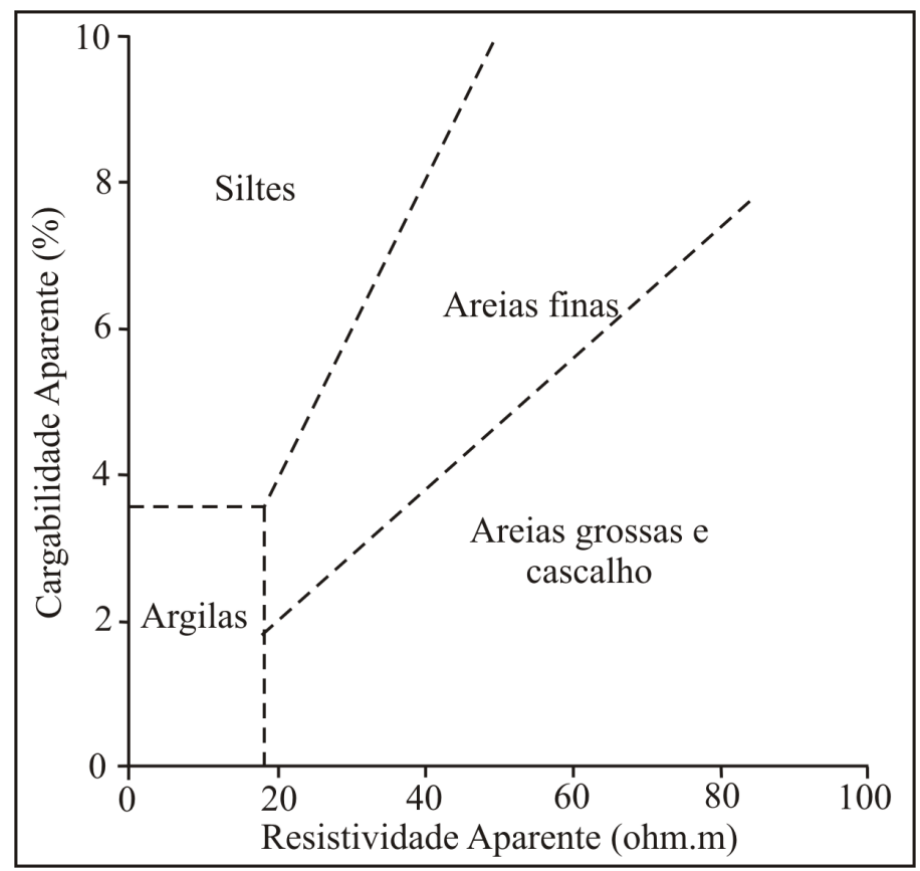

Figura 4.5: Associação de resistividades e cargabilidades aparentes com composições de sedimentos (modificado de DRASKOVITS et al., 1990).

A medida do parâmetro IP pode ser feita em função do tempo (IP - Domínio do tempo) ou em função da frequência (IP - Domínio da frequência).

\subsubsection{MÉTODO IP NO DOMÍNIO DO TEMPO}

Ao aplicarmos uma corrente "l" no terreno, através de dois eletrodos de corrente, "A" e "B", uma diferença de potencial " $\Delta V$ " é gerada e medida em outros dois eletrodos de potencial, "M" e "N". Após o corte da corrente, essa diferença de potencial não se mantém e nem se anula instantaneamente, mas decai gradualmente, e podemos descrever matematicamente esse decaimento em função do tempo para caracterizar o parâmetro IP. Durante o tempo de envio de corrente elétrica é estabelecida a diferença de potencial primária $(\Delta \mathrm{Vp})$, que polariza o meio subsuperficial. No espaço de tempo em que a corrente está ausente o potencial elétrico primário decairá descrevendo uma curva em função do tempo, $\Delta \mathrm{V}_{\mathbb{P}}=\mathrm{f}(\mathrm{t})$, chamada curva de descarga $I P$, conforme mostrado na figura 4.7. De acordo com Ward (1990) a amplitude da curva de descarga IP varia de acordo com o meio que está sendo investigado, 
de sua capacidade de polarização, e o efeito IP é medido comparando-se os valores de diferença de potencial elétrico residual existente num determinado espaço de tempo $t$ após a interrupção de corrente elétrica ao potencial primário. Os valores medidos da $\triangle \mathrm{VIP}$ (t) são muito menores que os valores da $\Delta \mathrm{VP}$, e a relação entre os dois pode ser expressa pelo parâmetro denominado cargabilidade $(\mathrm{M})$, conforme:

$$
\mathrm{M}=\frac{1}{\Delta \mathrm{V}_{\mathrm{P}}} \int_{\mathrm{t}_{1}}^{\mathrm{t}_{2}} \Delta \mathrm{V}_{\mathrm{IP}}(\mathrm{t}) \mathrm{dt}
$$

Quando $\Delta$ VIP (t) e $\Delta$ VP têm as mesmas unidades, a cargabilidade (M) pode ser medida em milissegundos, mas geralmente é expressa em $\mathrm{mV} / \mathrm{V}$ (milivolt por Volt) (Sumner, 1976). Para se ter resultados consideráveis fora do nível de ruído ou evitar a perda da sensibilidade da detecção do equipamento, a $\Delta$ VIP (t) deve ser medida num intervalo de tempo $t$ entre 0.1 e 10 segundos.

A figura 4.6 mostra o formato de onda da corrente elétrica durante a medição IP, com a variação de voltagem em função do tempo.

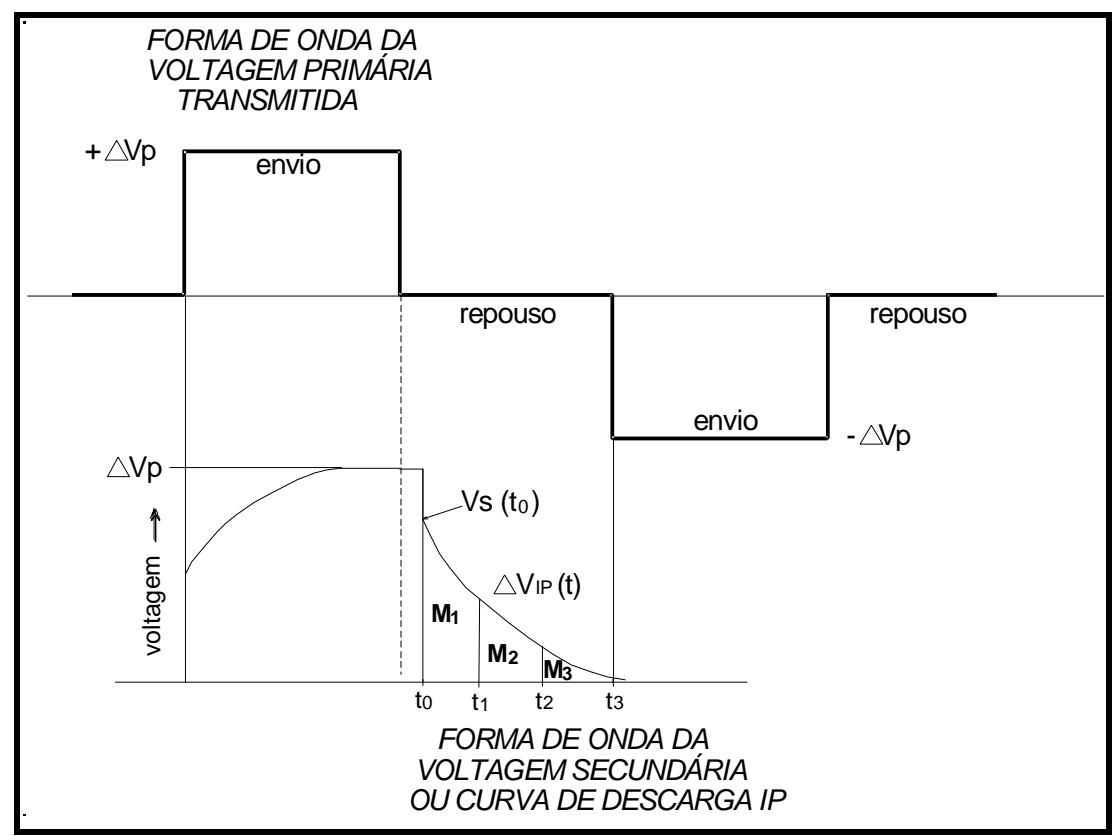

Figura 4.6: Formato da onda de corrente elétrica e a representação do efeito IP. Variação de $\Delta \mathrm{V}$ em função do tempo, ilustrando o momento de interrupção da passagem de corrente elétrica e o retardamento da perda de voltagem (modificado de Sumner, 1976). 


\subsubsection{FONTES DE EFEITO DE POLARIZAÇÃO INDUZIDA}

O armazenamento de energia química é o resultado de:

- variações na mobilidade dos íons no fluido presente na estrutura da rocha ou solo, caracterizando a polarização de membrana. Constitui o chamado background do efeito IP e ocorre em rochas que não contêm minerais metálicos;

- variações entre a condutividade eletrolítica e eletrônica quando há presença de minerais metálicos na rocha ou solo, caracterizando a polarização de eletrodo. Tem magnitude maior do que o efeito background, mas depende da presença dos minerais metálicos.

Nas medições de IP os dois efeitos são indistinguíveis.

\subsubsection{POLARIZAÇÃO DE MEMBRANA}

A condução eletrolítica é a predominante nas rochas e solos, uma vez que é a que ocorre na ausência de minerais metálicos e essa é a situação mais comum na prática. Sem esse tipo de mineral presente na matriz para facilitar a passagem de corrente, a estrutura da rocha deve ser permeável o suficiente para permitir esse fluxo. A maioria dos minerais constituintes das rochas possuem uma camada de carga negativa acumulada nas paredes dos poros, na interface superfície do poro-fluido, que portanto atrai íons com cargas positivas e repele íons com cargas negativas. Se essa concentração de íons positivos se estender pela zona do fluido até a profundidade da espessura do poro, e uma corrente elétrica for aplicada nessa situação, íons negativos irão se acumular em uma extremidade da zona e deixarão a outra vazia, criando uma polarização que passará a impedir o fluxo de corrente (figura 4.7). Quando a corrente é interrompida, os íons voltam para suas posições originais em um intervalo de tempo finito. Este é o efeito de polarização de membrana, também chamado de efeito IP normal. O efeito de polarização de membrana é muito pronunciado em argilas, que possuem poros particularmente pequenos, mas 
diferentes tipos de argilas fornecem respostas diferentes de efeito IP devido às diferentes composições químicas, pois os tamanhos dos raios aniônicos e catiônicos refletirão diretamente no fechamento dos poros (a montmorilonita apresenta valores altos de efeito IP, a caulinita valores baixos, por exemplo). Apesar disso, a magnitude de polarização não aumenta de forma constante com o aumento da concentração de minerais de argila, ela atinge um ponto máximo e depois começa a decrescer. Isso ocorre porque deve haver uma passagem alternativa maior no material, onde não ocorre o acúmulo de íons, caso contrário tanto o fluxo de corrente como a polarização seriam reduzidos. $O$ aumento da salinidade do fluido do poro também provoca uma queda no efeito de polarização (Telford et.al., 1990).

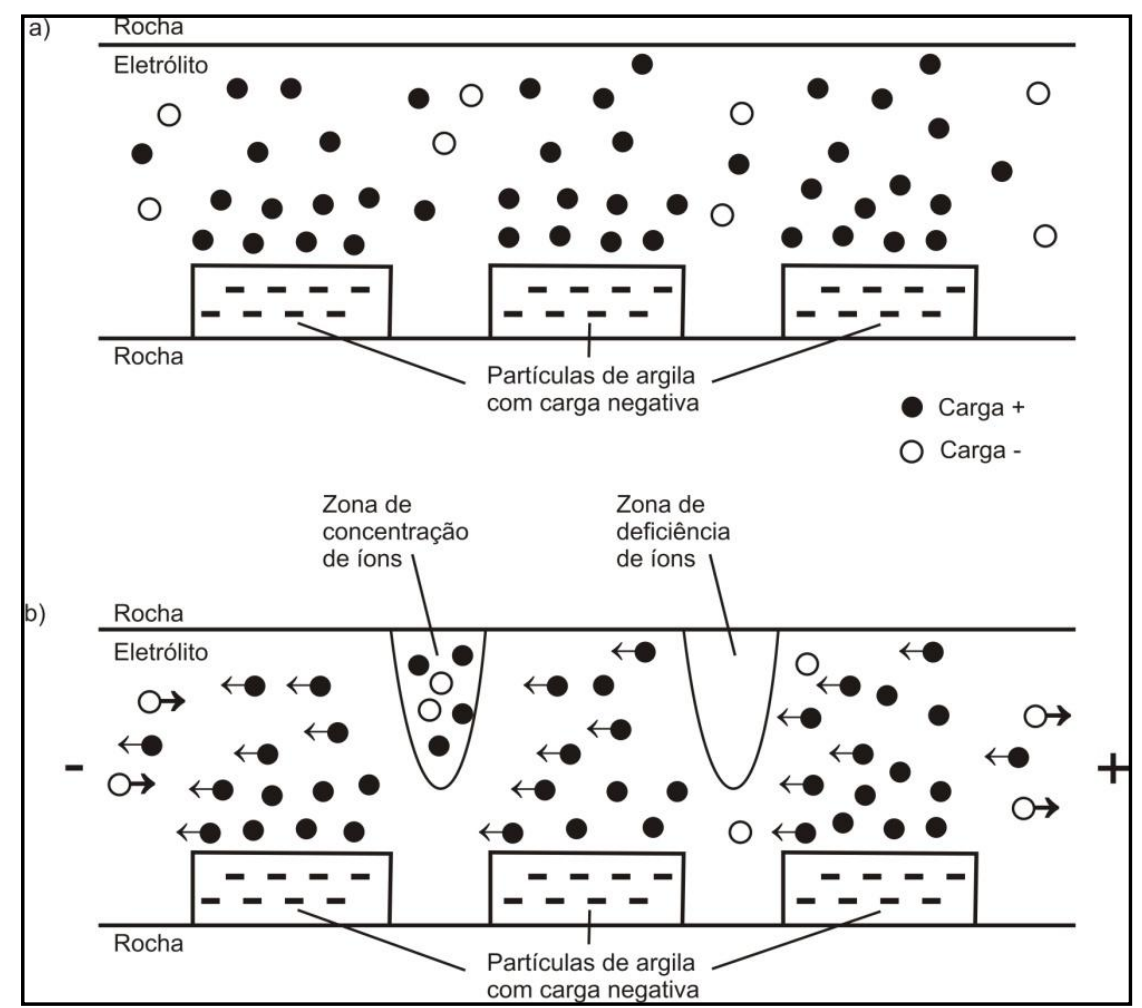

Figura 4.7: Efeito de polarização de membrana. a) Distribuição normal de íons em um arenito poroso; b) Polarização de membrana em um arenito poroso devido à aplicação de voltagem em corrente contínua (adaptado de Telford et.al., 1990). 


\subsubsection{POLARIZAÇÃO DE ELETRODO}

O efeito de polarização de eletrodo, também chamado de polarização eletrônica ou metálica, ocorre quando há minerais metálicos na composição da rocha/solo (comumente grafita ou sulfetos como pirita, calcopirita, galena, etc) e o fluxo de corrente é parcialmente eletrônico e parcialmente eletrolítico. $\mathrm{Na}$ interface entre o grão mineral e o fluido intersticial, na presença de elementos metálicos, a rede de cargas superficiais que se acumula possui sinais opostos em cada face, resultando em uma concentração de íons no eletrólito adjacente a cada uma (figura 4.8). Durante a passagem do fluxo de corrente, o elemento metálico troca elétrons com a solução iônica nos poros (ação de eletrólise) resultando em um efeito de sobretensão (overvoltage). Como a velocidade do fluxo de corrente no eletrólito é menor do que no metal, o acúmulo de íons é mantido pela voltagem externa, e quando a corrente é cortada a voltagem residual decai conforme os íons difusos voltam ao seu estado original (Telford et al, 1990).

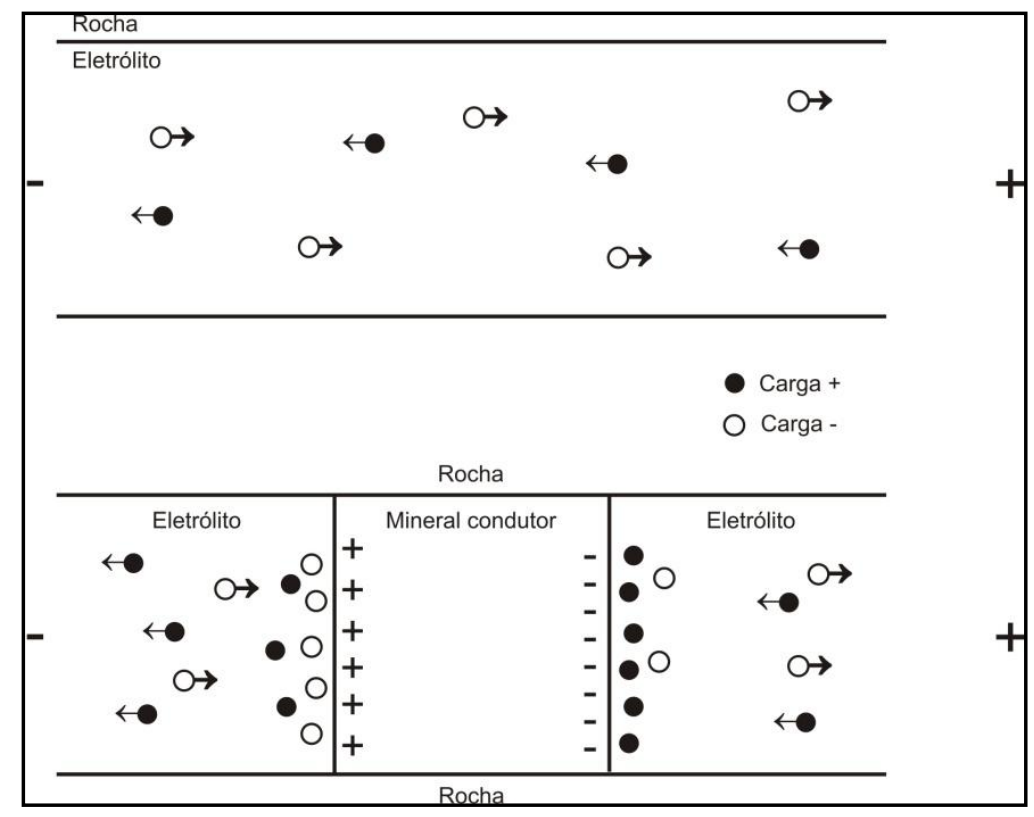

Figura 4.8: Fluxo eletrolítico no poro superior e polarização de eletrodo no poro inferior. (modificado de Telford et. al., 1990). 


\subsubsection{AQUISIÇÃO DE DADOS DE ELETRORRESISTIVIDADE E POLARIZAÇÃO INDUZIDA}

Os métodos da eletrorresistividade e polarização induzida envolvem medidas de uma impedância, com subsequente interpretação em termos de propriedades elétricas da subsuperfície e, finalmente, de subsuperfície geológica. Os equipamentos utilizados para a realização de ensaios de IP normalmente fazem simultaneamente medidas de resistividade, pois os dados utilizados para medir o efeito de IP são os mesmos usados para calcular a resistividade. Estes equipamentos compreendem uma fonte controlada para emissão de corrente elétrica, acoplada a um gerador (necessário para a emissão de correntes suficientemente altas para que seja possível a análise da curva de descarga) e uma unidade receptora que executa os trabalhos de captação das tensões geradas, compensação do potencial espontâneo (pois como os parâmetros de interesse são tensões residuais da curva de descarga, o potencial espontâneo é um fator indesejável) e a sincronização automática, através dos eletrodos, ao conjunto de emissão. A potência da fonte pode variar de centenas de watts até alguns kilowatts. $O$ circuito emissor pode medir valores entre 5 e $500 \mathrm{~mA}$, e o potencial normalmente lido no circuito receptor varia entre $10 \mathrm{mV}$ a $20 \mathrm{~V}$. Esses equipamentos podem trabalhar com corrente contínua ou corrente alternada de baixa frequência, preferivelmente menor que $60 \mathrm{~Hz}$ (Telford, et. al., 1990). Neste trabalho foi utilizado um resistivímetro que mede a voltagem aplicada e valores da curva de decaimento da voltagem, fornecendo dados de resistividade e cargabilidade, este e outros equipamentos utilizados serão descritos no Capítulo VI, item 6.1.

No método da eletrorresisitvidade existem várias técnicas de aquisição de dados em campo, sendo que cada uma delas ainda apresenta diferentes possibilidades de arranjos, e a combinação de técnica-arranjo a ser utilizado deve ser feita após uma análise do problema a ser investigado, do objetivo, da profundidade de investigação requerida, resolução desejada, etc. As técnicas de campo mais comuns são a Sondagem Elétrica Vertical (SEV) e o Caminhamento Elétrico (CE), que são utilizadas nesse trabalho. 
A técnica de caminhamento elétrico (CE) é utilizada quando se deseja investigar a variação lateral de resistividade em profundidades aproximadamente constantes, sendo aplicado, por exemplo, para se identificar mudanças de fácies geológicas, contatos geológicos, localizar falhas e fraturas, analisar extensão de contaminação em aquíferos, entre outros (Elis, 1999). A interpretação de dados de caminhamentos elétricos é principalmente qualitativa.

A técnica de sondagem elétrica vertical (SEV) é utilizada quando se deseja uma informação pontual, para observar a variação vertical da resistividade. Para interpretar dados de um sondagem elétrica, pressupõe-se que a subsuperfície se divida em camadas planas horizontais e que então a resistividade irá variar significativamente apenas com a profundidade, mas não lateralmente, e utiliza-se um modelo unidimensional para interpretar as medições (Ferreira, 2002). A medição alcança profundidades cada vez maiores à medida que se aumenta o afastamento entre os eletrodos de corrente, e a técnica apresenta resultados aproximadamente verdadeiros em diversas situações geológicas, como na identificação do nível freático, por exemplo.

As medidas são normalmente realizadas com um arranjo de quatro eletrodos, da maneira descrita no item 4.1 deste capítulo. A figura 4.9 mostra o esquema básico dos arranjos mais utilizados em campo e seus respectivos fatores geométricos. 


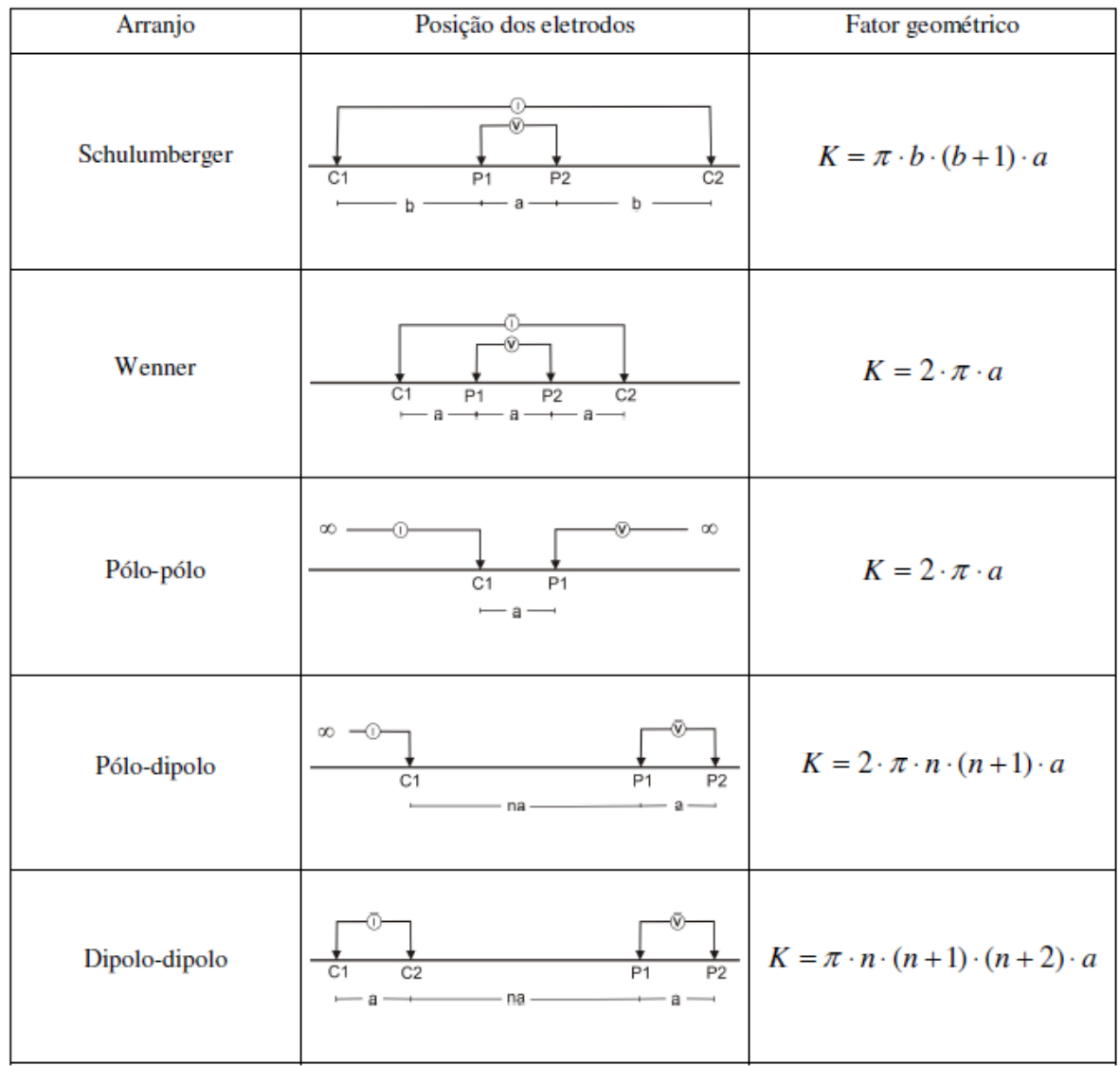

Figura 4.9: Arranjos eletródicos mais utilizados.

\subsubsection{AQUISIÇÃO 2D}

A aquisição 2D é geralmente realizada através da técnica de caminhamento elétrico (CE), obtendo uma combinação das variações verticais e laterais da resistividade do terreno ao se caminhar com o arranjo de eletrodos ao longo de perfis, efetuando medidas de resistividade. O procedimento consiste em se manter constante o arranjo e medir a diferença de potencial $(\Delta \mathrm{V})$ gerada pela passagem de corrente (I) no terreno. De acordo com Loke (2004) depende do tipo de estrutura a ser investigada, da sensibilidade do equipamento e do nível de ruído existente na área. O autor elenca os arranjos Wenner, dipolo-dipolo, Wenner-Schlumberger, polo-pólo e polo-dipólo (esquematizados na figura 4.9) como os mais utilizados em levantamentos elétricos 2D, e as características mais relevantes a serem observadas sobre os mesmos em: 
1. Profundidade de investigação;

2. A sensibilidade do arranjo para mudanças verticais e horizontais da resistividade em subsuperfície;

3. A cobertura horizontal dos dados;

4. A intensidade do sinal.

Dahlin e Zhou (2004) simulam numericamente a aquisição 2D com dez arranjos eletródicos, utilizando modelos sintéticos que refletiam algumas estruturas geológicas para avaliar suas vantagens e limitações, considerando a sensibilidade a ruído e efeitos de anomalia. O efeito de anomalia é utilizado na avaliação da eficiência da medição de um arranjo e considera-se que este deve ser significativamente maior do que o nível de ruído local. Os autores concluem que os efeitos de anomalia para os diferentes arranjos variam com a geologia local, e recomendam os arranjos pólo-dipolo, dipolo-dipolo e Schlumberger, entre outros, para levantamentos $2 \mathrm{D}$, sendo que a escolha final deve ser determinada pela geologia local, objetivo da investigação e considerações logísticas.

Durante a aquisição de dados para este trabalho utilizou-se o arranjo dipolodipólo no caminhamento elétrico, portanto serão comentadas as características apenas desse arranjo. Nele, os eletrodos $\mathrm{A}$ e $\mathrm{B}$ de corrente e $\mathrm{M}$ e $\mathrm{N}$ de potencial são dispostos segundo um perfil e o arranjo é definido pelo espaçamento $X=A B=M N$.

As medidas são efetuadas em vários níveis de profundidade $(n=1,2,3, \ldots)$ atribuídas às intersecções das linhas que partem do centro de $A B$ e $M N$ com ângulos de $45^{\circ}$ (figura 4.10). A profundidade de investigação cresce com $O$ espaçamento $(E)$ entre os centros dos dipolos transmissores e receptores, correspondendo, teoricamente, a E/2. A cada ponto de medida os dipolos se deslocam uma distância"X", os dados obtidos são plotados nas posições $(n=1,2 \ldots)$ e interpolados, gerando uma pseudo-seção de resistividade aparente, conforme mostra a figura 4.11 . 


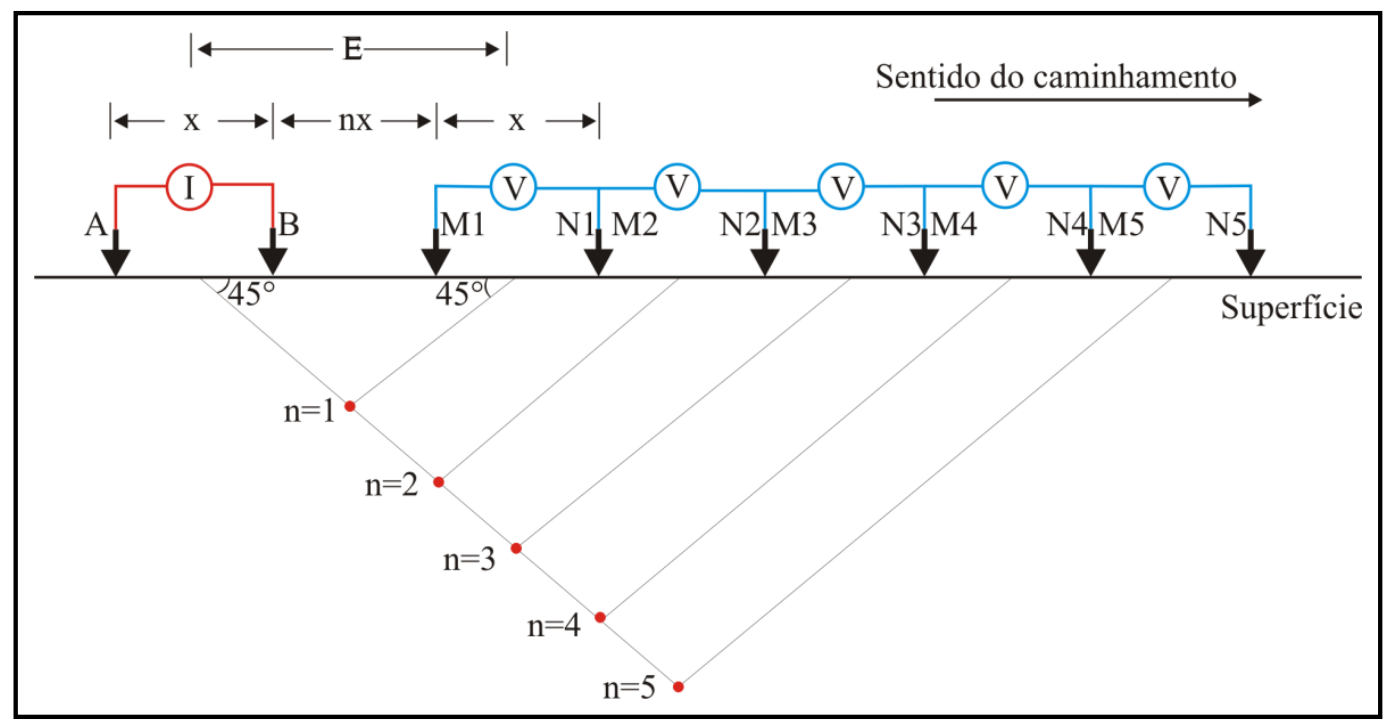

Figura 4.10: Disposição do arranjo dipolo-dipolo, com 5 níveis de investigação.

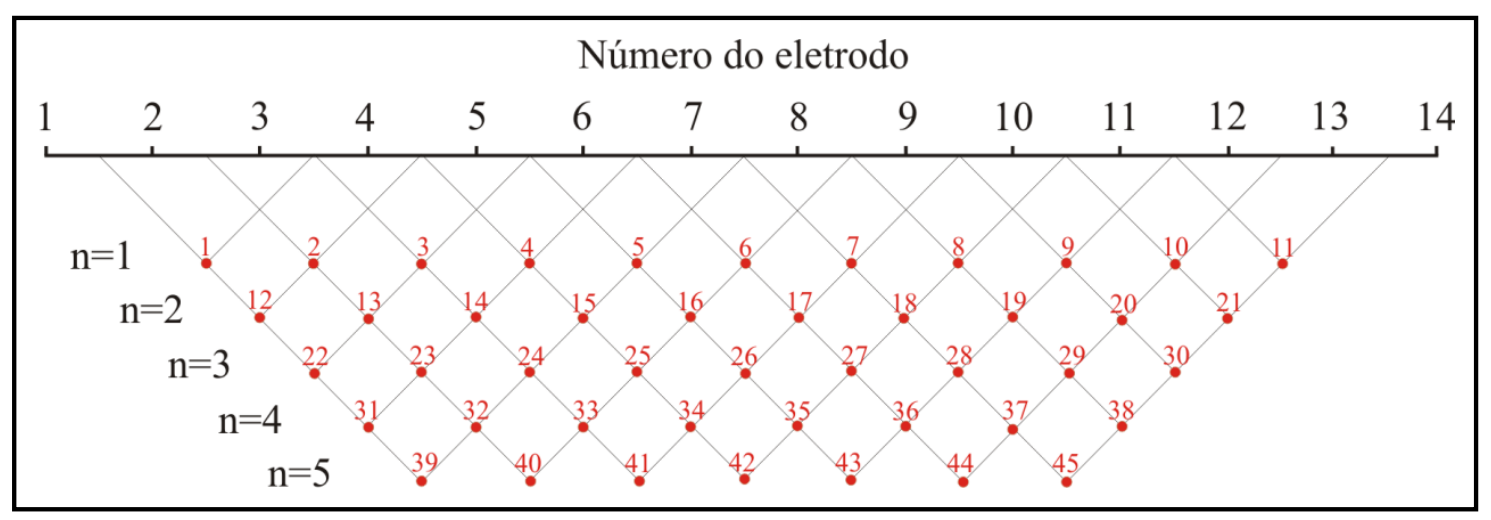

Figura 4.11: Plotagem dos pontos e sequência de medidas utilizadas para a construção da pseudoseção no arranjo dipolo-dipolo.

Nesse tipo de arranjo, o potencial diminui sensivelmente à medida que nos afastamos do dipolo $A B$, e as leituras mais afastadas se tornarão difíceis de serem obtidas com precisão. O arranjo dipolo-dipolo é considerado por Dahlin e Zhou (2004) como um arranjo que apresenta boa resolução, porém mais suscetível à contaminação por ruído. O arranjo é sensível para identificar mudanças horizontais de resistividade, mas pouco sensível ás mudanças verticais (diques/cavidades) e relativamente ruim para detectar estruturas horizontais (sills /camadas sedimentares), de acordo com Lago (2009). 


\subsubsection{AQUISIÇÃO 3D}

Considerando que a maioria das estruturas geológicas são, na realidade, tridimensionais, levantamentos com aquisição e interpretação 3D certamente proporcionariam resultados mais precisos e próximos da situação real, mas esse tipo de ensaio é menos usual do que o 2D devido ao elevado custo e tempo gasto para efetuar a aquisição, especialmente se a área a ser investigada for extensa.

Em um levantamento 3D completo, os eletrodos são posicionados em uma malha regular com o mesmo espaçamento nas direções perpendiculares " $x$ " $e$ "y". O arranjo eletródico mais utilizado em um ensaio como esse é o polo-polo, onde o número máximo de medidas $n_{\max }$ depende do número de eletrodos $n_{e} \mathrm{e}$ é dado por $n_{\max }=n_{e} n_{e-1) / 2}$. Após estarem posicionados, cada eletrodo da malha será usado como eletrodo de corrente e depois como eletrodo de potencial. Devido à reciprocidade, só é necessário medir o potencial nos eletrodos com índices maiores do que o eletrodo de corrente, conforme mostrado na figura 4.12 (A). Com essa técnica, um grid de 5 por 5 eletrodos, por exemplo, teria um conjunto de dados de 300 pontos. Esse levantamento, com um arranjo com vários eletrodos, leva muito tempo de aquisição, mas é possível diminuir o número de medidas sem prejudicar a qualidade do modelo a ser obtido através de um levantamento diagonal cruzado. Nessa técnica as medidas são feitas apenas nas linhas horizontal, vertical e na diagonal com $45^{\circ}$ que passam pelo eletrodo de corrente, conforme ilustrado na figura 4.12(B) modificado de Ustra (2008).

Um conjunto de dados 3D também pode ser construído utilizando-se dados de perfis 2D paralelos, técnica para a qual o arranjo dipolo-dipolo é mais indicado, devido ao padrão de sua função de sensibilidade, que quantifica o grau com que uma mudança de resistividade em uma seção em subsuperfície influencia o potencial medido (quanto maior o valor da função, maior a influência da região em subsuperfície na medida), de acordo com Ustra (2008).

Loke (2002) elege o arranjo dipolo-dipolo como o mais sensível a efeitos tridimensionais, podendo tolerar um espaçamento maior entre as linhas de levantamento (até aproximadamente 3 vezes o espaçamento entre eletrodos) e 
ainda conter informação 3D significante. No caso de perfis 2D paralelos, os dados serão combinados em um conjunto de dados 3D e invertidos, gerando um modelo 3D, que certamente será menos preciso do que um modelo gerado pela técnica 3D completa, mas deverá mostrar as principais variações de resistividade.

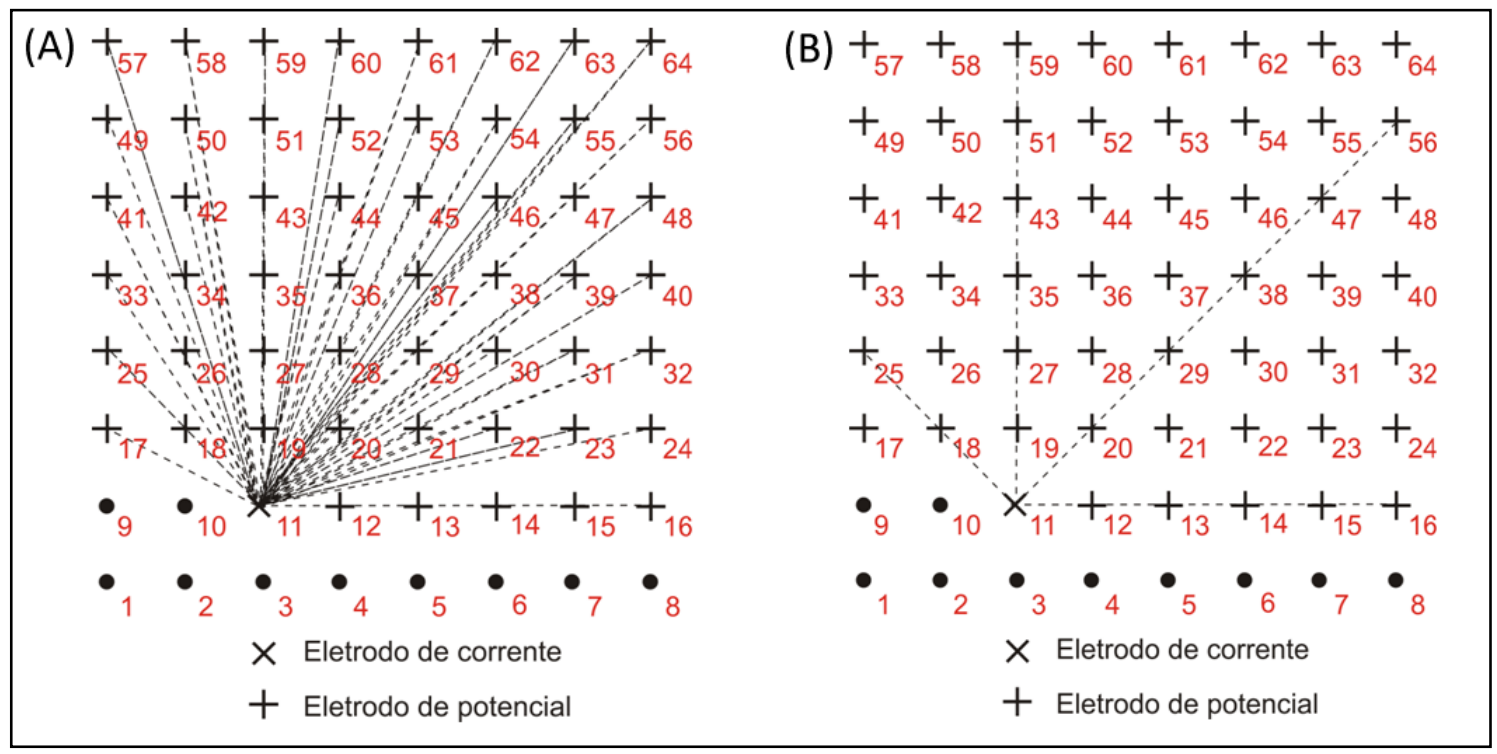

Figura 4.12: Posição dos eletrodos de potencial correspondentes a um único eletrodo de corrente no arranjo 3D completo em $(A)$ e no arranjo 3D diagonal cruzado em (B). Modificado de Loke e Barker (1996).

\subsubsection{INTERPRETAÇÃO DE DADOS DE ER e IP}

\subsubsection{INTERPRETAÇÃO QUALITATIVA}

A interpretação de dados geofísicos pode ser realizada de forma qualitativa e quantitativa. A interpretação qualitativa 2D (que não é diferente para 1D) para os métodos da eletrorresistividade e o método IP tem como objetivo identificar, diferenciar e delimitar zonas anômalas em dados de resistividade elétrica e cargabilidade aparentes. Geralmente os resultados obtidos através desses métodos são plotados graficamente e levam a denominação de "pseudo-seção" de resistividade elétrica aparente e/ou cargabilidade aparente. Nessa técnica, proposta por Hallof (1957, apud Griffiths \& Barker, 1994), cada ponto investigado na subsuperfície possui uma posição e profundidade teórica 
específica, de acordo com o espaçamento entre eletrodos e o arranjo eletródico utilizado.

A utilização da interpretação qualitativa através de pseudo-seções pode ocasionar interpretações ambíguas, pois não reflete a distribuição de resistividade elétrica ou cargabilidade verdadeira e nem a profundidade real do meio investigado. Para este tipo de interpretação é imprescindível o uso da integração de informações diretas para diminuir as ambiguidades geofísicas.

\subsubsection{INTERPRETAÇÃO QUANTITATIVA}

No caso da interpretação de SEVs (aquisição 1D), os valores de resistividade aparente obtidos são plotados em relação aos valores da distância $A B / 2$, fornecendo a curva de resistividade aparente, a qual é passível de interpretação quantitativa. A interpretação de uma SEV objetiva determinar a distribuição espacial dos estratos com diferentes resistividades no subsolo, partindo dos dados de resistividade aparente medidos na superfície. A seguir é feita a interpretação do significado geológico dos estratos com diferentes resistividades. A interpretação da curva de SEV baseia-se em leis físicomatemáticas, o que a torna um processo trabalhoso e de difícil execução. Por isso a interpretação é realizada por meio de programas específicos. A interpretação pode ser feita usando-se os métodos comparativo, direto e inverso. Na presente pesquisa empregou-se somente o método direto. $\mathrm{Na}$ interpretação direta, admite-se um modelo inicial e calcula-se a curva teórica correspondente com o auxílio do programa computacional, comparando-se com a curva de campo. Nesse trabalho utilizou-se o programa IPI2win. Procurando criar um modelo mais confiável, busca-se um ajuste mínimo entre as curvas (curva teórica e curva de campo), modificando os valores dos parâmetros. É importante lembrar que esse modelo deve ser baseado com informações geológicas locais, sendo o ajuste controlado pelo intérprete.

A técnica de interpretação quantitativa de pseudo-seções de resistividade objetiva obter um modelo de distribuição dos parâmetros medidos em subsuperfície similares aos valores medidos em campo, e gera modelos $2 \mathrm{D}$ da subsuperfície terrestre com uma melhor resolução espacial, melhor definição da geometria do alvo e maior precisão quanto à profundidade investigada, 
quando comparada com a interpretação qualitativa. Através de técnicas numéricas com o método da inversão, o programa busca, a partir dos dados de campo, um modelo que mais se aproxime dos dados reais. Os dados de campo são comparados com a pseudo-seção sintética resultante da simulação feita pelo programa e o modelo é considerado satisfatório quanto menores forem as diferenças entre as pseudo-seções de campo e sintética (Loke, 1999). De acordo com Loke (2000) para se determinar a distribuição em subsuperfície de resistividade elétrica verdadeira se utiliza a técnica de inversão, que atualmente está implementada nos programas computacionais específicos permitindo um processamento relativamente rápido de uma grande quantidade de dados. A Figura 4.13 ilustra a rotina básica de um algoritmo de inversão para dados de resistividade elétrica.

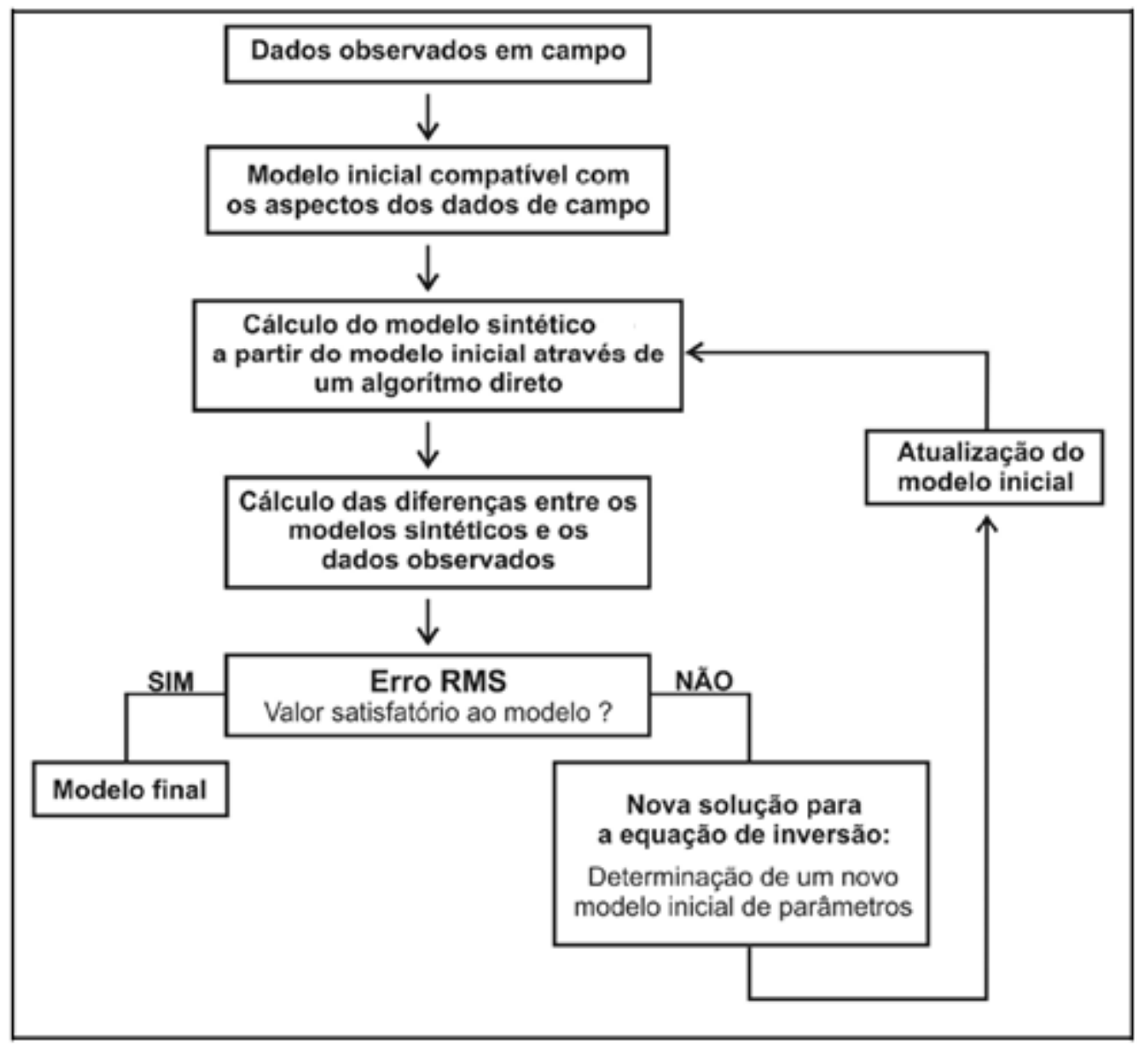

Figura 4.13: Rotina básica de inversão de dados de resistividade elétrica (Adaptado de Narayan et al, 1994). 
De acordo com Olayinka \& Yaramanci (2000) os dois tipos de inversão mais utilizados na interpretação de dados de eletroresistividade e IP são a inversão por suavização (smooth inversion) e a inversão por blocos ou polígonos (block inversion). $\mathrm{O}$ software de inversão $2 \mathrm{D}$ de dados de resistividade elétrica e cargabilidade RES2DINV faz uso do método da inversão por suavização utilizando o método matemático dos mínimos quadrados (smoothnessconstrained least squares method). De acordo com Loke \& Barker (1996) esse método utiliza a inversão baseada em células, onde o software reconhece a subsuperfície como blocos retangulares possuindo valores constantes para a propriedade ou parâmetro físico investigado. O arranjo dos blocos está vinculado ao número de pontos investigados em subsuperfície, baseado na pseudo-seção de resistividade elétrica aparente e cargabilidade aparente (posição e profundidade teórica dos pontos investigados) (Loke \& Barker, op.cit.). A profundidade teórica para cada ponto investigado é diferente para cada espaçamento entre eletrodos e para cada arranjo eletródico. O software RES2DINV se baseia nos critérios definidos por Edwards (1977) para estimar as profundidades de investigação. A Figura 4.14 ilustra a malha retangular e a posição dos blocos que simulam a subsuperfície terrestre. Para a realização do cálculo da matriz de dados o software se utiliza dos métodos Gauss- Newton e quasi-Newton (Loke \& Barker, 1996).

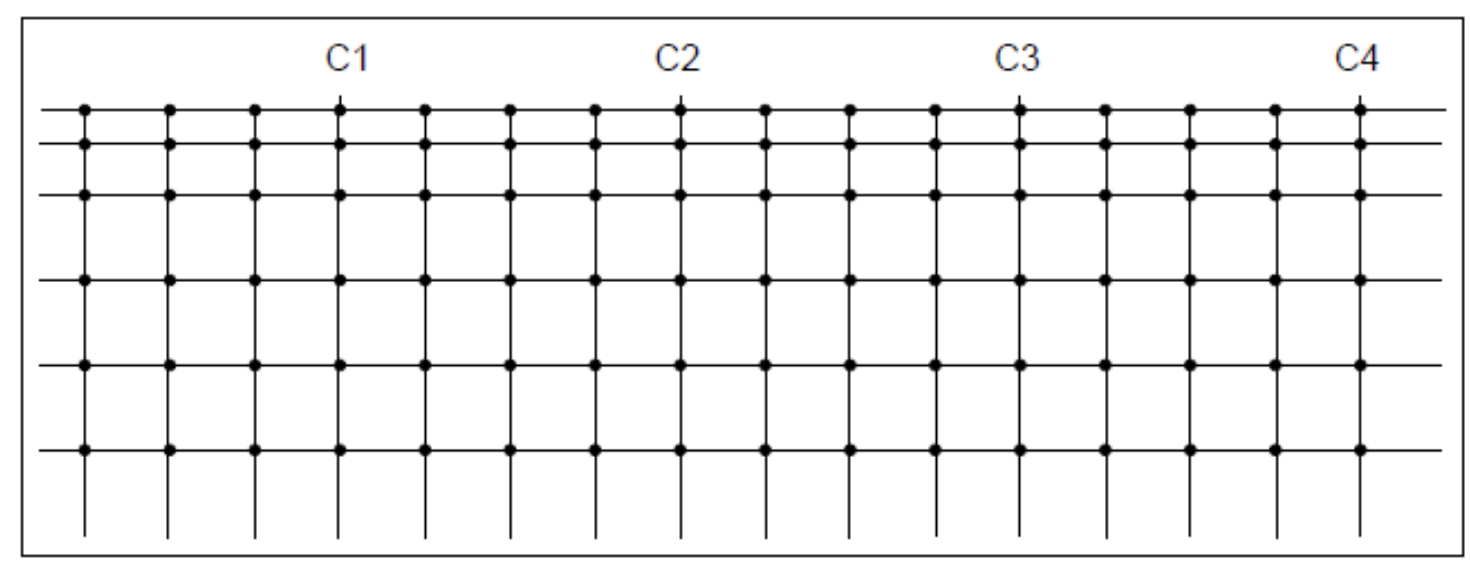

Figura 4.14: Parte da rede de células bidimensional utilizada para a modelagem 2D, mostrando as posições dos eletrodos (modificado de Loke, 1999). 


\subsection{MÉTODO ELETROMAGNÉTICO INDUTIVO (EM)}

$\mathrm{O}$ método eletromagnético indutivo surgiu dos trabalhos de $\mathrm{H}$. Lundberg e $\mathrm{K}$. Sundberg, que entre 1919 e 1922 observaram as variações na intensidade do campo magnético durante seus trabalhos com exploração elétrica com campos variáveis (Keller \& Frischknecht, 1966). Sundberg e H. Hedström desenvolveram o uso da propagação de campos eletromagnéticos de baixas frequências como utilizamos hoje entre 1925 e 1940, e o equipamento como conhecemos atualmente, com os transmissores e receptores móveis, foi introduzida entre 1940 e 1950 (Santos, 2009). Devido à simplicidade, velocidade e baixo custo de aplicação, o método foi intensamente empregado em investigações ambientais a partir da década de 80 (Elis, 1999), detecção de cavidades (Doolitle \& Collins, 1998), exploração arqueológica (Dalan, 1991; Gomes, 2003), entre outros.

O método eletromagnético indutivo mede a condutividade elétrica em subsuperfície com dentro de uma condição conhecida como operação em baixo número de indução, que será descrita mais adiante. A passagem de uma corrente elétrica alternada através de uma bobina transmissora resulta na geração de um campo magnético primário que se propagará no subsolo. $\mathrm{Na}$ presença de um corpo condutor no subsolo, assumido como meio homogêneo, o campo magnético primário resultará em correntes alternadas secundárias que geram um campo magnético secundário. A corrente induzida resultante da soma dos campos gerados será captada por uma bobina receptora, posicionada dentro na área de influência dos campos primário e secundário (McNeill, 1980). Os equipamentos EM-31, EM-34 e EM-38 apresentam diferentes frequências de operação e realizam medidas diretas da condutividade em profundidades teóricas pré-estabelecidas, sendo muito sensíveis ao aumento da condutividade no terreno devida à presença de contaminantes (uma adição de 25 ppm de material na água subterrânea causa um aumento da condutividade em aproximadamente $1 \mathrm{mS} / \mathrm{m}$, de acordo com McNeill (1980). A figura 4.15 esquematiza o princípio de operação do método EM. 


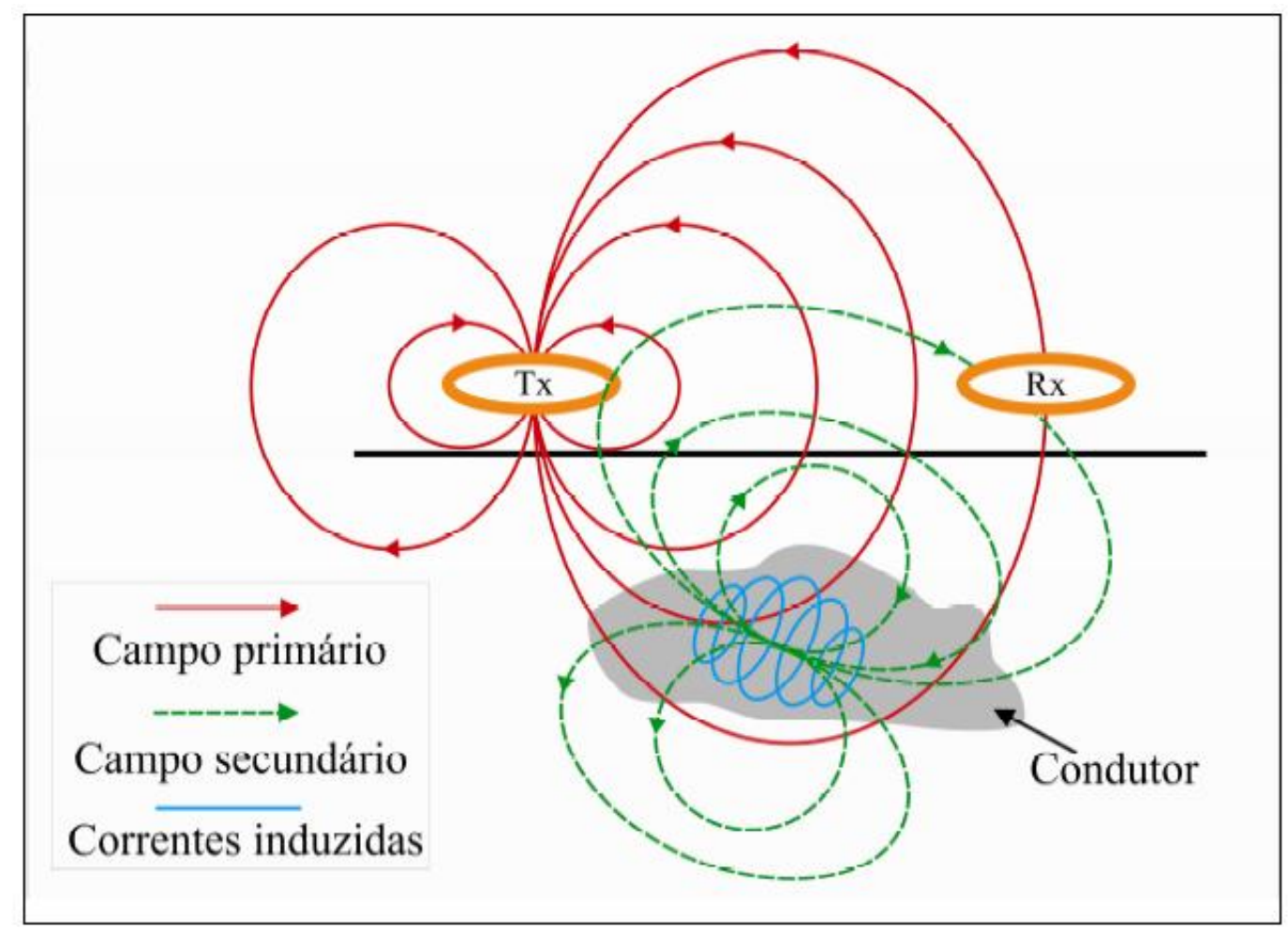

Figura 4.15: Princípio de operação do método EM. "Tx"é a bobina transmissora; "Rx" a bobina receptora.

\subsubsection{FUNDAMENTOS TEÓRICOS}

O campo eletromagnético pode ser dividido em uma componente elétrica e uma componente magnética, ambas mensuráveis, de maneiras diferentes. Os campos elétrico e magnético são funções da posição $(r, x, y, z)$ e do tempo $t$ (segundos), ou da freqüência $f(\mathrm{~Hz})$ e podem ser descritos em termos de vetores de intensidade de campo $E \mathrm{e} H$, ou de vetores de densidade de fluxo $D$ e indução magnética $B$. Campos EM - dois componentes diretamente mensuráveis: campos elétrico $(E)$ e magnético $(H)$.

A teoria eletromagnética é fundamentada nas equações de Maxwell. $O$ acoplamento dos campos E e H são descritos pelas leis de Ampére e Faraday. A Lei de Ampére mostra que o campo magnético é produzido pela corrente de deslocamento e pela densidade de corrente elétrica.

$\nabla \times \overrightarrow{\mathrm{H}}=-\frac{\partial \overrightarrow{\mathrm{D}}}{\partial \mathrm{t}}+\overrightarrow{\mathrm{J}}$

(equação 4.16)

Para prospecção EM em baixas frequências, o campo magnético gerado pela densidade de corrente elétrica é mais importante. 
Onde $\frac{\partial \mathrm{D}}{\partial \mathrm{t}}$ é a corrente de deslocamento e $\mathrm{J}$ é a densidade de corrente.

Na Lei de Faraday o campo elétrico $(E)$ é produzido pela variação da indução magnética $(B)$ em relação ao tempo.

$$
\nabla \times \overrightarrow{\mathrm{E}}=-\frac{\partial \overrightarrow{\mathrm{B}}}{\partial \mathrm{t}}
$$

A bobina transmissora (Tx) é energizada com uma corrente alternada em uma frequência baixa e é colocada em um meio uniforme, onde uma bobina receptora $(\mathrm{Rx})$ também está posicionada. O campo magnético variante induz fracas correntes no solo, que, em contato com um corpo condutor, produzem as chamadas correntes parasitas (eddy currents). Estas correntes geram um campo magnético secundário $(\mathrm{Hs})$ que é recebido junto com o campo magnético primário ( $\mathrm{Hp}$ ) pela bobina receptora. A bobina receptora, portanto, recebe um campo resultante (a soma dos vetores dos dois componentes). De acordo com McNeill (1980) o campo magnético secundário tem a mesma frequência do transmissor, mas difere em fase, intensidade e direção, tornando possível a identificação das anomalias condutivas .

A razão do espaçamento entre as bobinas $(S)$ dividido pelo skin depth $(\delta)$ é conhecido como o "número de indução" (B).

$\mathrm{B}=\frac{\mathrm{s}}{\delta}$

Quando o número de indução é muito menor do que 1, então a razão entre Hs e $\mathrm{Hp}$ no receptor é diretamente proporcional à condutividade aparente $\left(\sigma_{\mathrm{a}}\right)$. Nestas condições, conhecidas como operação a baixo número de indução (McNeill, 1980), o valor de condutividade elétrica aparente do terreno pode ser calculado pela equação:

$$
\sigma_{\mathrm{a}}=\frac{4}{\omega \mu_{0} \mathrm{~s}^{2}}\left(\frac{\mathrm{H}_{\mathrm{s}}}{\mathrm{H}_{\mathrm{p}}}\right)
$$


$\sigma_{\mathrm{a}}=\mathrm{a}$ condutividade aparente $(\mathrm{mS} / \mathrm{m})$

$\omega=2 \pi f$, sendo $f(\mathrm{~Hz})$

$\mu 0=$ permeabilidade magnética no vácuo

$\mathrm{s}=$ espaçamento entre as bobinas $(\mathrm{m})$

\subsubsection{AQUISIÇÃO E INTERPRETAÇÃO DE DADOS ELETROMAGNÉTICOS}

O equipamento usado neste trabalho é o EM34 da Geonics, que é composto por duas bobinas: uma transmissora Tx e outra receptora Rx. Acoplada a bobina transmissora existe um módulo de controle e emissão de corrente elétrica MC, alimentado por uma bateria. À bobina receptora está acoplado um módulo de leitura ML. Os módulos são ligados por um cabo de referência $(C R)$. A disposição das bobinas é dada de duas maneiras, conforme a profundidade de investigação (Figura 4.16).

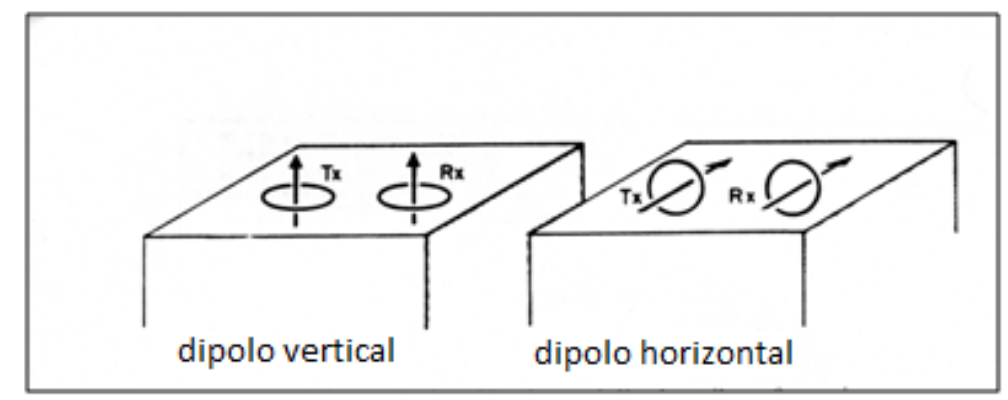

Figura 4.16: Disposição das bobinas em dipolo vertical e horizontal.

As frequências de operação do equipamento, bem como as profundidades teóricas de exploração, variam de acordo com a disposição e o espaçamento entre as bobinas, esses dados estão explicitados na Figura 4.17.

\begin{tabular}{|c|c|c|c|}
\hline $\begin{array}{c}\text { Espaçamento } \\
\text { entre as bobinas }\end{array}$ & $\begin{array}{c}\text { Freqüêtocia de } \\
\text { operação }\end{array}$ & $\begin{array}{c}\text { Profundidade de } \\
\text { exploração para Dipolo } \\
\text { Horizontal }\end{array}$ & $\begin{array}{c}\text { Profundidade de } \\
\text { exploração para Dipolo } \\
\text { Vertical }\end{array}$ \\
\hline $10 \mathrm{~m}$ & $6.4 \mathrm{kHz}$ & $7.5 \mathrm{~m}$ & $15 \mathrm{~m}$ \\
\hline $20 \mathrm{~m}$ & $1.6 \mathrm{kHz}$ & $15 \mathrm{~m}$ & $30 \mathrm{~m}$ \\
\hline $40 \mathrm{~m}$ & $0.4 \mathrm{kHz}$ & $30 \mathrm{~m}$ & $60 \mathrm{~m}$ \\
\hline
\end{tabular}

Figura 4.17: Espaçamento entre bobinas, freqüência de operação e profundidade de investigação de acordo com a disposição das bobinas (Adaptado de McNeill, 1980). 
Os ensaios de campo são geralmente caminhamentos, que, devido a praticidade de operação e transporte dos equipamentos, são realizados com muita rapidez. Como as profundidades de investigação são pré-determinadas, os equipamentos são bastante limitados para a execução de sondagens.

Os dados de condutividade podem ser plotados em perfis, em função da distância, e um conjunto de perfis permite a confecção de mapas. A interpretação desses dados na maioria das vezes é qualitativa, porém já existem softwares para quantificação desses dados. Neste trabalho a interpretação foi realizada por meio de um programa de inversão em desenvolvimento.

A etapa de inversão dos dados foi feita com a utilização do programa EM-342D (Santos, 2006) utilizando o algoritmo de inversão Smooth S. Este programa é desenhado para inversão de dados de condutividade aparente coletados com o equipamento EM-34. O objetivo do processo de inversão é obter uma distribuição em subsuperfiície de condutividade elétrica, considerando que esta propriedade varia suavemente. O processo de inversão é baseado no algoritmo não-linear da inversão dado em (Sasaki, 1989). Este algoritmo usa um modelo plano para Terra, dividido em blocos retangulares, cuja distribuição e o tamanho depende da localização e o espaçamento entre as bobinas utilizadas na aquisição dos dados. É utilizada uma sub-rotina de modelagem, baseada na resposta de uma suavização acumulativa que é utilizada para calcular a resposta aparente da condutividade do modelo (McNeill, 1980).

A entrada de dados para o programa são os valores de condutividade aparente, a distância entre as bobinas e sua posição relativa (vertical ou horizontal). O processo de inversão fornece um perfil de distribuição de condutividade em subsuperfície, de forma semelhante aos programas de inversão 2D de resistividade. 


\section{CAPÍTULO V - AQUISIÇÃO E PROCESSAMENTO DOS DADOS}

\subsection{EQUIPAMENTOS UTILIZADOS}

$\mathrm{Na}$ aquisição dos dados de resistividade e polarização induzida deste trabalho, com a técnica de caminhamento elétrico, foi utilizado o resistivímetro Syscal R2 (módulo de transmissão/recepção e conversor 250 W DC/DC) e o Elrec Pro (módulo de recepção). O Syscal R2 realizou a função de transmissão de corrente elétrica ( $\mathrm{Tx}$ - only time domain) e o Elrec Pro realizou as medidas de resistividade e cargabilidade aparentes ( $\mathrm{Rx}$ - only time domain). Para se estabelecer um sincronismo entre os módulos, o módulo Tx injeta um valor de corrente através dos eletrodos metálicos, que deve ser informado (pelo operador do equipamento) ao módulo $\mathrm{Rx}$, e os módulos são sincronizados pelo formato de onda de corrente. Os eletrodos de potencial são conectados ao módulo $\mathrm{Rx}$ e detectam os valores de resistividade e cargabilidade aparentes em cada ponto. Para a aquisição dos dados de resistividade através da técnica de sondagem elétrica vertical (SEV) o resistivímetro Syscal R2 foi utilizado em módulo de emissão e recepção, junto a um conversor de voltagem 250W DC/DC (usado nas duas técnicas de aquisição). As figuras 5.1 e 5.2 mostram os equipamentos como utilizados no campo.

Além dos resistivímetros, foram utilizados vários equipamentos auxiliares, como baterias $12 \mathrm{~V}$, eletrodos metálicos para injeção de corrente, eletrodos não polarizáveis para medição de potencial, cabos de conexão aos eletrodos, de injeção de corrente e de medição de potencial, solução de sulfato de cobre para os eletrodos de potencial, trenas e marretas para a montagem da linha de aquisição. A solução saturada de sulfato de cobre é colocada dentro dos eletrodos porosos, que são constituídos por um tubo de PVC com uma haste interna em forma de espiral, feita de cobre (figura 5.3). A haste do eletrodo fica então imersa em solução saturada de seu próprio sal, e a base de cerâmica do eletrodo permite que esta solução vaze lentamente, estabelecendo uma resistividade de contato com o solo, minimizando a "poluição" dos dados por ruídos de polarização de eletrodo. 


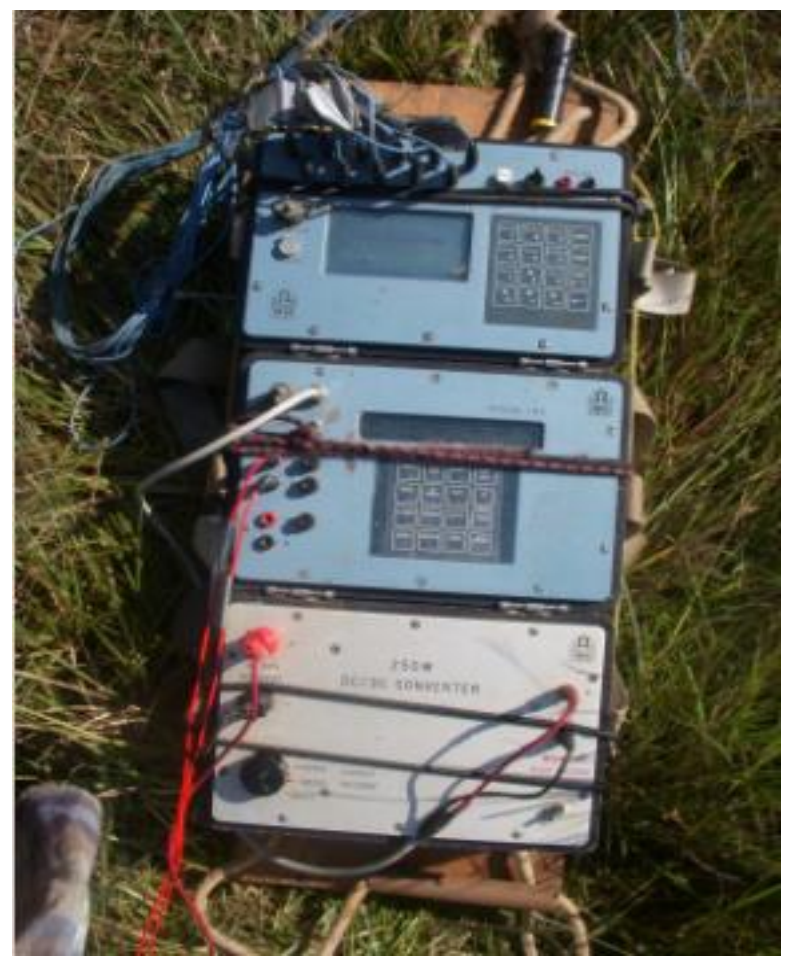

Figura 5.1: Syscal R2, Elrec Pro e conversor de voltagem, utilizados na aquisição com a técnica de caminhamento elétrico.

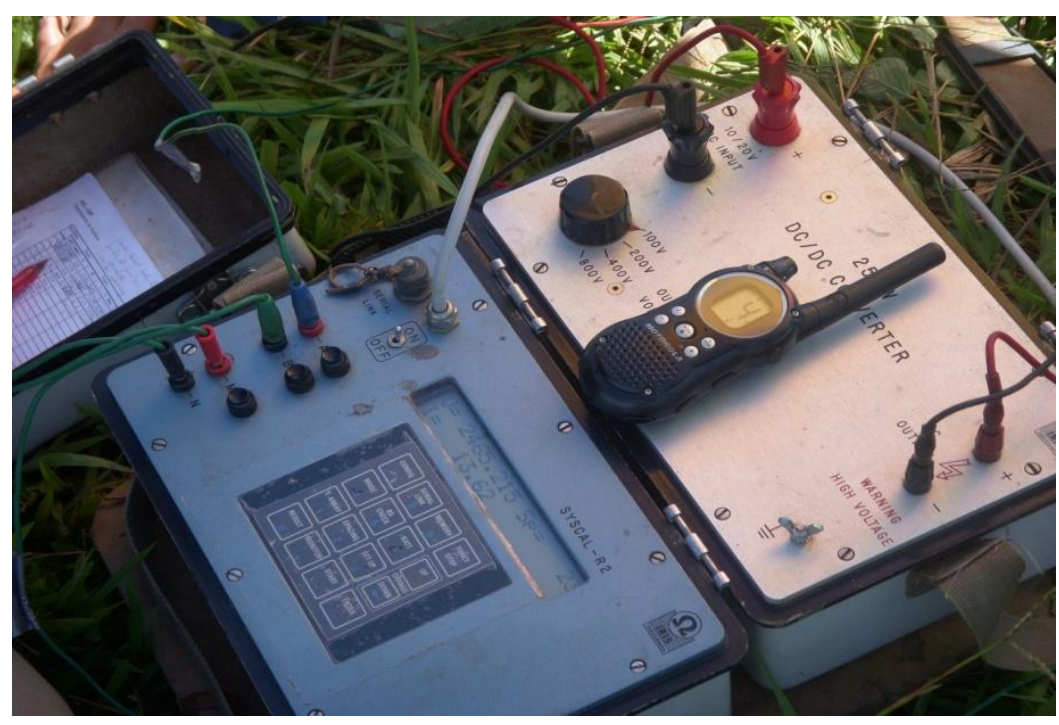

Figura 5.2: Syscal R2 e conversor de voltagem, utilizado na aquisição com a técnica de sondagem elétrica vertical. 


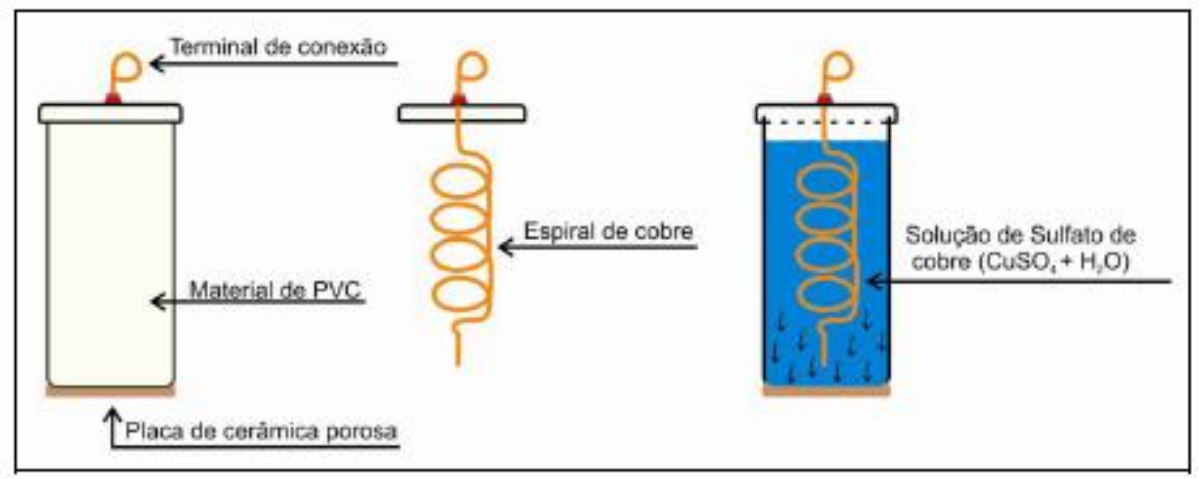

Figura 5.3: Esquema dos eletrodos não polarizáveis, com solução de sulfato de cobre $\left(\mathrm{CuSO}_{4}\right)$, utilizados no caminhamento elétrico.

$\mathrm{Na}$ aquisição dos dados eletromagnéticos o equipamento utilizado neste trabalho foi o EM-34, da Geonics, com espaçamento entre bobinas de 10 e 20 metros. A figura 5.4 mostra este equipamento.

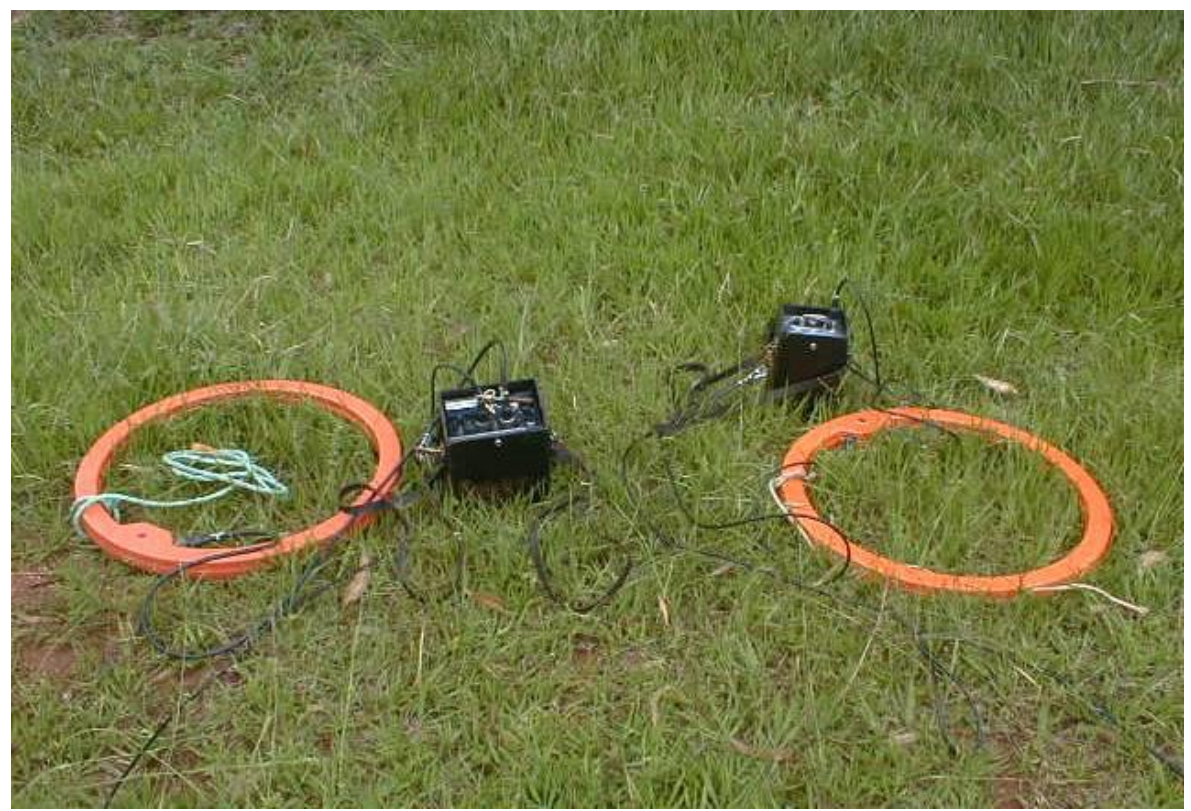

Figura 5.4: Equipamento EM 34, composto por bobina transmissora, bobina receptora, módulo de controle e transmissão de corrente e módulo de leitura.

\subsection{TRABALHOS REALIZADOS EM CAMPO}

Com o objetivo de verificar a resposta geoelétrica em arenitos asfálticos da Formação Pirambóia, foram realizadas cinco linhas de caminhamento elétrico 
para aquisição de dados de resistividade e cargabilidade aparentes (métodos ER e IP), três sondagens elétricas verticais (SEVs) com arranjo Schlumberger e uma linha de caminhamento eletromagnético. A aquisição dos dados foi realizada em duas etapas de campo, a primeira em março de 2012 e a segunda em novembro de 2012. A primeira linha realizada (L1) foi locada na extremidade superior da frente de lavra, que apresentava uma estratificação de camadas propícia para a verificação da resposta da camada com óleo, pois consistia de uma camada bem preenchida pelo óleo entre duas camadas de arenito muito pouco impregnados, facilmente identificáveis na própria frente de lavra. Essa linha foi aberta com 120 metros e foi utilizada a técnica de caminhamento elétrico com o arranjo dipolo-dipolo, com três espaçamentos diferentes entre os eletrodos (2.5, 5 e 10 metros), para se obter uma informação mais detalhada da resposta do material e profundidades de investigação. Sobre a mesma linha foi realizado o caminhamento eletromagnético, para comparação com os resultados de resistividade. A aquisição EM é rápida e pode constituir uma boa alternativa para levantamentos posteriores em áreas maiores e levantamentos mais regionais.

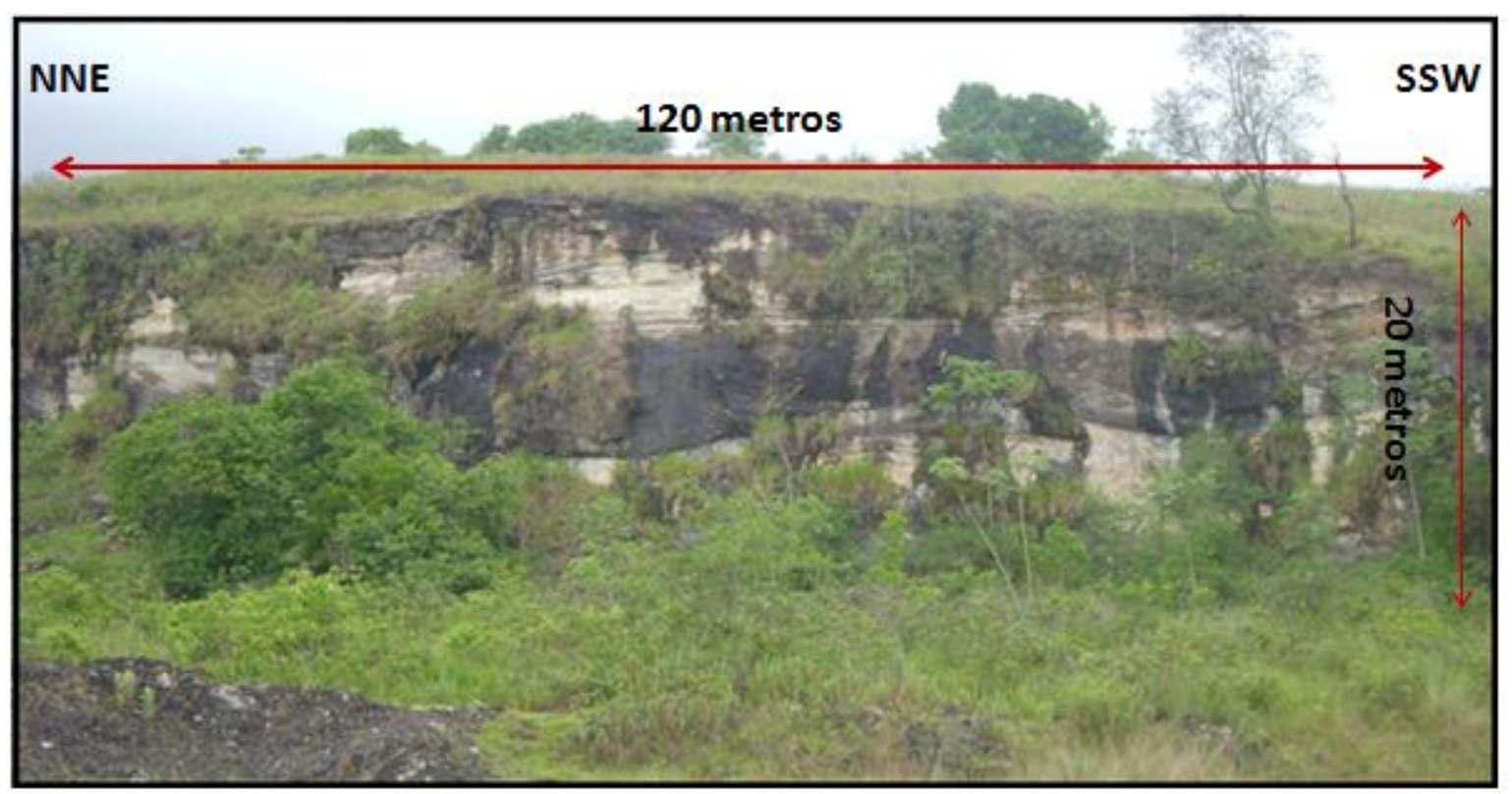

Figura 5.5: Foto da frente de lavra sobre a qual foram realizados as linhas $L 1$ a $L 4$ e SEV 1. No nível da base do afloramento foram feitas a linha L5 e a SEV 3. 
A "SEV 1" foi realizada ao lado da linha L1, que se encontra mais próxima do afloramento e mais fácil de se relacionar os resultados às feições observadas no paredão exposto. Foram realizadas três linhas paralelas à linha L1, denominadas L2, L3 e L4, com a intenção de se obter informações sobre a geometria da camada preenchida por óleo. Essas linhas foram realizadas com espaçamento do dipolo de 10 metros. A segunda sondagem elétrica vertical, "SEV 2", foi realizada em outro lado da pedreira, próxima ao local onde foi perfurado um poço pela Petrobrás no final da década de 1970, para comparação estratigráfica com os intervalos descritos a partir de seus testemunhos. A terceira sondagem elétrica vertical, "SEV 3", foi realizada na base da cava da pedreira, onde também foi feita uma linha de caminhamento elétrico (aquisição com método ER e IP), denominada L5, também com 10 metros de espaçamento entre os eletrodos.

Por fim foram realizadas algumas medições de controle em afloramentos de arenito asfáltico na área, com arranjo Wenner. A figura 5.5 mostra 0 afloramento exposto no paredão, em cujo topo foram realizadas as linhas L1 a L4 e a SEV 1, e a figura 5.6 mostra o esquema das linhas L1 a L5 realizadas na pedreira Betumita, e a localização das SEVs 1 a 3, vistas em planta.

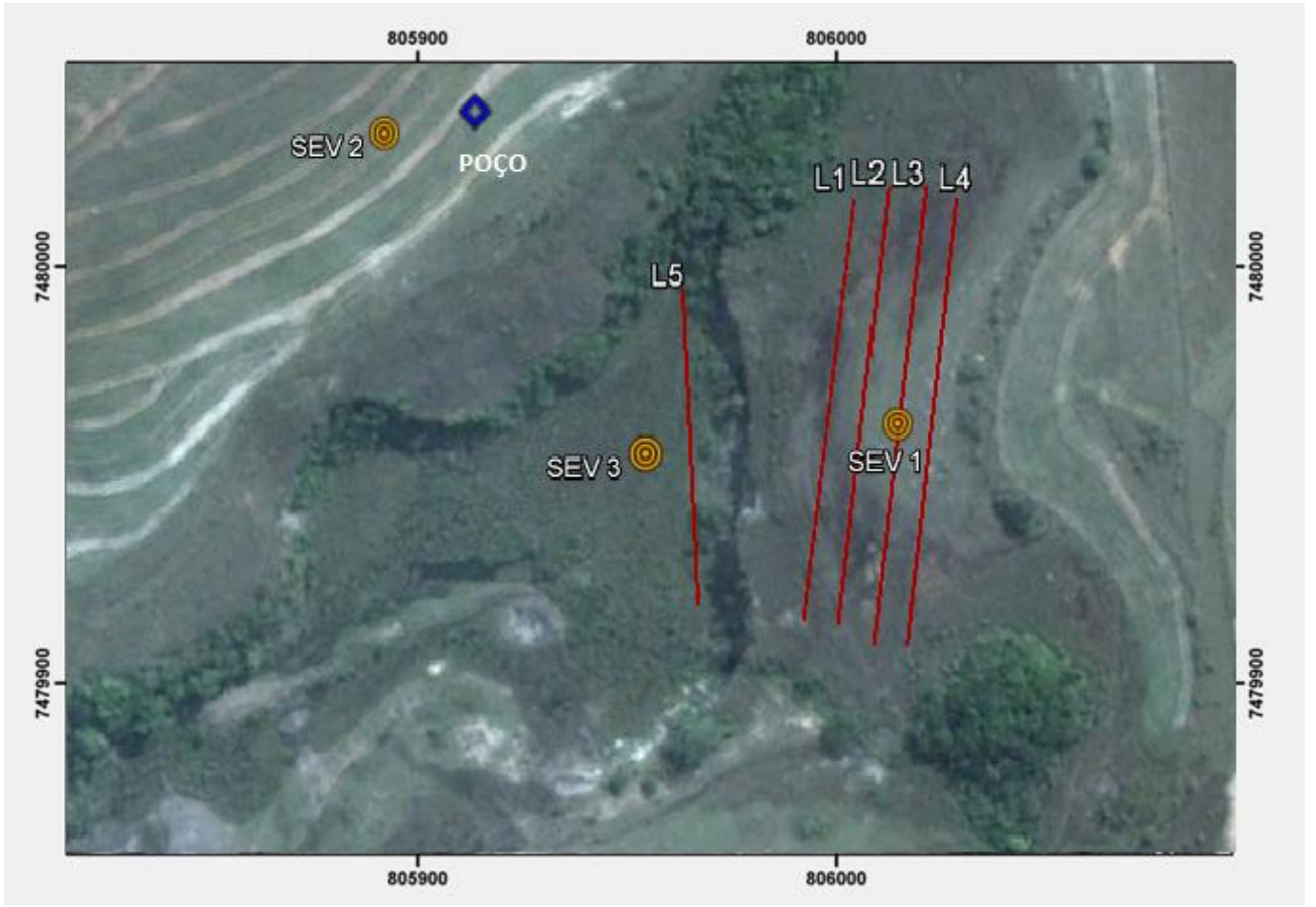

Figura 5.6: Esquema da distribuição dos caminhamentos elétricos e sondagens elétricas realizados. As linhas L1 a L5 representam os CE, as Sevs estão marcadas por círculos amarelos e o poço perfurado pela Petrobras em azul. 


\section{CAPÍTULO VI - INTERPRETAÇÃO E DISCUSSÃO DOS RESULTADOS}

\subsection{SONDAGENS ELÉTRICAS VERTICAIS}

Os dados de SEV foram interpretados com o software IPI2win, fornecendo modelos de camadas, resistividades e espessuras. Em seguida, com base nas posições das SEVs e de informações geológicas, as camadas geoelétricas foram interpretadas em termos de estratos geológicos.

A SEV1 foi realizada no topo do afloramento originado da exploração da Pedreira Betumita, mesmo local dos caminhamentos elétricos L1 a L4, com a intenção de que sua sucessão de níveis geoelétricos pudesse ser associada aos estratos geológicos observados no afloramento exposto, considerado fundamental para o diagnóstico do padrão geoelétrico diferencial esperado para a camada de arenito asfáltico. A camada de arenito asfáltico apresentou baixos valores de resistividade ( $<20$ ohm.m), o que a princípio pode parecer contraditório, diante da elevada resistividade do petróleo. Porém, devido a idade desses corpos e sua colocação próxima da superfície, as camadas asfáticas podem ter sofrido o ataque de microorganismos que se alimentam do óleo e geram subprodutos com alto teor de sólidos dissolvidos, ccausando uma redução da resistividade do ambiente. A figura 6.1 apresenta os resultados da SEV1 e sua interpretação.

A SEV 1 foi interpretada com um modelo de 5 camadas. As camadas superiores (camadas 1 a 4) puderam ser correlacionadas satisfatoriamente aos estratos observados no afloramento. As camadas 1 e 2 representam as camadas de solo e/ou sedimento predominantemente arenoso sem presença óleo, com resistividades médias a altas. Logo a seguir, na terceira camada, a resistividade diminui bruscamente, a partir de 5 metros da superfície, coincidente com o início da camada de arenito asfáltico no afloramento, sendo por isso interpretada com esse estrato geológico. A quarta camada apresenta um aumento de resistividade, sendo interpretada como arenito sem óleo. A quinta camada apresenta de novo uma diminuição de resistividade, o que 
sugere ocorrer ou uma nova camada de arenito asfáltico com o mesmo comportamento da superior ou sedimento arenoso saturado.

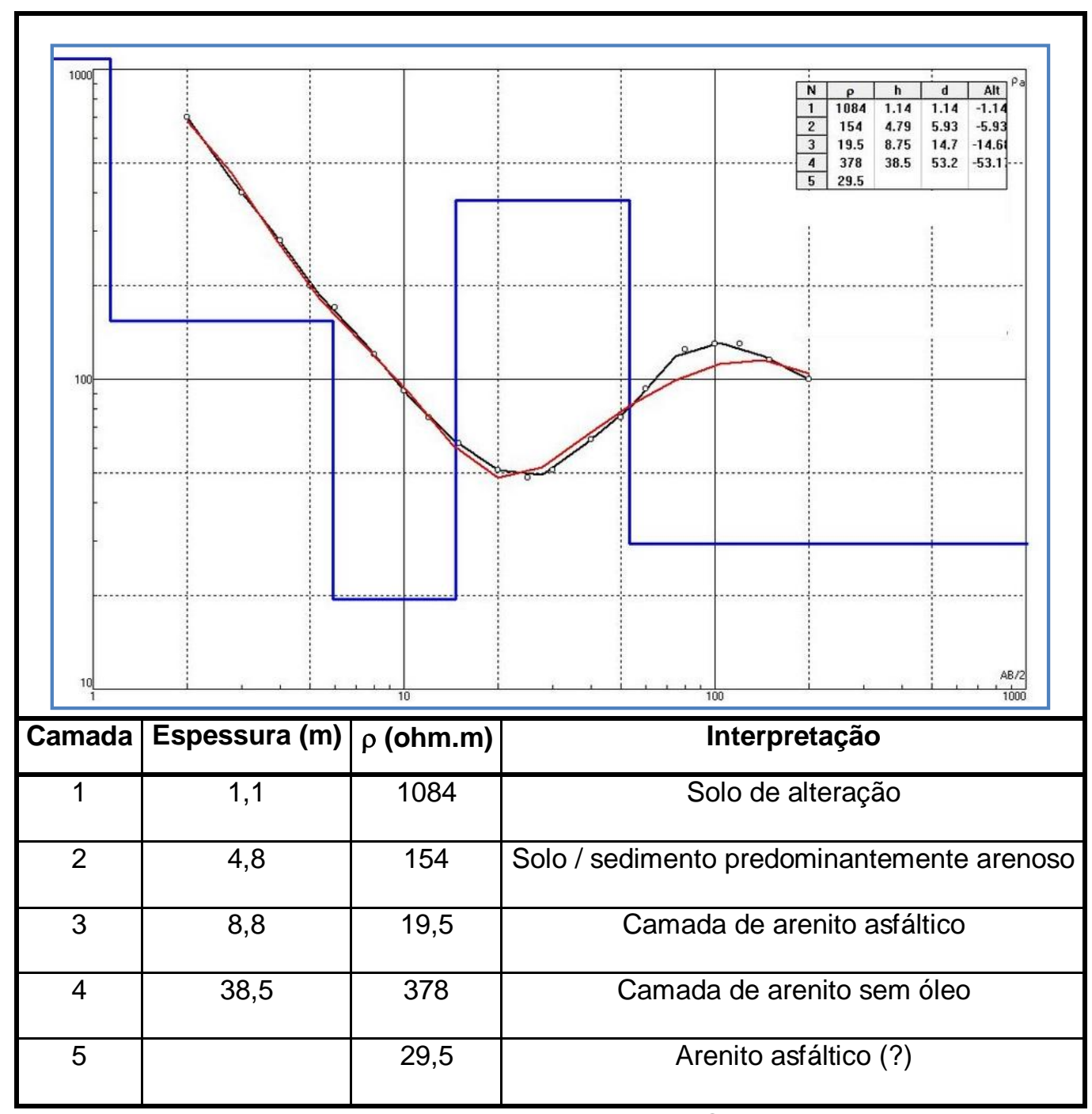

Figura 6.1: Interpretação da SEV1

Os resultados da SEV 1 se encaixam no contexto descrito por Steveaux et al. (1980) em relatório da Paulipetro, segundo o qual uma das sequências observadas na Betumita se inicia, no topo, por um capeamento areno-argiloso de espessura variando de 1 a 4 metros, seguido por um arenito estéril de estrutura plano-paralela. Abaixo deste, segundo os autores, segue um banco de arenito asfáltico bem preenchido, homogêneo, com espessura observada de cerca de 5 metros, que por sua vez faz contato com uma camada de arenito síltico pouco preenchido (seu grau de saturação diminui em direção ao topo da 
camada, até se tornar estéril) e, finalmente, uma nova camada de arenito bem preenchido e homogêneo na base da coluna.

A SEV 2 foi locada cerca de 180 metros à noroeste do local da SEV 1, aproximadamente em mesma cota topográfica, ao lado de um furo de sondagem perfurado pela Petrobras na década de 1970, com a intenção de comparar os resultados com a descrição do mesmo.

Os resultados dessa SEV são apresentados na Figura 6.3. As três primeiras camadas são interpretadas como solo e sedimento predominantemente arenosos. A seguir, a partir de 13 metros de profundidade, inicia-se a camada de baixa resistividade associada ao arenito asfáltico, e a cerca de 40 metros de profundidade observa-se uma camada de resistividade muito alta (1202 ohm.m). O furo de sondagem citado (furo 9-PAA-13-SP) detectou óleo no intervalo entre 15 e 47,50 metros de profundidade, concordando satisfatoriamente com a camada elétrica atribuída ao arenito asfáltico.

De acordo com Thomaz Filho (1982), a campanha de sondagem da Petrobras relatou a presença de um dique de diabásio não aflorante próximo à Betumita, o que poderia explicar os altos valores de resistividade encontrados na quinta camada. Um dique de diabásio de direção NW também é relatado em outra ocorrência de arenito asfáltico próxima à Betumita, e em algumas áreas no Alto Estrutural de Anhembi observa-se um solo residual de coloração vermelhoescuro e cimentação ferruginosa, característico de alteração de rochas básicas (Cabral, 2006). 


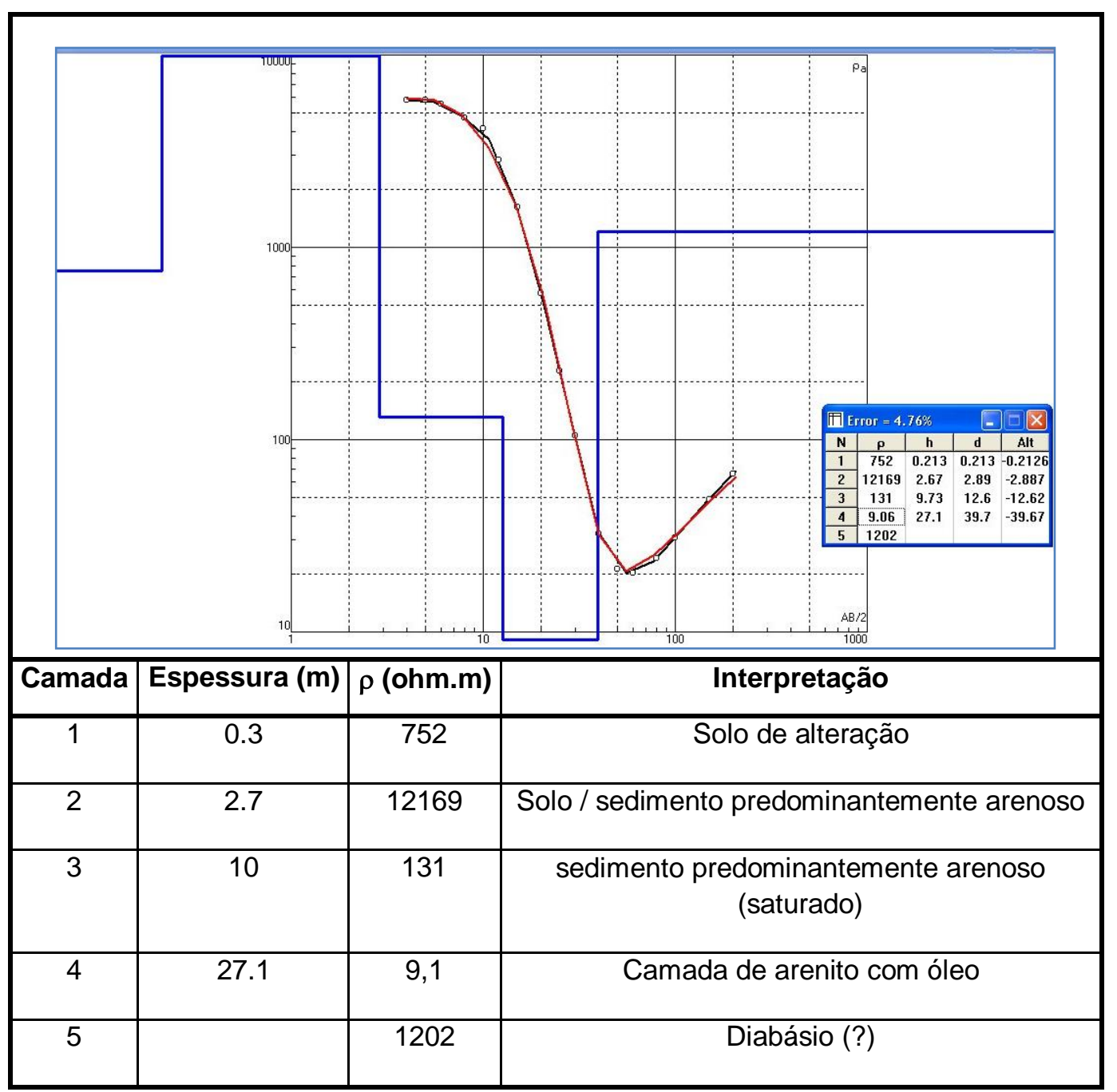

Figura 6.2: Interpretação da SEV2

A SEV 3 foi realizada na base da cava, considerando que a camada de arenito asfáltico já havia sido lavrada. Dessa forma, a primeira camada investigada seria a camada de arenito sem óleo (ou com pequena impregnação) abaixo da camada de arenito asfáltico exposta no afloramento investigado com a SEV 1 Seus resultados são observados na figura 6.3. 


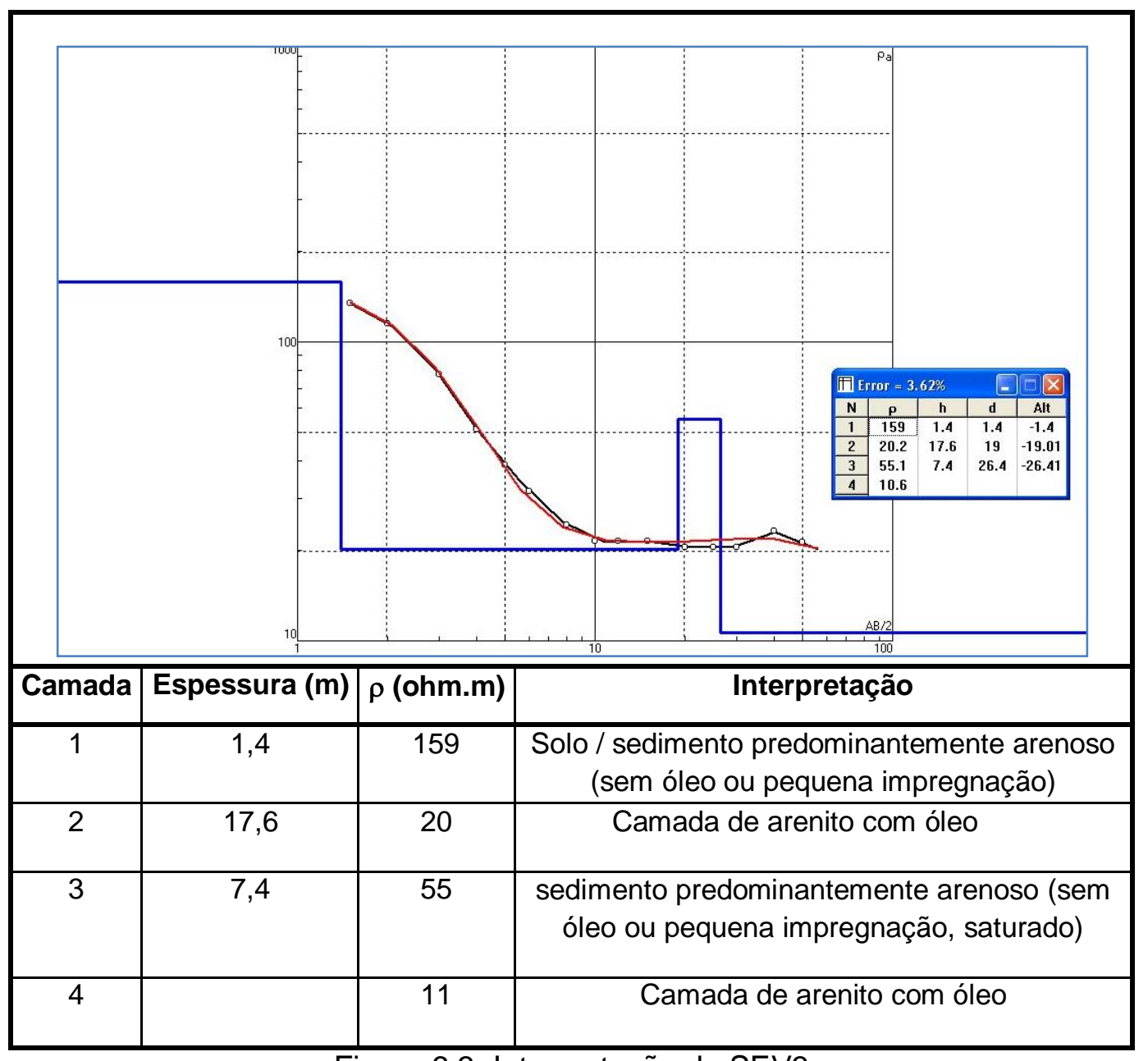

Figura 6.3: Interpretação da SEV3

Esta SEV foi interpretada com um modelo de 4 camadas. A camada superior, de pequena espessura, pode ser relacionada a um solo superficial ou à continuidade da camada basal de arenito pouco impregnado observado na base do afloramento no paredão. A seguir são interpretadas duas camadas com óleo (20 e 11 ohm.m) com uma camada de resistividade levemente mais alta (55 ohm.m), interpretada como camada de arenito sem óleo ou com pouco óleo. A presença de uma nova camada de arenito asfáltico concordaria com a descrição de Steveaux et al. comentada na SEV 1. 


\subsection{CAMINHAMENTO ELÉTRICO (CE)}

\subsubsection{Dados de resistividade}

Após o processamento dos dados de resistividade dos caminhamentos elétricos (ER) foram obtidas seções 2D paralelas ao paredão exposto na antiga pedreira, que puderam ser comparadas com o afloramento exposto no mesmo. Da mesma forma que nos resultados das SEVs, as camadas relacionadas aos arenitos asfálticos apresentaram baixos valores de resistividade ( $<20$ ohm.m). As figuras 6.4, 6.5 e 6.6 apresentam os resultados de resistividade da Linha 1, obtidos com os espaçamentos de eletrodos de 2,5 metros, 5 metros e 10 metros, respectivamente. Essas diferentes aberturas foram utilizadas para verificar qual a relação espaçamento e resolução seria a mais adequada ao estudo da camada asfáltica. Como pode ser observado nas figuras, os arranjos de mais detalhes não apresentaram feições dentro da camada asfáltica que justificassem seu uso. Essas aberturas menores entre eletrodos detalham apenas o contato com o solo superficial. Além disso, o arranjo de 10 metros é o que melhor define o contato do arenito asfáltico com a camada mais pobre em óleo da base do afloramento. Este contato é caracterizado por um aumento de resistividade (em direção à superfície).

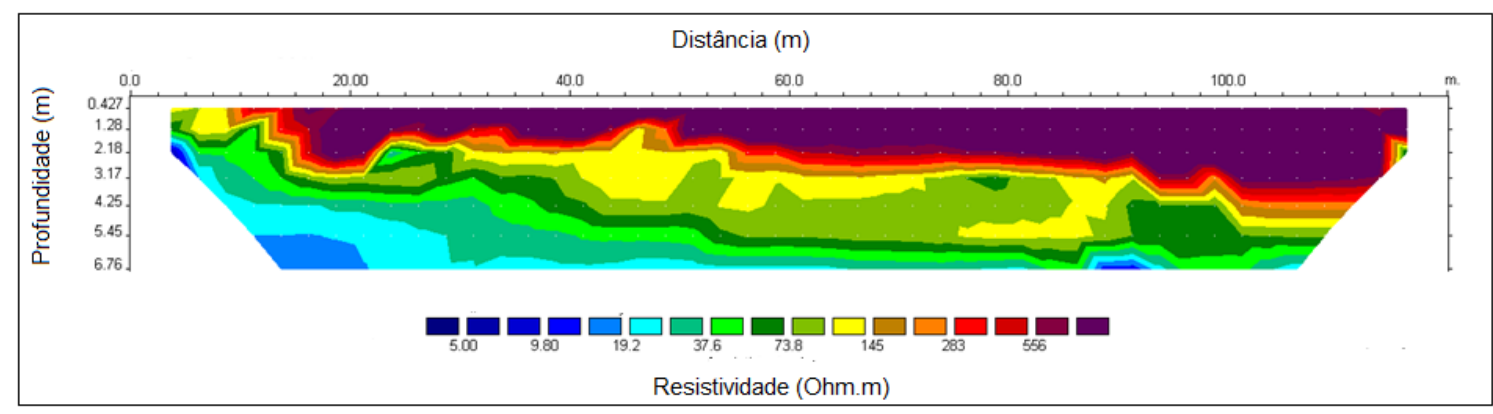

Figura 6.4: Seção de resistividade da linha "L1", com espaçamento entre eletrodos de 2,5 metros. 


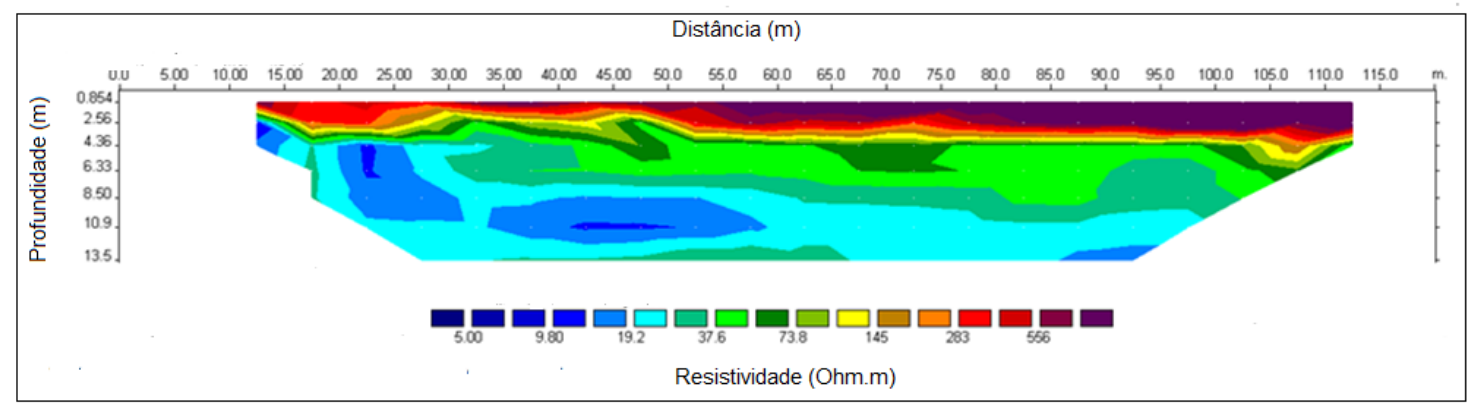

Figura 6.5: Seção de resistividade da linha "L1" com espaçamento de 5 metros entre eletrodos.

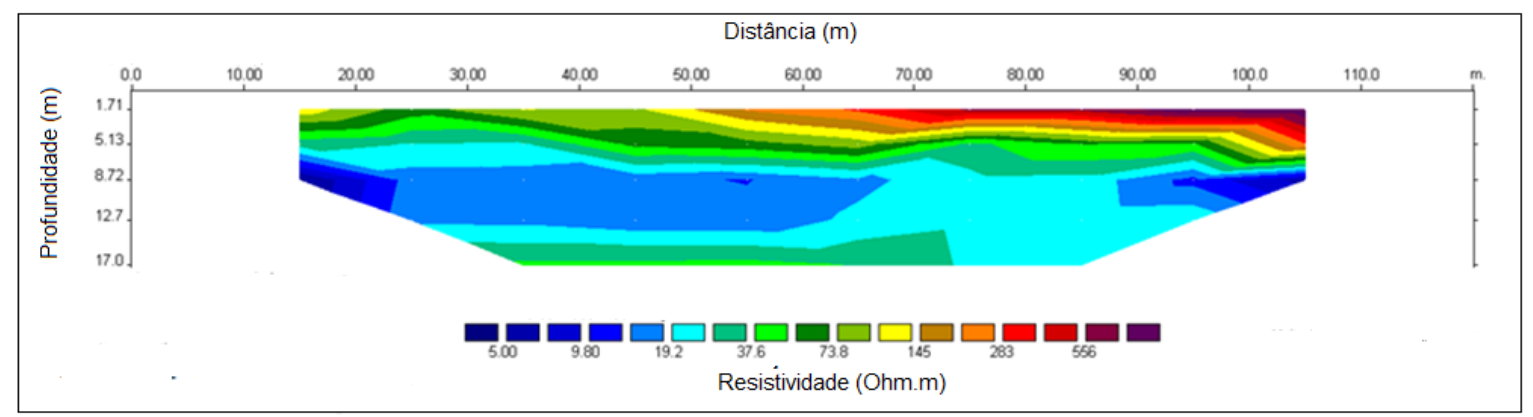

Figura 6.6: Seção de resistividade da linha "L1" com espaçamento de 10 metros entre eletrodos.

Os dados dos ensaios com diferentes espaçamentos foram concatenados em um mesmo arquivo e submetidos à rotina de inversão. Dessa forma, a seção resultante deve apresentar maior resolução na superfície e também permitirá a visualização do contato na base do afloramento. O resultado é apresentado na figura 6.7, onde essas feições são observadas. Para mostrar as feições de resistividade e suas relações com o afloramento, uma fotografia do afloramento indica a parte do perfil de resistividade correspondente. 


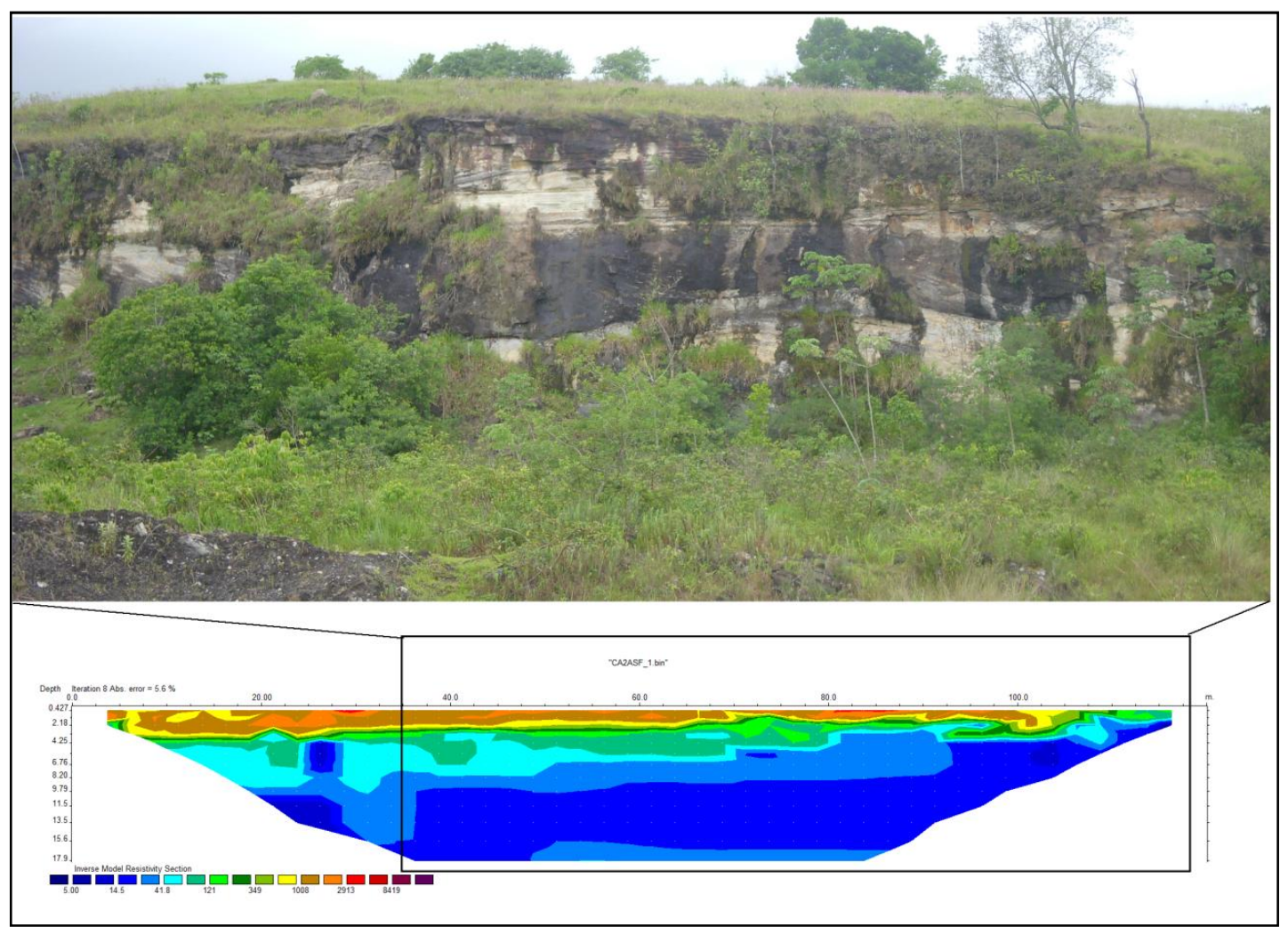

Figura 6.7: Seção composta da Linha 1 com os ensaios para diferentes espaçamentos entre eletrodos e sua relação com o afloramento.

Os ensaios para as linhas 2, 3 e 4 foram realizados apenas com a abertura de 10 metros entre os eletrodos. Os resultados dessas linhas são apresentados nas figuras 6.8, 6.9 e 6.10 e mostram feições semelhantes aos observados na Linha 1: solo superficial mais resistivo (> 150 ohm.m), a camada asfáltica mais condutora (<35 ohm.m) e um aumento da resistividade na base dos perfis.

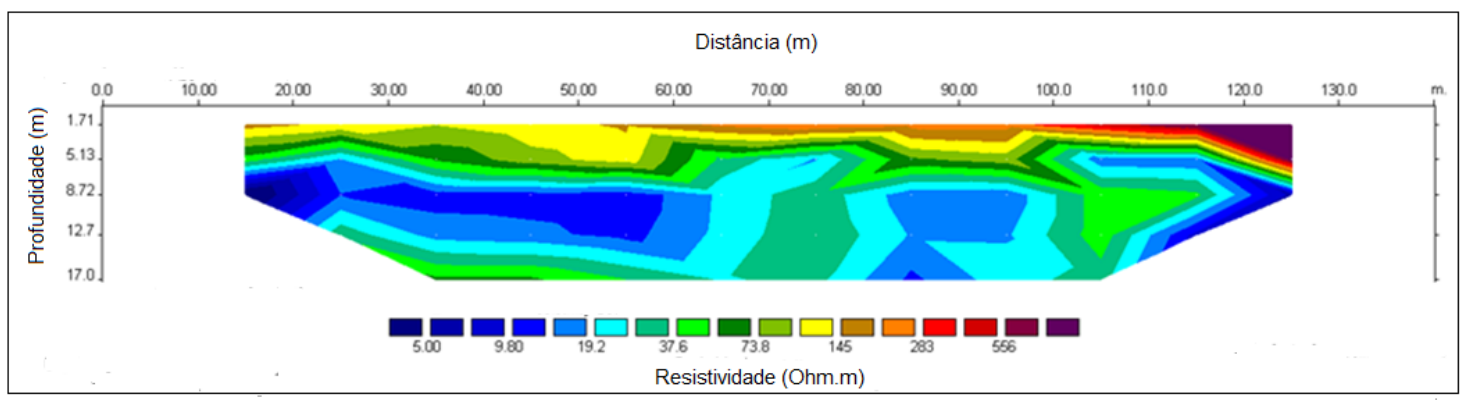

Figura 6.8: Seção de resistividade da linha "L2", com espaçamento de 10 metros entre os eletrodos. 


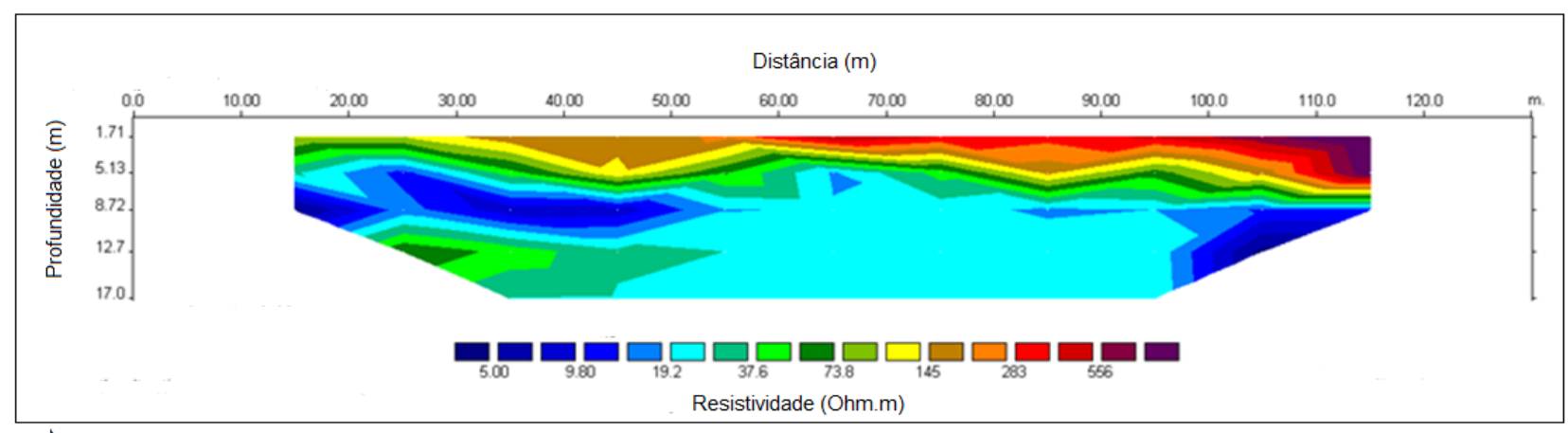

Figura 6.9: Seção de resistividade da linha "L3", com espaçamento de 10 metros entre eletrodos.

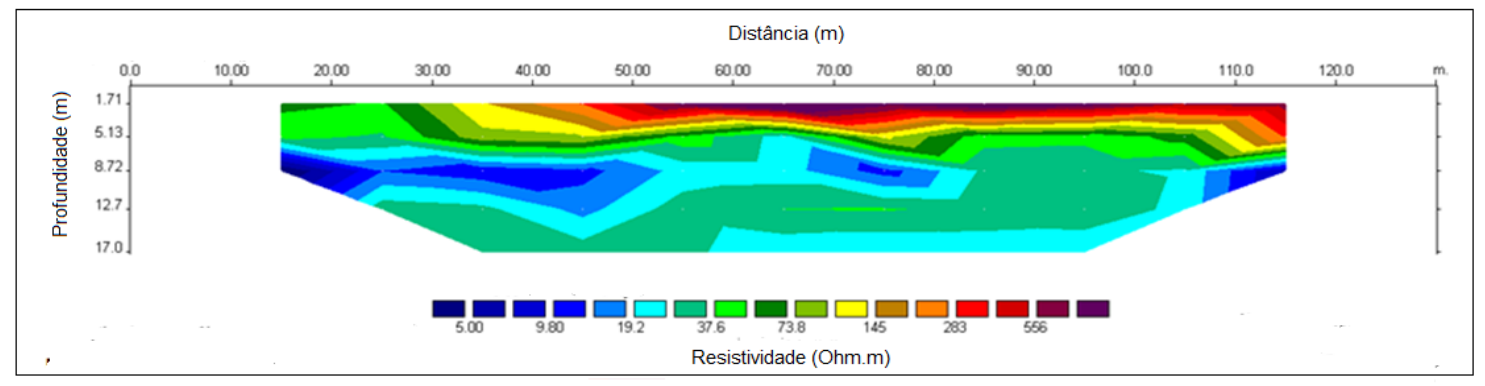

Figura 6.10: Seção de resistividade da linha "L4", com espaçamento de 10 metros entre eletrodos.

Para efeito de visualização dos estratos geológicos interpretados com a SEV 1 e sua adequação aos perfis gerados com os caminhamentos elétricos sob a mesma, uma combinação dos resultados da SEV e do perfil de CE é mostrada na figura 6.11 . 


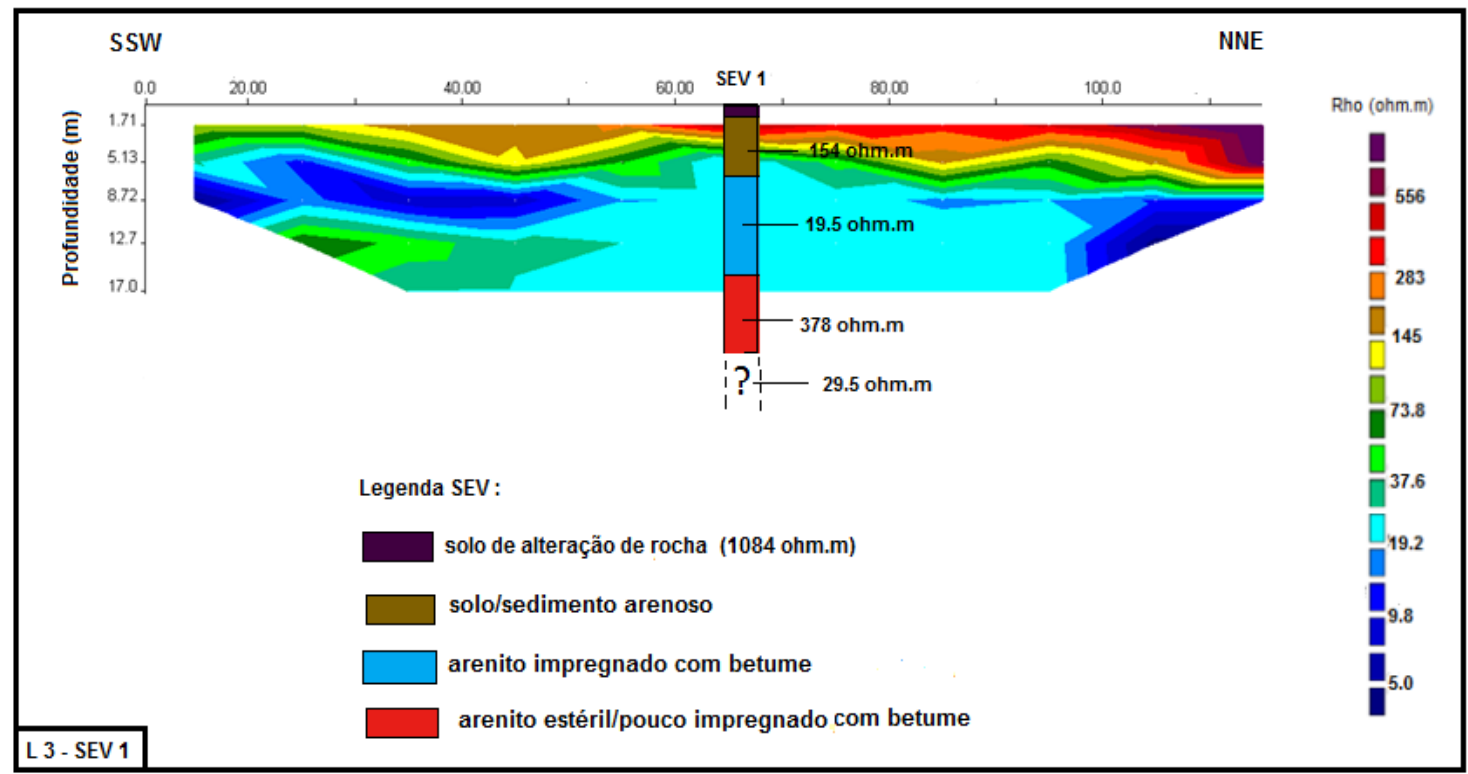

Figura 6.11: Sobreposição das camadas interpretadas com a SEV 1 e a linha L3 ( no ponto onde a mesma foi realizada).

A Linha 5 foi realizada na base da cava e mostra, de forma concordante com os resultados da SEV 3, que sugere que abaixo da camada com menor conteúdo em óleo da base da cava, volta a ocorrer uma camada condutora, com menos de 20 ohm.m. Essa camada é interpretada como arenito asfáltico (figura 6.12).

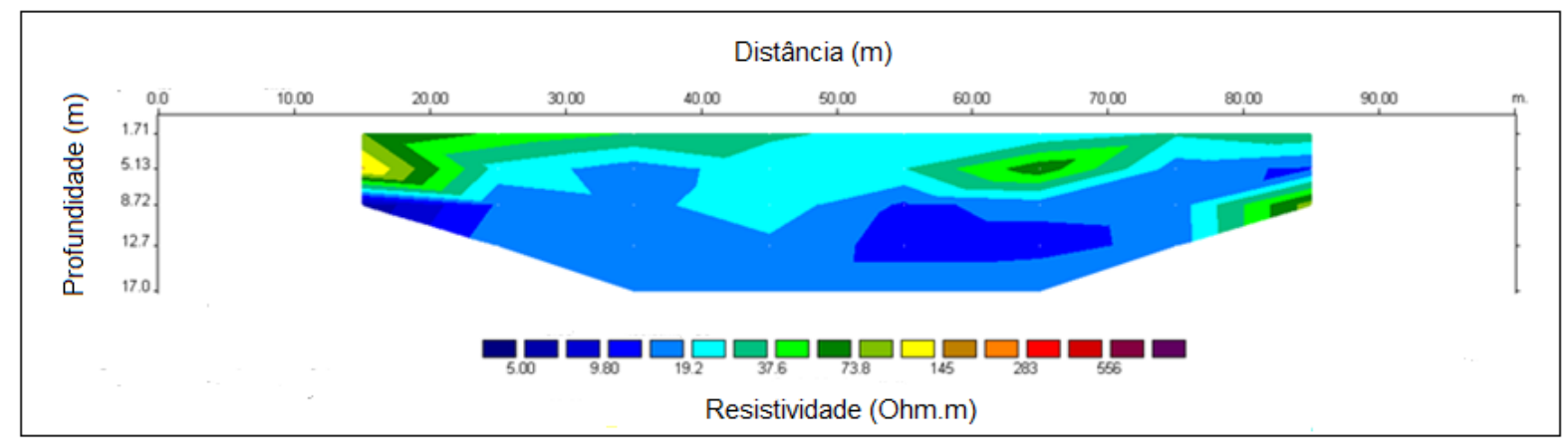

Figura 6.12: Seção de resistividade da linha "L5", com espaçamento de 10 metros entre os eletrodos.

Como a SEV 3 foi realizada sobre a linha L5, os resultados interpretados com esta SEV podem ser observados sobrepostos ao perfil correspondente (perfil da linha 5) na figura 6.13. 


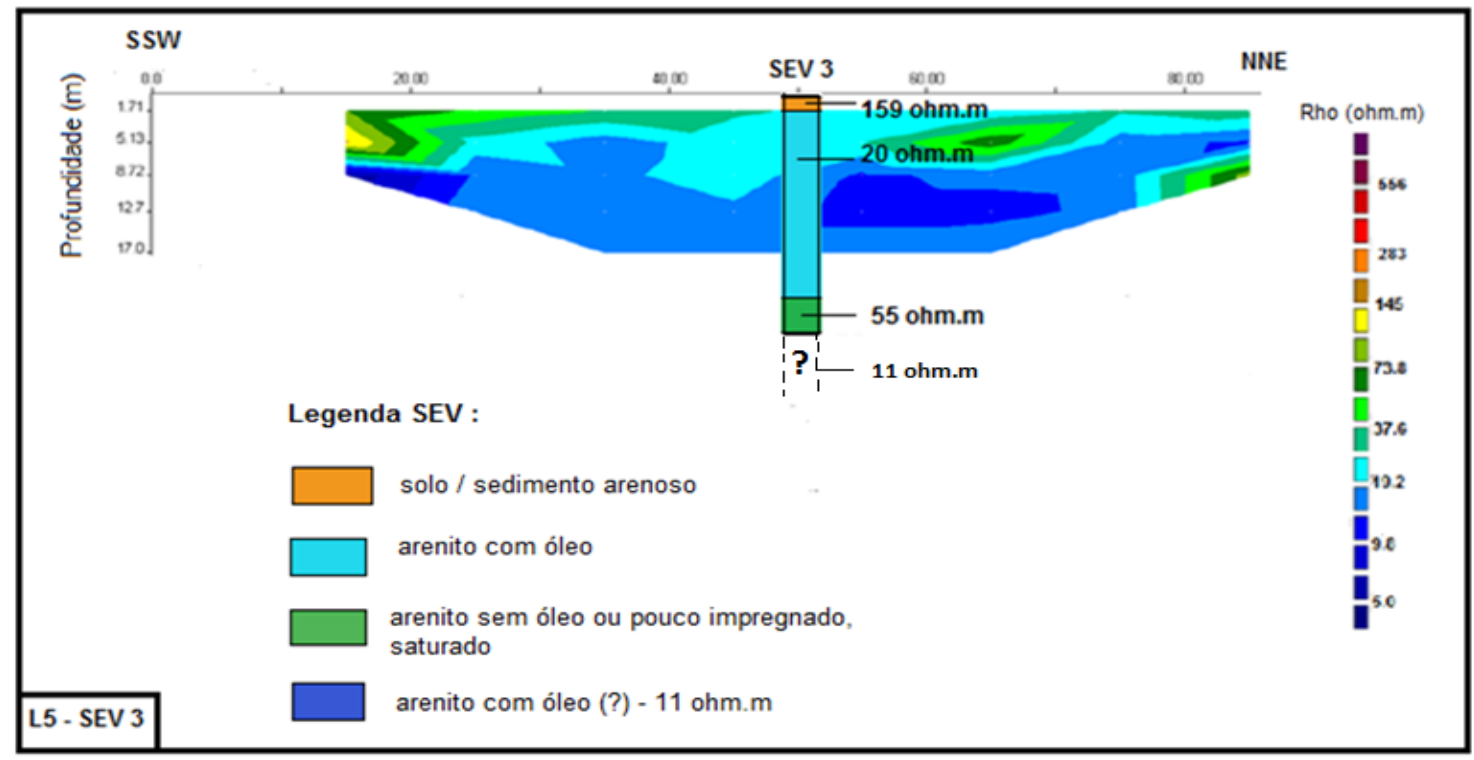

Figura 6.13: Sobreposição das camadas interpretadas com a SEV 3 e a linha L5.

Para uma melhor visualização espacial dos resultados obtidos através dos caminhamentos elétricos, foi feita uma composição dos resultados dos perfis 2D obtidos, apresentados na figura 6.14. Nesta figura pode-se observar as relações entre os perfis, onde a camada de arenito asfáltico tem continuidade lateral e espessura aproximadamente constante.

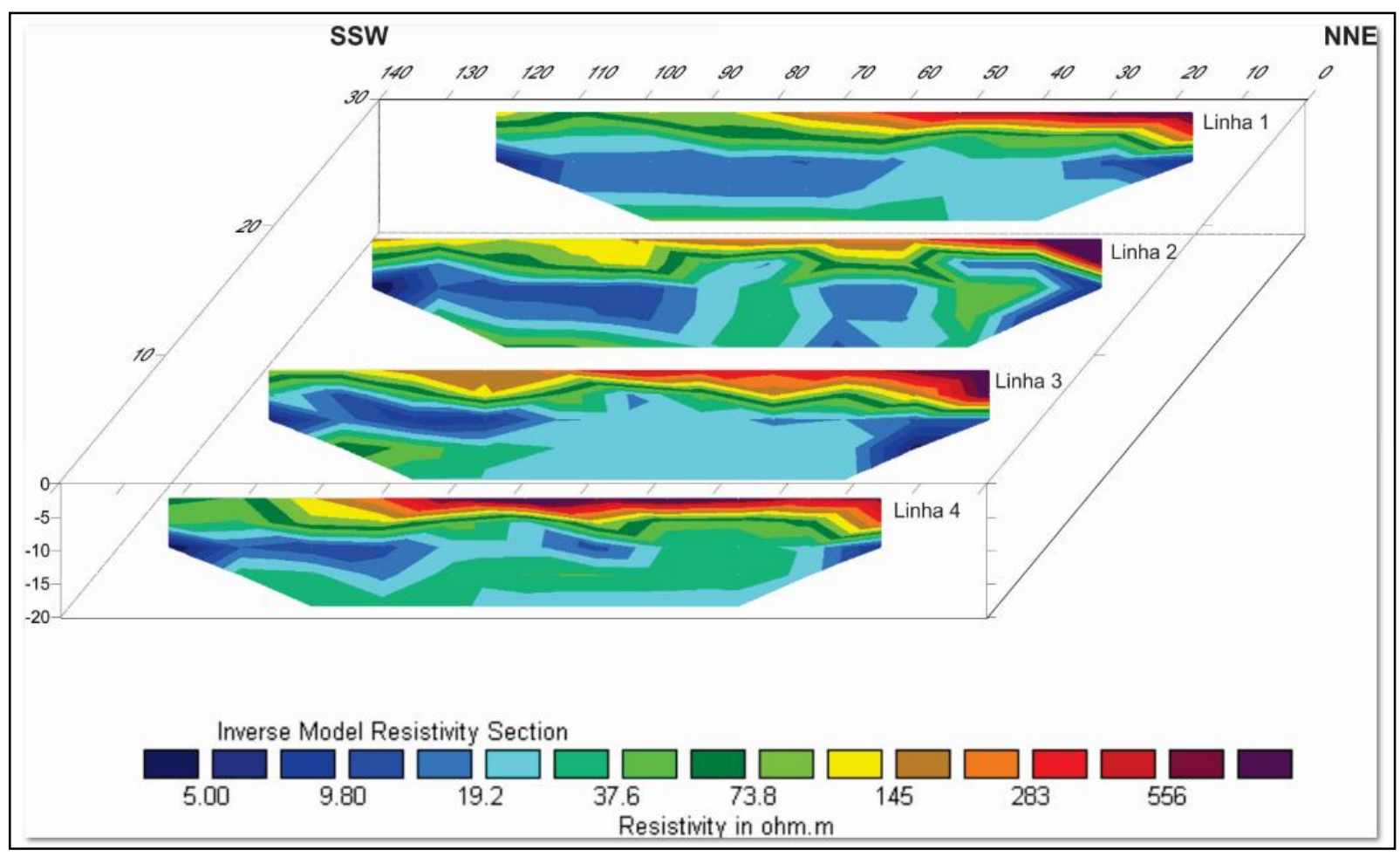

Figura 6.14: Visualização do conjunto de perfis 2D de resistividade. 
Como os perfis foram levantados com arranjo dipolo-dipolo com espaçamento de dipolos de 10 metros e equi-espaçados de 10 metros, foi possível associálos em um mesmo banco de dados e submetê-los a um processo de inversão 3D com o uso do software RES3Dinv. O resultado foi exportado para um programa de visualização 3D (Voxler, Golden Software, 2009) que possibilitou uma visualização da camada asfáltica dentro do afloramento existente na Pedreira Betumita. Esta imagem, apresentada na figura 6.15, define a geometria da camada asfáltica, com resistividade inferior a 20 ohm.m. A camada apresenta-se com geometria tabular e leve mergulho para NNE, como observa-se, porém de forma menos clara, na figura 6.14.

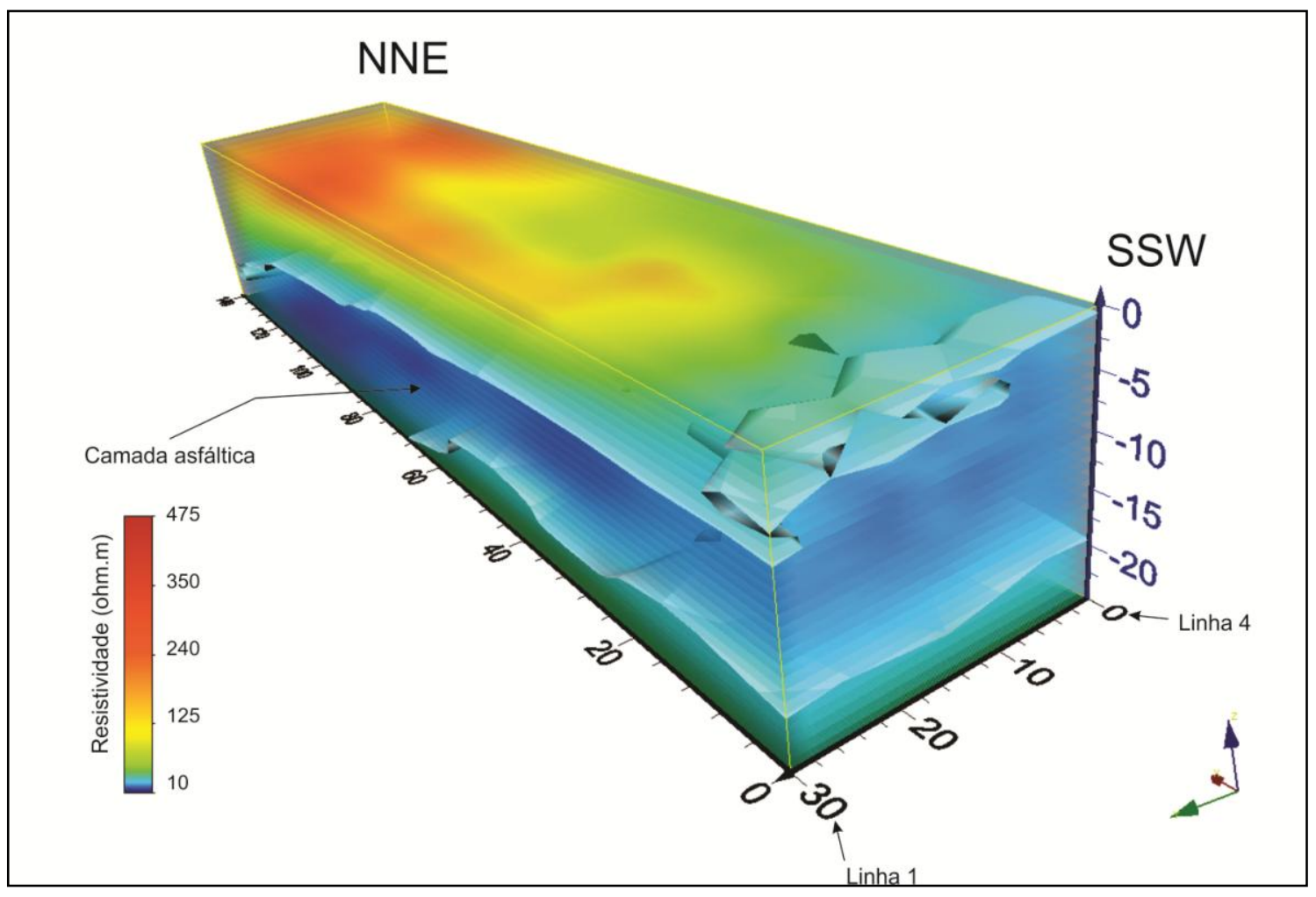

Figura 6.15: Modelo 3D da camada de arenito asfáltico.

Os resultados obtidos neste projeto foram, em um primeiro momento, inesperados. A resposta elétrica comumente encontrada em áreas com presença de hidrocarbonetos, assim como de contaminantes derivados de hidrocarbonetos é uma anomalia de resistividade mais elevada em relação ao meio, devido à presença dos compostos orgânicos, que intrinsecamente possuem resistividades muito altas. A mesma resposta era esperada para os 
casos de contaminação por hidrocarbonetos, até que diversos estudos e observações geofísicas conduzidas por Sauck (2000) o levaram a propor um modelo que considera derrames de hidrocarbonetos como sistemas dinâmicos e variáveis, que com o tempo alteram seu comportamento elétrico de resistivo para condutor. Essa mudança de comportamento é ocasionada pela atividade de biodegradação dos hidrocarbonetos, que se caracteriza por um processo de degradação pela ação de micro-organismos (fungos e bactérias), causando a redução de massa dos compostos em subsuperfície e a geração de subprodutos (ácidos carbônicos e orgânicos) que aumentam o teor de sólidos dissolvidos no ambiente. Esse enriquecimento em sólidos na zona de biodegradação altera as condições químicas do sistema modificando suas propriedades elétricas. Apesar da área de estudo não constituir um campo maduro de hidrocarbonetos, onde isso ocorre frequentemente, os afloramentos se encontram muito próximos à superfície, o que facilitaria o processo de biodegradação.

Diante do acima exposto e baseado no trabalho de Cabral (2006), que realizou um estudo geoquímico das ocorrências de arenitos asfálticos da Formação Pirambóia por meio de biomarcadores, pode-se sugerir que a baixa resistividade dos arenitos asfálticos deve-se, entre outros fatores, à biodegradação. Nesse trabalho (Cabral, op. cit.) foram coletadas 18 amostras de afloramentos de arenitos betuminoso, sendo 5 da Pedreira Betumita, das quais o óleo foi recuperado por extração à ultrassom e submetido a cromatografia líquida para separação das frações de hidrocarbonetos (alifáticos, aromáticos e compostos NSO) que foram, posteriormente, analisadas por cromatografia gasosa. O óleo apresentou maior quantidade de compostos NOS, seguido pelos compostos aromáticos e, em menor quantidade, os compostos alifáticos. A degradação do óleo dentro do reservatório ocorre de maneira seletiva pelos microorganismos presentes nas águas meteóricas e diversos estudos em laboratório e em campo demonstraram que as frações de hidrocarbonetos saturados (alifáticos), aromáticos e a de asfaltenos (compostos NOS) apresentam diferentes susceptibilidades ao ataque microbiano. A ordem decrescente de biodegrabilidade relativa seria: alifáticos ou saturados $>$ aromáticos $>$ resinas $\mathrm{e}$ asfaltenos (NOS), de acordo com Connan (1984), Peters e Moldowan (1993) e 
Garcia et al. (2011). Além disso, o próprio processo de biodegradação provoca um aumento no teor de enxofre do óleo (além do aumento da densidade específica, acidez e viscosidade).Portanto, a distribuição e abundâncias relativas dos biomarcadores indicam que o óleo presente nesses arenitos asfálticos possui um baixo grau de evolução térmica e níveis severos de biodegradação. A autora (Vargas, op cit.) também utilizou biomarcadores para caracterizar o ambiente deposicional do óleo, concluindo que ele provém de uma rocha geradora depositada em um ambiente marinho com coluna d'água estratificada, hipersalina e anóxica, descrição que concorda com o ambiente deposicional atribuído à Formação Irati, depositado em mar interno do tipo epicontinental resultante de diversos ciclos transgressivos - regressivos (Hachiro, 1991). A figura 6.16 mostra a comparação entre cromatrogramas de óleos da Formação Pirambóia na área de estudo e da Formação Irati.

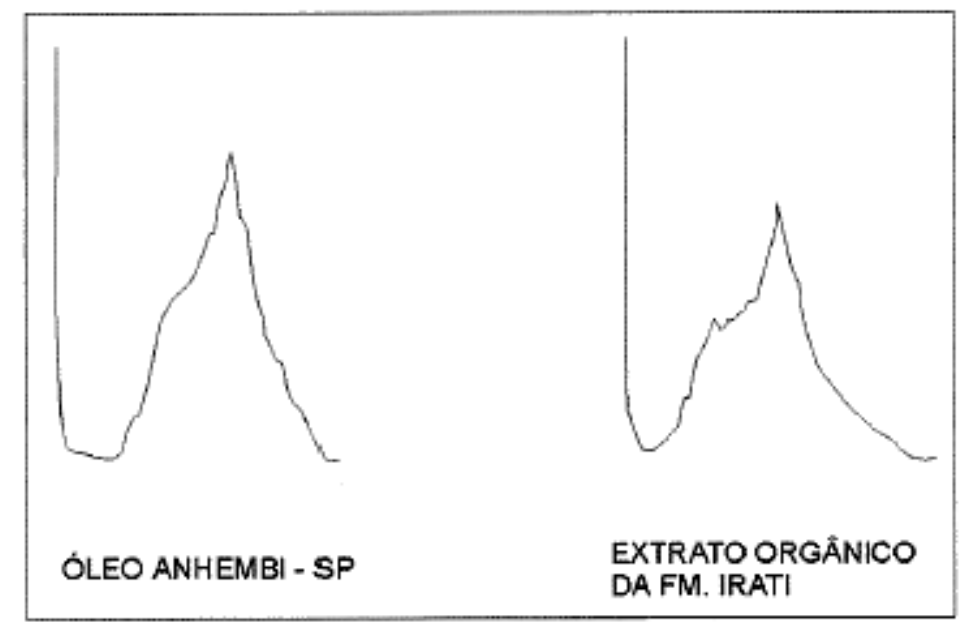

Figura 6.16: Comparação entre os cromatogramas da Fm. Pirambóia e Fm. Irati (Quadros, 1982, apud Thomaz Filho, 1982).

\subsubsection{Polarização Induzida}

Para as linhas com espaçamento de 10 metros, foram realizados ensaios de polarização induzida juntamente com a resistividade. Embora os resultados de IP normalmente sejam muito mais sujeitos a ruído que os de resistividade, as 
seções apresentaram um comportamento semelhante, com baixos valores de cargabilidade para a camada asfáltica. A geometria da camada definida pela cargabilidade é mais irregular, porém a grosso modo mantém o mesmo comportamento.

Na figura 6.17 é apresentada a seção da Linha L1. Nesta seção pode-se observar que a camada asfáltica definida pela resistividade apresenta valores de cargabilidade mais baixos que o solo / sedimento sem óleo que ocorre na superfície do terreno. Os valores de cargabilidade para a camada são sempre inferiores a $5 \mathrm{mV} / \mathrm{V}$, ao passo que para a porção superficial são superiores a 10 $\mathrm{mV} / \mathrm{V}$.

Esse comportamento se repete para as linhas $L 2$ e $L 4$, apresentadas nas figuras 6.18 e 6.20, respectivamente. No caso da Linha L3 (figura 6.19) o contraste de resistividade entre o solo / sedimento superficial (que mantém valores superiores a $10 \mathrm{mV} / \mathrm{V}$ ) é muito maior, sendo que a camada de arenito asfáltico apresenta valores inferiores a $2 \mathrm{mV} / \mathrm{V}$. Isso pode ocorrer a variações na composição da camada ou mesmo a possíveis ruídos durante a coleta de dados.

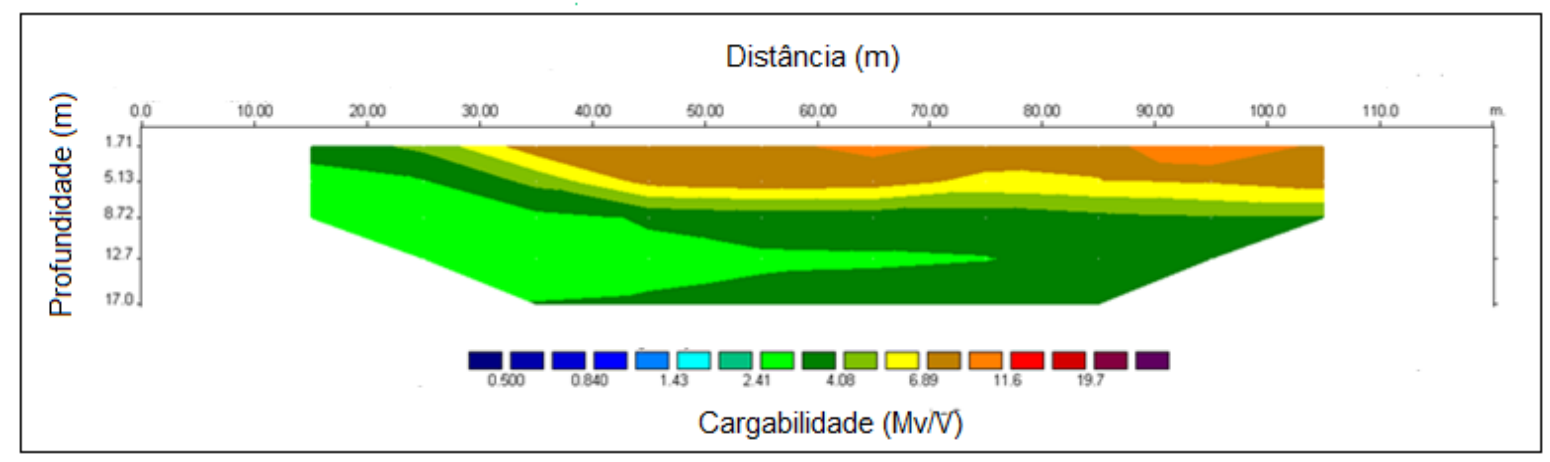

Figura 6.17: Seção de cargabilidade da linha "L1". 


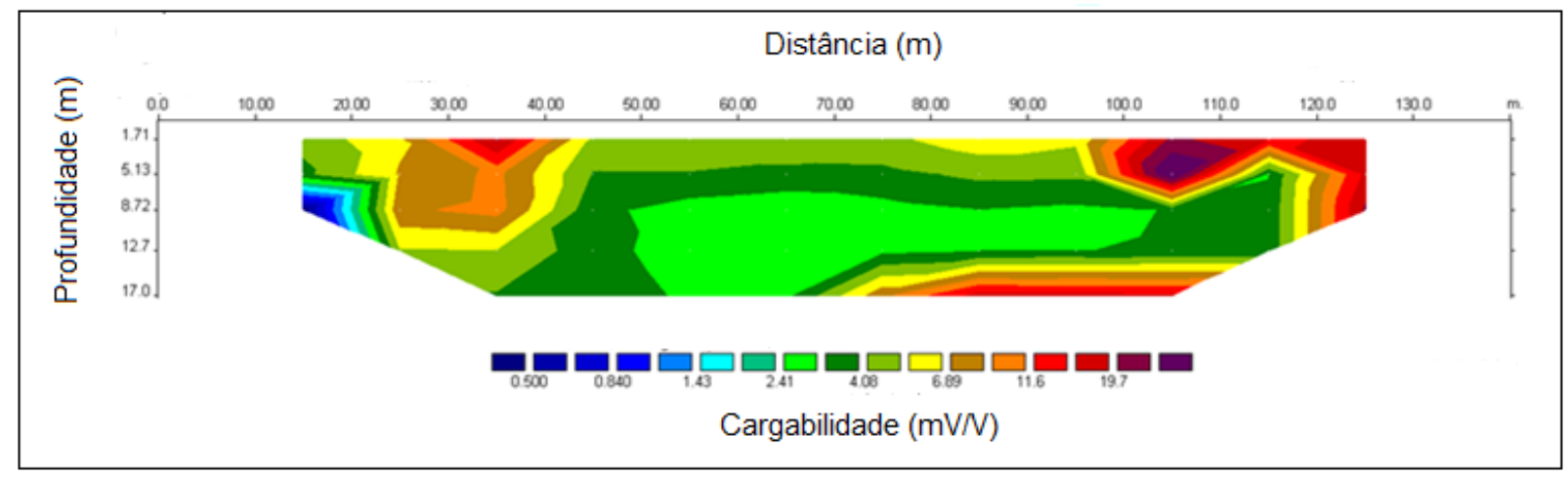

Figura 6.18: Seção de cargabilidade da linha "L2".

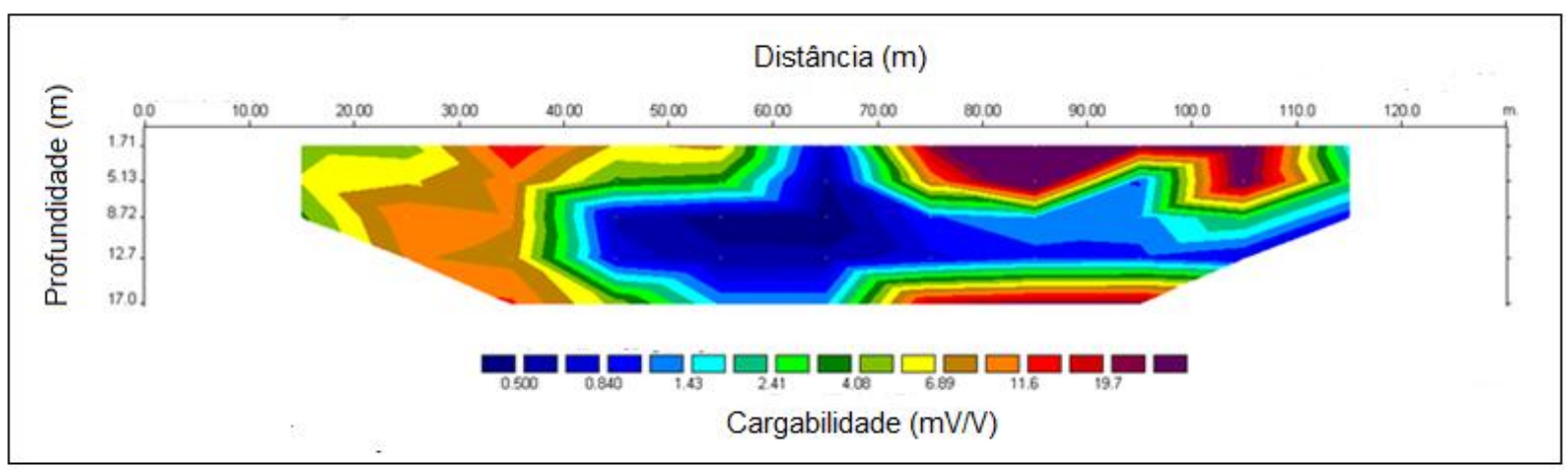

Figura 6.19: Seção de cargabilidade da linha "L3".

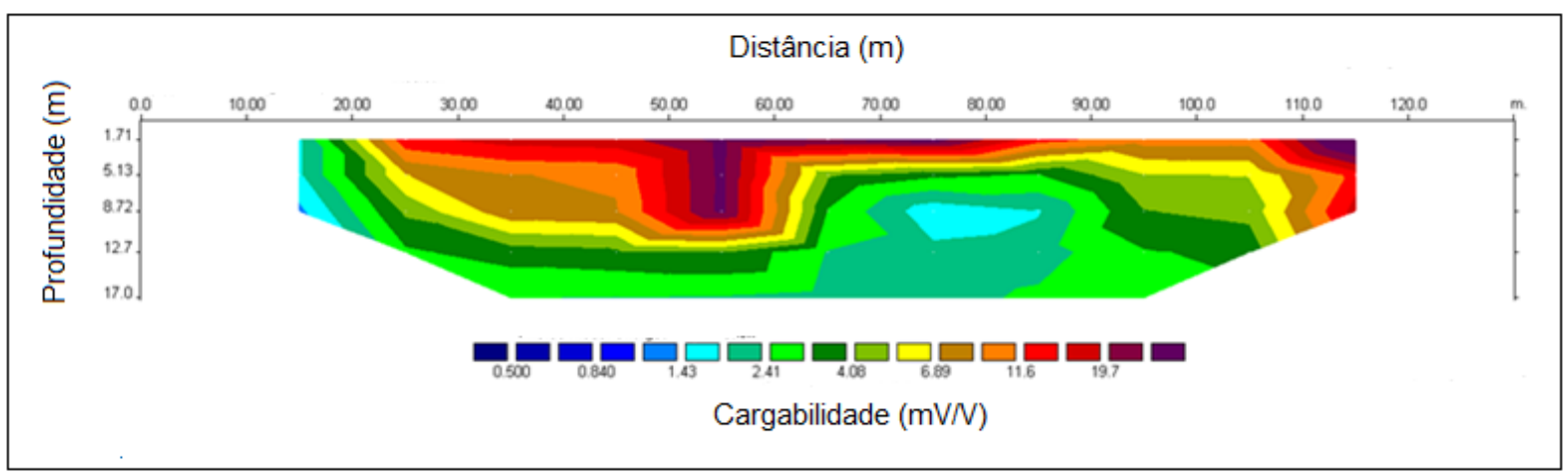

Figura 6.20: Seção de cargabilidade da linha "L4".

O mesmo comportamento da Linha L5 de resistividade foi confirmado pelos resultados de polarização induzida. Novamente ocorrem baixos valores de cargabilidade, inferiores a $5 \mathrm{mV} / \mathrm{V}$, logo abaixo da camada com menor conteúdo em óleo da base da cava (> $7 \mathrm{mV} / \mathrm{V})$, sugerindo que volta a ocorrer uma camada de arenito asfáltico (figura 6.21). 


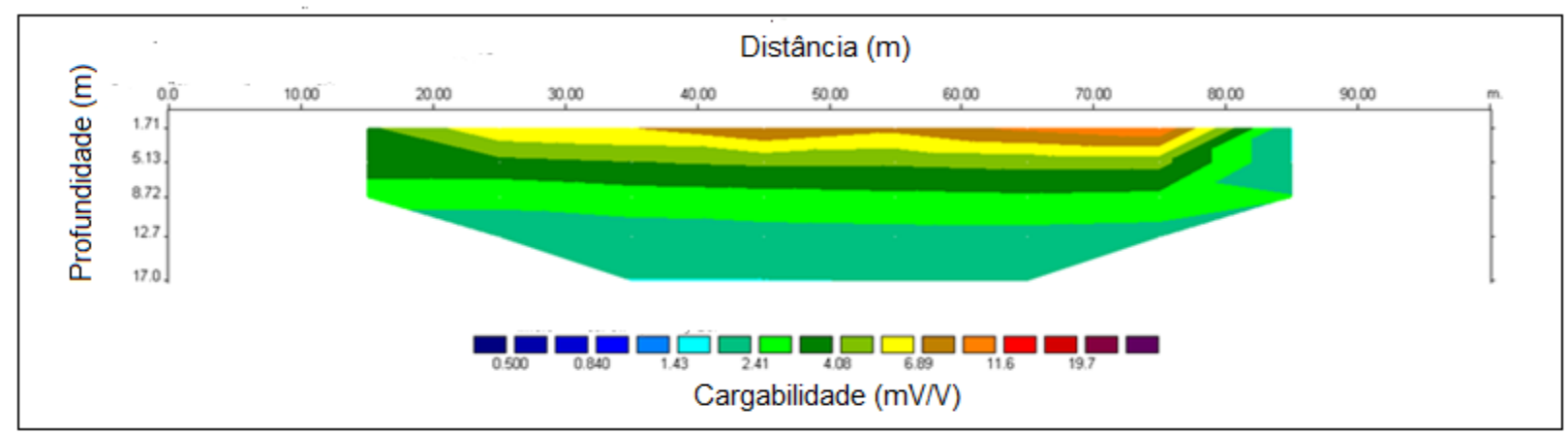

Figura 6.21: Seção de cargabilidade da linha "L5".

Os resultados obtidos mostram que em todas as seções os valores de cargabilidade na camada asfáltica foram mais baixos que o arenito sem óleo. 0 baixo efeito IP observado indica que o óleo, apesar da biodegradação, não é material polarizável, ou apresenta menor capacidade de polarização que as argilas existentes na matriz do arenito sem óleo. Dessa forma, a associação de baixos valores de resistividade e de cargabilidade podem ser uma guia para a prospecção dessas camadas. No entanto torna-se necessário realizar ensaios em outros locais com ocorrências de arenito asfáltico para verificar se 0 comportamento se mantém.

\subsection{LEVANTAMENTOS ER EM AFLORAMENTOS}

Foram feitas algumas medições com o método ER e arranjo eletródico Wenner diretamente em três afloramentos acessíveis de arenito asfáltico, para efeito de confirmação dos valores de resistividade obtidos nos caminhamentos elétricos, como uma medição de controle. $O$ Wenner é um arranjo robusto que consiste de 4 eletrodos posicionados em sequência AMNB equi-espaçados de uma distância “a”, e que apresenta uma profundidade de investigação moderada (aproximadamente 0,5 vezes o espaçamento "a" usado), se comparado a outros arranjos eletródicos. No caso, se aplicou uma distância "a" de apenas 1 metro, de modo que $A B / 3=1$. As medidas foram repetidas várias vezes em cada um dos afloramentos, utilizando eletrodos de potencial ora metálicos, ora porosos, para verificar a repetibilidade dos valores. Os resultados obtidos mostraram um valor médio de resistividade entre 10,4 e 23,8 Ohm.m, 
concordando com os baixos valores atribuídos ao arenito asfáltico nos perfis dos caminhamentos elétricos. As figuras 6.22 e 6.23 mostram imagens dessas medições.

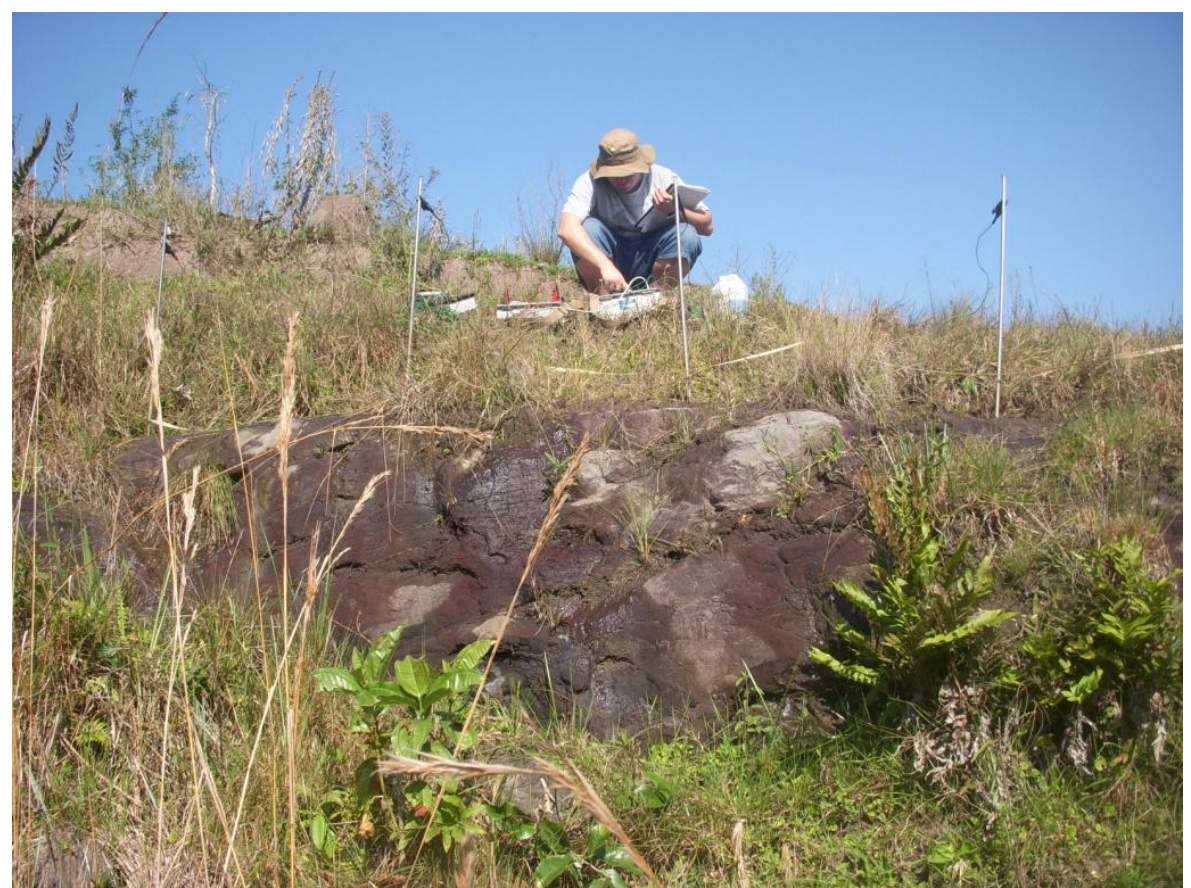

Figura 6.22: Medição em afloramento de arenito asfáltico com arranjo Wenner.

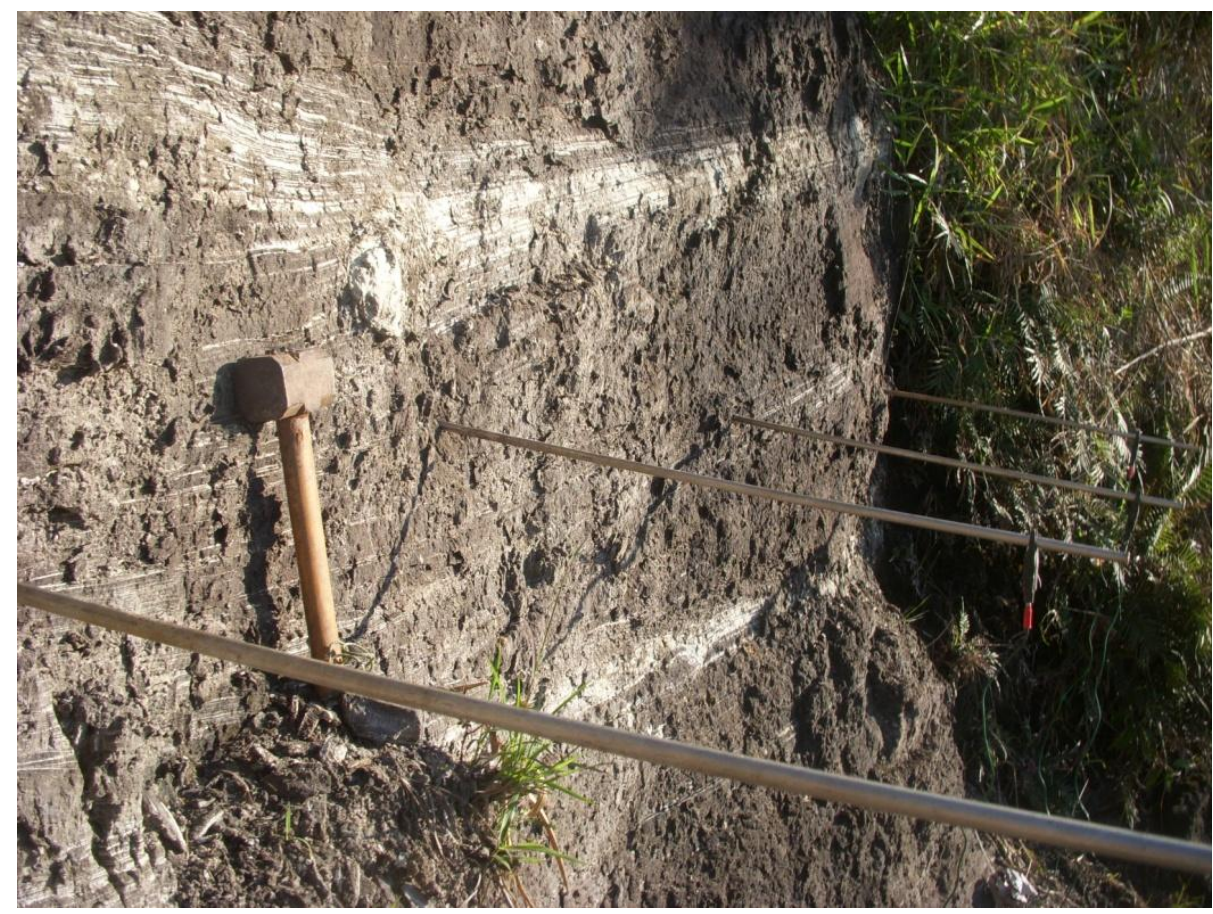

Figura 6.23: Medição em afloramento em flanco do paredão. 


\subsection{DADOS DE CAMINHAMENTO ELETROMAGNÉTICO}

A coleta de dados em ensaios com o método eletromagnético de baixa frequência é muito mais rápido que os ensaios de resistividade, que requerem contato de eletrodos com o solo. Dessa forma, foi realizado um ensaio com o equipamento EM34 na Linha L1 para comparar com os resultados de resistividade e verificar se esse pode ser um bom método para estudo da camada asfáltica em áreas de grande extensão.

Os resultados são apresentados na figura 6.22. De uma forma geral apresenta as mesmas feições que a linha de caminhamento elétrico, com a camada apresentando leve mergulho para NNE. A camada inferior também ocorre, porém em profundidade maior que no ensaio de resistividade. Esse ensaio conduzido com espaçamento entre bobinas de 10 e 20 metros, com profundidades teóricas de exploração de 7,5, 15 e 30 metros, certamente tem menor resolução espacial que o caminhamento e por isso deve ocorrer essa diferença, embora os dados de EM tenham sido submetidos a um processo de inversão também.

De qualquer forma, para grandes áreas o método certamente será de grande contribuição, possibilitando a identificação de locais de interesse para ensaios de maior detalhe com outros métodos geofísicos.

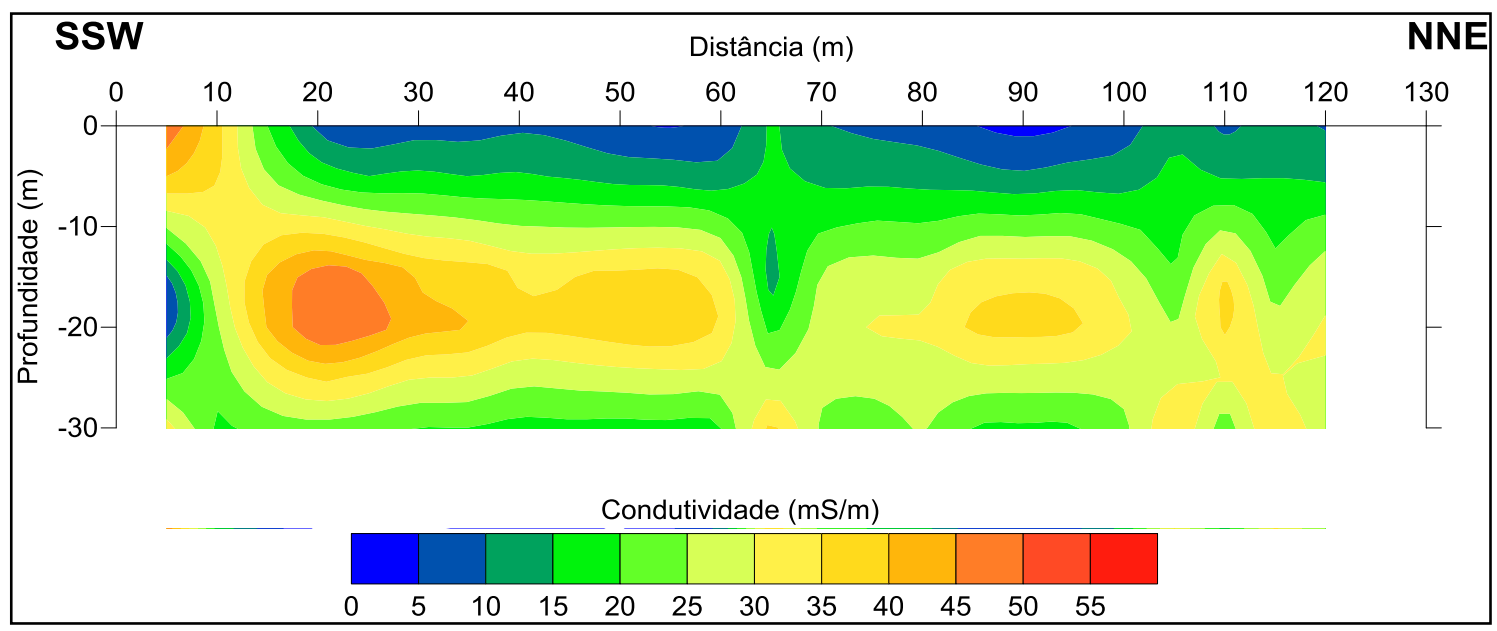

Figura 6.24: Seção de condutividade da linha "L1". 


\section{3 - CONCLUSÕES E RECOMENDAÇÕES}

A resposta elétrica comumente encontrada em áreas com presença de óleo, assim como de contaminantes derivados de hidrocarbonetos, é uma anomalia de resistividade mais elevada em relação ao meio. Dessa forma, em um primeiro momento, era esperada uma resposta de alta resistividade para 0 arenito asfáltico. Isso não ocorreu, sendo o arenito asfáltico caracterizado por baixos valores de resistividade. Esse comportamento pode ser explicado pelo alto grau de biodegradação dos hidrocarbonetos no local. Vários estudos mostram que o caráter resistivo natural sofre alterações conforme o tempo em que se mantém no solo ou rocha, devido à presença de produtos e subprodutos dos processos de biodegradação sofrido pelo óleo no meio ambiente. A ação bacteriológica gera ácidos carbônicos e orgânicos que alteram as condições químicas do sistema, enriquecendo em sólidos dissolvidos a área próxima, modificando assim suas propriedades elétricas. Isso ocorre em campos maduros de hidrocarbonetos. No caso, os afloramentos de arenito asfáltico da área se encontram próximos à superfície e vários trabalhos de análise microbiológica confirmaram níveis severos de biodegradação, que comprovadamente gera subprodutos com alto teor de sólidos dissolvidos, transformando o ambiente de resistivo para condutor.

Os ensaios de resistividade 1D, 2D e 3D mostraram a geometria da camada asfáltico, de forma concordante com o que se observa no afloramento.

Para confirmar os resultados de baixa resistividade obtidos nos ensaios convencionais, ensaios com arranjo Wenner diretamente no afloramento foram executados e apresentaram também baixas resistividades.

Ensaios de polarização induzida também delimitam a camada com geometria semelhante aos resultados de resistividade. A camada foi caracterizada por baixos valores de cargabilidade, ou seja, os hidrocarbonetos, mesmo biodegradados, são pouco polarizáveis.

A seção obtida com o método eletromagnético mostra que embora os resultados de caminhamento elétrico sejam mais detalhados, esse método pode ser utilizado para uma abordagem preliminar em áreas mais extensas.

Este trabalho foi desenvolvido em uma das várias ocorrências de arenito asfáltico do Estado de São Paulo. Embora os estudos realizados nessa e em 
outras várias ocorrências indiquem alto grau de biodegradação do óleo, seria interessante a realização de estudos geoelétricos em outras ocorrências para verificar se o comportamento de baixa resistividade se repete, e assim aplicálos também em áreas mais centrais da bacia. 


\section{VIII - REFERÊNCIAS BIBLIOGRÁFICAS}

ANDRADE, S.M.; SOARES, P.C. 1971. Geologia de semi detalhe no centro leste de São Paulo. Rio de Janeiro. Petrobras. DESUL. Relatório n.407, 52p.

AQUINO, V.F. 2000. Métodos geofísicos eletromagnéticos aplicados ao diagnóstico do solo e das águas subterrâneas em área de infiltração de resíduos industriais. Dissertação de Mestrado, Instituto de Geociências, Universidade de São Paulo, São Paulo - SP, 121 p.

ARAÚJO, L.M.; TRIGUIS, J.A.; CERQUEIRA, J.R.; FREITAS, L.C da S.; 2000. The atypical Permian Petroleum System of the Paraná Basin, Brazil. In M.R. Mello \& B.J. Katz (eds) - Petroleum systems of South Atlantic margins. AAPG Memoir, v 73, p377-402.

ARAÚJO, C.C. (2003) - Gênese das Ocorrências de Arenito Asfáltico da Borda Leste da Bacia do Paraná, SP - tese de doutoramento - Instituto de Geociências, Universidade de São Paulo, 135p.

ARAÚJO, C.C; YAMAMOTO, J.K.; MADRUCCI, V. 2003. Análise morfoestrutural em área de ocorrência de arenito asfáltico, Bacia do Paraná, São Paulo. (artigo). Revista do Instituto Geológico, São Paulo, 24(1/2), 25-41.

ARAÚJO, C.C.; YAMAMOTO, J.K.; ROSTIROLLA, S.P. 2004. Distribuição espacial e caracterização geológica dos arenitos asfálticos da borda leste da Bacia do Paraná no Estado de São Paulo. (artigo). Revista Brasileira de Geociências 34(2): 187-200.

ARAÚJO, C.C.; YAMAMOTO, J.K.; ROSTIROLLA, S.P.; MADRUCCI, V.; TANKARD, A. 2005. Tar sandstones in the Paraná Basin of Brazil: structural and magmatic controls of hydrocarbon charge. Marine and petroleum geology, n. 22. p.671-685. 
ARAÚJO, C. C; YAMAMOTO, J. K. ; ROSTIROLLA, S. P. - 2006- Arenitos asfálticos na Bacia do Paraná: estudo das ocorrências no Alto Estrutural de Anhembi. Boletim de Geociências da Petrobrás. Rio de janeiro, v.14, n 1, p. 47- 70 Nov.2005/maio/2006.

ARTUR, P.C.; SOARES, P.C. 2002. Paleoestruturas e petróleo na Bacia do Paraná. (artigo) Revista Brasileira de Geociências 32(4):433-448, dezembro de 2002.

ATEKWANA, E.A.; SAUCK, W.A. \& WERKEMA Jr., D.D. 2000. Investigations of geoelectrical signatures at a hydrocarbon contaminated site. Journal of Applied Geophysics, 44. p. $167-180$.

AZAMBUJA, E.;COSTA, A.F.U; NANNI, A.S. 1999. O emprego da prospecção geofísica na avaliação de plumas de contaminação por hidrocarbonetos. IV Congresso Brasileiro de Geotecnia Ambiental. São José dos Campos. SP.

BENSON, A.K.; PAYNE, K.L.; STUBBEN, M.A. 1997. Mapping groundwater contamination using dc resistivity and VLF geophysical methods - A case study. Geophysics, 62(1):80-86.

BOCARDI, L.B.; ROSTIROLLA, S.P.; DEGUCHI, M.G.F.; MANCINI, F. 2008. História de soterramento e diagêneses em arenitos do Grupo Itararé implicações na qualidade de reservatórios. (artigo). Revista Brasileira de geociências, 38(1-suplemento):207-216, março de 2008.

BORGES, W.R. 2007. Caracterização geofísica de alvos rasos com aplicações no planejamento urbano e meio ambiente: estudo sobre o sítio controlado do IAG/USP. Tese de Doutorado. Instituto de Astronomia, Geofísica e Ciências Atmosféricas da USP, São Paulo, SP. 256 p.

BRAGA, A. C. O. 1997. Métodos geoelétricos aplicados na caracterização geológica e Geotécnica Formações Rio Claro e Corumbataí, no município de 
Rio Claro-SP. Tese (Doutorado em Geociências e Meio Ambiente) Instituto de Geociências e Ciências Exatas, Universidade Estadual Paulista, Rio Claro. 200 p.

BRAGA, A. C. O. 1999. Métodos de prospecção em hidrogeologia. Apostila interna do Curso de Geologia, Instituto de Geociências e Ciências Exatas, Universidade Estadual Paulista, Rio Claro.

BRAGA, A.C.O. \& CARDINALI, M.T. 2005. Aplicação da resistividade e cargabilidade em estudos de contaminação de sedimentos por derivados de Hidrocarbonetos. Revista Brasileira de Geofísica, Vol. 23(2): 181-190.

CABRAL, C.V. 2006. Análise de biomarcadores nos arenitos asfálticos da borda leste da Bacia do Paraná. Dissertação de M.Sc. Universidade Federal do Rio de Janeiro, COPPE. Rio de Janeiro, Brasil, $211 \mathrm{f}$.

CAETANO-CHANG, M.R.; WU, F.T. 2003 .Diagêneses de arenitos da Formação Pirambóia no centro-leste paulista. (artigo) Departamento de Geologia Aplicada, Instituto de Geociências e Ciências exatas, UNESP, Rio Claro, SP. V 22, N. especial, p.33 a 39.

CASAGRANDE, J.; KÜCHLE, J.; HOLZ, M. Análise tectono- estratigráfica da sucessão Eo-Permiana da Bacia do Paraná aplicada ao mapeamento de potenciais corpos reservatórios. 2007. Artigo. 4 PDPETRO. Campinas, SP.

GIRO,H.M.;TOMASO,K.;TRIGUIS,J.;CARRASQUILLA,A.A;TRAVASSOS,J.;CU NHA JR., L.S;ALMEIDA,A.C. (2003). Estudo geofísico e geológico dos arenitos asfálticos da Formação Pirambóia, Bacia do Paraná. Eighth International Congress of The Brazilian Geophysical Society, Rio de Janeiro, Brasil.

COLLON, A. 1897. Le petrole dans les environs du Mont de Bofete et Porto martins, dans l'Etat de São Paulo. Instituo Geográfico e Geológico. Secretaria de Agricultura do Estado de São Paulo, 69 p. 
COSTA NETO,C 1980. Folhelhos oleígenos: matéria prima que o Brasil tem. Química Nova, Rio de Janeiro, p. 64-103.

DAHLIN, T.; LOKE, M.H. 1997. Quasi - 3D resistivity imaging - mapping of three-dimensional structures using two dimensional DC resistivity techniques. Procs. $3^{\text {rd }}$ Meeting Environmental and Engineering Geophysics. Aarhus, Denmark, 8-11 september 1997.

DAHLIN, T. 2000. Short Note on electrode charge-up effects in DC resistivity data acquisition using multi-electrode arrays. Geophysical Prospecting, 48, p. 181-187.

DAHLIN, T.; ZHOU, B. 2004. A numerical comparison of 2D resistivity imaging with 10 electrode arrays. Geophysical Prospecting, 52, p. 379-398.

DALAN, R. A. 1991. Defining archaeological features with electromagnetic surveys at the Cahokia Mounds State Historic Site. Geophysics, Vol. 56(8):1280-1287.

DEMAISON, G.; HUIZINGA, B.J. 1991. Genetic classification of petroleum systems. AAPG Bulletin, 75:1626-1643.

DIAS, K. D. N. - 2008 - Análise estratigráfica da formação Pirambóia, permiano superior da Bacia do Paraná, leste do Rio Grande do Sul- dissertação de mestrado - Universidade Federal do Rio Grande do Sul.

DOOLITLE, J.A.; M.E. COLLINS. 1998. A comparison of EM induction and GPR methods in areas of karst. Geoderma, Vol. 85: 83 - 102.

DOS ANJOS, C.W.D. 2008. Fatores condicionantes na gênese dos argilominerais dos folhelhos negros e pelitos associados da Formação Irati no norte da Bacia do Paraná. Tese de doutorado. Universidade de Brasília. 
DOW, W.G. 1972. Application of oil correlation and source rock data to exploration in Williston Basin. AAPG Bulletin, 56:615

DRASKOVITS, P.; HOBOT, J.; VERÖ, L.; SMITH, B. 1990. Induced polarization survey applied to evaluation of groundwater resources, Pannonian Basin, Hungary. USA. Investigations in Geophysics, oo 4 - Induced Polarization Applications and Case Histories. Society of Exploration Geophysicists, Ed Stanley H. Ward, p.379 - 396.

EDWARDS, L. S. 1977. A modified pseudosection for resistivity and inducedpolarization. Geophysics, 42, p. $1020-1036$.

ELIS, V.R. 1999. Avaliação de aplicabilidade de métodos elétricos de prospecção geofísica no estudo de áreas utilizadas para disposição de resíduos. Tese de Doutorado, Instituto de Geociências e Ciências Exatas, UNESP, Campus de Rio Claro - SP, 264 p.

FACHIN, S.J.S. 2007. Ensaios geoelétricos $2 D$ no antigo lixão de Ribeirão Preto - SP: avaliação de parâmetros de aquisição e monitoramento ambiental do problema. Tese de Mestrado. Instituto de Astronomia, Geofísica e Ciências Atmosféricas da USP, São Paulo, SP.142 p.

FERREIRA, M.P. 2010. Condicionantes faciológicos e estruturais dos hidrocarbonetos da Formação Pirambóia, Bacia do Paraná. (Trabalho de formatura). Instituto de Geociências. Universidade de São Paulo.

FRANZINELLI, E. 1972. Arenitos asfálticos do Estado de São Paulo. Tese de doutoramento. Instituto de Geociências, Universidade de São Paulo.

GALLAS, J.D.F. 2000. Principais métodos geométricos e suas aplicações em prospecção mineral, hidrogeologia, geologia de engenharia e geologia ambiental. Tese de Doutoramento. Instituto de Geociências e Ciências Exatas, UNESP, Rio Claro, SP. 
GARCIA, M.A; RIBEIRO, H.J.P.S.; SOUZA, E.S.; TRIGUIS, J.A. . 2011. Correlação entre a faciológica e a geoquímica orgânica dos Tar Sands da formação Pirambóia, Triássico da Bacia do Paraná, fazenda Betumita, no Estado de São Paulo. Artigo. UNESP. Geociências. Vol. 30, n. 3, pag 357-369. São Paulo.

GEOTOMO SOFTWARE. RES2DINV, version 3.53. 2003. Rapid $2 D$ resistivity \& Ip inversion using the least-square method - Geoelectrical Imaging 2-D \& 3D. Geotomo Software, Penang, Malaysia. 129 p.

GOMES, M.J. da S., 2003. Utilização de métodos geofísicos em sambaquis fluviais, região do Vale do Ribeira de lguape. Dissertação de Mestrado. FFLCH/USP, São Paulo, SP, 135p.

GOULART, E.P.; JARDIM, N.S. 1982. Avaliação Geoquímica das Formações Ponta Grossa e Irati - Bacia do Paraná. Paulipetro, CESP/IPT. P41-74.

GRIFFITHS, D.H.; BARKER, R.D. 1994. Electrical imaging in archaeology. Journal of Archaelogical Science, 21p. p.153-158.

HACHIRO, J., 1991, Litotipos, associações faciológicas e sistemas deposicionais da Formação Irati no estado de São Paulo. Dissertação de Mestrado, Instituto de Geociências, Universidade de São Paulo.

HACHIRO, J.,1996, O Subgrupo Irati (neo-Permiano) da Bacia do Paraná, São Paulo.Tese de Doutoramento. Instituto de Geociências, Universidade de São Paulo.

INTERPEX LIMITED. RESIX IP2DI. 1996. Resistivity and Induced Polarization data interpretation software. Interpex, Golden, Colorado.

KELLER, V.G.; FRISCHKNECHT, F.C., 1966. Electrical methods in geophysical prospecting. Oxford, Pergamon Press. 517 p. 
LAGO, A.L. 2009. Investigação geofísica $2 D$ e $3 D$ com aplicação em meio ambiente: estudo sobre uma área de disposição de resíduos de óleo lubrificante no município de Ribeirão Preto - SP. Tese de doutoramento. Instituto de Astronomia, Geofísica e Ciências Atmosféricas, Universidade de São Paulo.

LIMA, O.; SATO, H.K.; PORSANI, M.J. 1995. Imaging industrial contaminant plumes with resistivity techniques. Journal Applied Geophysics, 34.

LISBOA, A.C. 2006. Caracterização geoquímica orgânica dos folhelhos NeoPermianos da Formação Irati - borda leste da Bacia do Paraná, São Paulo. Dissertação de M.Sc. Universidade Federal do Rio de Janeiro, COPPE. Rio de Janeiro, Brasil, 171p.

LISBOA, A.C.; AZEVEDO, D.A.; GONÇALVES, F.T.T.; LANDAU, L. 2005. Aplicação da Geoquímica Orgânica no Estudo dos Folhelhos Oleígenos Neopermianos da Formação Irati - Borda Leste da Bacia do Paraná - São Paulo, Brasil. 3o Congresso Brasileiro de P\&D em Petróleo e Gás, Salvador, BA (anais).

LOKE, M. H. \& BARKER, R. D. 1996. Rapid least-squares inversion of apparent resistivity pseudosections by a quasi-Newton method. Geophysical Prospecting, 44. p. $131-152$.

LOKE, M. H. 1999. Software User's Manual. Res2dInv version 3.3. for Windows 3.1 and 95 - Rapid $2 D$ resistivity and IP inversion using the least-squares method. Penang, Malaysia, 35p.

LOKE, M. H. 2000. Electrical imaging surveys for environmental and engineering studies: a practical guide to 2-D and 3-D surveys. Report Geotomo LLC, Penang, Malaysia. 67. p. 
LOKE, M.H. 2002. RES2DMOD. Rapid 2D resistivity forward modeling using the finite-difference and finite-elements methods. Disponível em http:www.geoletrical.com.

LOKE, M. H. 2004. Tutorial: 2-D and 3-D electrical imaging surveys. 136 p.Disponível em : http://www.geoelectrical.com.

MAGALHÃES, J. A. F. 2010. Modelagem termal de intrusões de diabásio e suas influências em sistemas petrolíferos da Bacia do Paraná. Monografia de conclusão do curso de bacharelado em Geologia. Departamento de Geociências. Universidade Federal Rural do Rio de Janeiro.

MAGOON, L.B. \& DOW, W.G. 1994. "The petroleum system-from source to Trap". AAPG Memoir, n. 60, p.3-23.

McNEILL, J.D. 1980. Eletromagnetic terrain conductivity measurement at low induction numbers. Nota técnica oํ 6, Geonics, 15p.

MARQUES, S.G. 2007. Metodologia geofísica para contaminação por hidrocarbonetos - estudo de caso em posto de combustíveis. Dissertação de mestrado. Instituto de Geociências - USP.

MATOS, J.P.L.; CASTRO, D.L.; PEDROSA JR, N.C. . 2010. Comportamento geoelétrico da sequência drifte da Bacia Potiguar (RN/CE). Revista Brasileira de Geofísica (2010) 28(3):481-494.

MATOS, S.L.F. (1995). O contato entre o Grupo passa Dois e a Formação piramboia na borda leste da bacia do Paraná no Estado de São Paulo. São Paulo, 110p.(dissertação de mestrado). Instituto de geociências, Universidade de São Paulo.

MILANI, E.J.; DE MELO, J.H.G.; DE SOUZA, P.A.; FERNANDES, L.A.; FRANÇA, A.B. 2007. Bacia do Paraná. Boletim de Geociências da PETROBRAS, v. 15, n. 2, p. 265-287. 
MILANI, E. J.; KINISHITA, E. M.; ARAÚJO, L. M.; CUNHA, P. R. C. 1990. Bacia do Paraná: Possibilidades Petrolíferas da calha Central. Boletim de Geociências, PETROBRAS, Rio de Janeiro, v.4 (1), pp.21-34.

MILANI, E.J.; FACCINI, U.U.; SCHERER, C.M.; ARAÚJO, L.; CUPERTINO, J.A. 1998. Sequences and stratigraphic hierarchy of the Paraná basin (Ordovician-Cretaceous), Southern Brazil. Boletim IG - USP: Série Científica, v.29.

MILANI, E.J.; FRANÇA, A. B. e MEDEIROS, R. Á. (nov 2006/mai 2007). Roteiros Geológicos, Rochas geradoras e rochas-reservatório da Bacia do Paraná - Boletim de Geociências da Petrobrás.

MINOZZO, M. 2009. Métodos geofísicos aplicados na avaliação ambiental em uma indústria química na cidade de São Paulo - SP. Dissertação de mestrado. Instituto de Astronomia, Geofísica e Ciências Atmosféricas, Universidade de São Paulo.

MOREIRA, C.A. \& DOURADO J.C. 2005. Análise de contaminantes de fase líquida não aquosa (NAPLs) por aplicação do método eletromagnético indutivo (EM). Revista Brasileira de Geofísica, São Paulo, Vol. 23 (3): 213-220.

MOREIRA, C.A.; DOURADO, J.C. 2006. Monitoramento da atenuação natural de pluma de contaminação pelo método de radar de penetração no solo (GPR). Revista Brasileira de Geofísica, 25(4): 389-398.

MOREIRA, C.A.; DOURADO J.C. \& BRAGA, A.C.O. 2006. Aplicação da técnica de caminhamento elétrico em área contaminada por derivados de petróleo. Revista Brasileira de Geofísica, São Paulo, Vol. 24 (3): 383-392.

NARAYAN, S.; DUSSEAULT, M.B. \& NOBES, D.C. 1994. Inversion techniques applied to resistivity inverse problems, 10. p. 669-686. 
OLAYINKA, A.I. \& YARAMANCI, U. 2000. Use of block inversion in the 2-D interpretation of apparent resistivity data and its comparison with smooth inversion. Journal of Applied Geophysics, 64. p. 63-81.

OLIVEIRA, F. de P. 1889. Reconhecimento geológico do Vale do Rio Paranapanema. Boletim da Comissão Geográfica e Geológica, São Paulo, 2: 331. (Reeditado em IGG, São Paulo, 8(3), 213-241, 1950).

OLIVEIRA,E.P. (1920) Rochas petrolíferas do Brasil. Rio de Janeiro, Serviço geológico e mineralógico do Brasil, p101-102.

OLIVEIRA,E.P. (1940) História da pesquisa de petróleo no Brasil. Rio de Janeiro. Serviço de publicidade agrícola, 208p.

OLIVEIRA, A.F. , 2011 - O Sistema Petrolífero Irati-Pirambóia no Estado de São Paulo: migração de hidrocarbonetos avaliada pela análise de inclusões fluidas - dissertação de mestrado - Instituto de Geociências - Universidade de São Paulo.

ORELlANA, E. 1972. Prospeccion Geoelectrica en Corriente Continua. Ed. Paraninfo, Madrid, 523p.

QUADROS, L. P. 1982 . Avaliação geoquímica da Bacia do Paraná. Anais do XXXII Congresso Brasileiro de Geologia, Salvador, Bahia , v.5: 2349 - 2352.

QUINTAS, M.C.L. 1994. O embasamento da Bacia do Paraná: reconstrução geofísica de seu arcabouço. São Paulo, 218 p. Tese de doutoramento. Instituto de Astronomia, Geofísica e Ciências Atmosféricas. Universidade de São Paulo.

QUINTAS, M.C.L.; MANTOVANI, M.S.M.; ZALÁN,P.V. 1999. Contribuição ao estudo da evolução mecânica da Bacia do Paraná. (artigo). Revista Brasileira de Geociências 29(2):217-226. 
SANTOS, A.R.; GRIEP, G.H. 2008. Detecção de plumas de contaminação por hidrocarbonetos no subsolo através do método radar de penetração do solo (GPR). Monografia. Universidade Federal do Rio Grande, RS.

SANTOS, V.R.N. dos. 2009. Emprego dos métodos eletromagnético indutivo e GPR no mapeamento de redes de interferências instaladas no sítio controlado de geofísica rasa do IAG - USP. Dissertação de Mestrado. Instituto de Astronomia, Geofísica e Ciências Atmosféricas, Universidade de São Paulo.

SASAKI, Y. 1989. Two-dimensional joint inversion of magnetotelluric and dipoledipole resistivity data. Geophysics, 54 .

SCHENEIDER, R.L.; MUHLMANN,H.;TOMMAS, I.; MEDEIROS, R.A, DEAMON, R.F., NOGUEIRA. 1974. Revisão estratigráfica da Bacia do Paraná. Congresso Brasileiro de Geologia, 28.v.1.

SHARMA, P.V. 1997. Environmental and engineering geophysics. Cambridge University Press, $475 \mathrm{p}$.

SILVA, A.J.P.; LOPES, R.C.; VASCONCELOS, A.M.; BAHIA, R.B.C. Bacias Sedimentares paleozoicas e meso-cenozóicas interiores. CPRM- Serviço geológico do Brasil. In: Geologia, Tectônica e Recursos Minerais do Brasil, capítulo II.

SOUZA, I.V.A.F.; MENDONÇA FILHO, J.G.; MENEZES, T.R. Avaliação da influência térmica das intrusivas ígneas no principal horizonte potencialmente gerador da Bacia do Paraná: Formação Irati. $3^{\circ}$ Congresso Brasileiro de P\&D em Petróleo e Gás, Salvador, BA (anais).

STEVEAUX, J.C.; SANTOS, M.V.; SEIGNEMARTIN, C.L. 1980. Geologia do bloco 49, balizado pelas cidades de Avaré, Itapeva e Itapetininga. São Paulo. Paulipetro CESP/IPT.90 p. (Relatório BP-016/80). 
STEWART, M.T. 1982. Evaluation of electromagnetic methods for rapid mapping of salt-water interfaces in coastal aquifers. Ground Water, Vol.20, (5): 538-545.

SUMNER, J.S.1976. Principles of Induced Polarization for Geophysical Exploration. Elsevier Scientific Publishing Co., Amsterdan, 227p.

TELFORD, W.M.; GELDART, L.P. \& SHERIFF, R.E. (1990). Applied geophysics. Cambridge University Press. Second Edition. 770 p.

THOMAZ FILHO, A. (1982) - Ocorrência de arenito betuminoso em Anhembi $(S P)$ - cubagem e condicionamento geológico. In: Congresso Brasileiro de Geologia, 37, Salvador, 1982. (Anais, Salvador, SBG, v.5, p.2344-2348).

THOMAZ FILHO, A.; MIZUSAKI, A.M.P.; ANTONIOLI, L. 2008. Magmatism and petroleum exploration in the Brazilian Paleozoic basins. Marine and Petroleum Geology, n. 25.

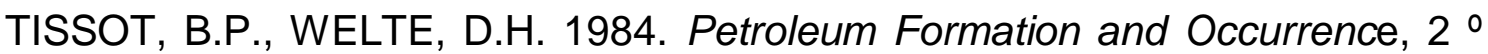
ed. Berlin, Springer-Verlag.

TRIGUIS, J.A. 1986. An organic geochemical investigation of heat-effected sediments in the Paraná basin (Brazil). Newcastle, UK, 140 p. (tese de Doutoramento). University of Newcastle Upon Tyne.

USTRA, A.T. 2008. Utilização dos métodos eletroresistividade e polarização induzida com aquisç̧ão de dados 3D para caracterização geoambiental de uma área à jusante do aterro de resíduos sólidos urbanos de Bauru - SP. Tese de Mestrado. Instituto de Astronomia, Geofísica e Ciências Atmosféricas da USP. São Paulo - SP. 205 p. 
WARD, S. H. 1990. Resistivity and Induced Polarization Methods. Geotechnical and Environmental Geophysics. Investigations in Geophysics, SEG. Vol. 5: 147189.

WASHBURNE,C.W. (1930) Geologia do petróleo do Estado de São Paulo. Rio de Janeiro, Departamento nacional de produção mineral, Ministério da Agricultura, 228p.

WHITE, I.C. 1908. Relatório sobre as "Coal Mesures" e rochas associadas do sul do Brasil. Comissão de Estudos das Minas de Carvão de Pedra do Brasil, Relatório final, 1-201. (Reeditado no 7ํㅡondwana Symposium, DNPM, Rio de Janeiro, 1988).

YOSHIDA, R.; GAMA JR., E. 1982. Geologia da Bacia do Paraná: reavaliação da potencialidade e prospectividade em hidrocarbonetos. Instituto de Pesquisas Tecnológicas de São Paulo, São Paulo.

ZALÁN, P. V.; WOLF, S.; CONCEIÇÃO, J. C. J.; MARQUES, A.; ASTOLFI, M. A. M.; VIEIRA, I. S.; APPI, V. T.; NETO, E. V. S.; CERQUEIRA, J.R.; MARQUES, A. 1990. The Paraná Basin,Brasil: Origem e evolução de bacias Sedimentares. AAPG Memoir - pp: 601-708.

ZALAN, P.V; WOLFF, S.; CONCEIÇÃO, J.C.J.; ASTOLFI, M.A.M.; VIEIRA, I.S.; APPI, V.T.; ZANOTTO, A.; MARQUES,A. (1991). Tectonics and sedimentation of the Paraná Basin. In: Gondwanna Seven Proceedings. São Paulo, Instituto de Geociências - USP, p83-117.

ZHOU, B.; DAHLIN, T. 2003. Properties and effects of measurements errors on $2 D$ resistivity imaging surveying. Near Surface Geophysics, 1, pp 105-117. 